The Effect of Catalyst Sublimation Temperature on the Purity of Multi-Walled Carbon Nanotube Vertically Aligned Arrays

A Thesis
Presented to
the faculty of the School of Engineering and Applied Science
University of Virginia
in partial fulfillment
of the requirements for the degree
Master of Science
by

Kimberly Scheider

August

2016 
APPRONAL SHEET

The thesis

is submitted in partial fulfillment of the requirements

for the degree of

Master of Science

AUTHOR

The thesis has been read and approved by the examining committee:

\begin{tabular}{c} 
Pamela Norris \\
\hline Advisor \\
Petra Reinke \\
\hline Patrick Hopkins \\
\hline
\end{tabular}

Accepted for the School of Engineering and Applied Science:

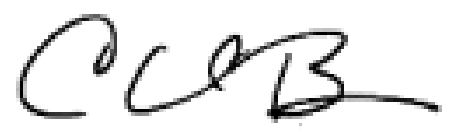

Craig H. Bensan, Dean, School of Engineering and Applied Science

August

2016 


\title{
THE EFFECT OF CATALYST SUBLIMATION TEMPERATURE ON THE GROWTH AND PURITY OF MULTIWALLED CARBON NANOTUBE VERTICALLY ALIGNED ARRAYS
}

\author{
A Dissertation Presented to the \\ Faculty of the School of Engineering and Applied Science \\ University of Virginia \\ In Partial Fulfillment \\ of the Requirements for the Degree of \\ Master of Science \\ Material Science Engineering
}

Kimberly Scheider

August 2016 


\section{Abstract}

Current thermal interface materials including solders, greases, and phase change materials do not have the mechanical compliance required to fill cavities, and thermal conductance necessary to dissipate heat generated in modern microelectronic devices. The inability to dissipate heat properly from the microprocessor device creates a thermal bottleneck which limits device efficiency and leads to early life degradation. Individual multiwalled carbon nanotubes have a high thermal conductivity on the order of 3000 $\mathrm{Wm}^{-1} \mathrm{~K}^{-1}$ which far surpasses the thermal conductivity range of $0.19-8 \mathrm{Wm}^{-1} \mathrm{~K}^{-1}$ for present day thermal interface materials. The promising mechanical and thermal properties of carbon nanotubes (CNT) led to the development of CNT arrays, with expectations of creating an interface material with both high thermal conductivity and compliance. This led to a wealth of research and investment dollars in the scientific community to characterize the growth parameters necessary to produce high quality carbon nanotube arrays for thermal applications. Although significant progress has been made, synthesis of high purity carbon nanotube arrays at the industrial level is not cost effective and those produced do not possess the exceptional heat transfer capabilities predicted computationally.

The most widely available and cost effective means of producing carbon nanotubes arrays is by chemical vapor deposition (CVD). This experimental study varied the ferrocene catalyst sublimation temperature over a range of $100^{\circ} \mathrm{C}-180^{\circ} \mathrm{C}$, in CVD growth, to determine the impact on structural formation of vertically aligned carbon nanotube arrays. The diameter distribution, areal density, array height, and CNT density are calculated using measurements from scanning electron microscope and transmission electron microscope images to assess array quality. Raman spectroscopy was used as a tool to quantify the amount of disordered carbon within the array. It is found that decreasing the sublimation temperature improved the carbon nanotube arrays for thermal interface material applications using the current growth procedure. 


\section{Dedicated to my parents, Eric and Debra:}

without your support, I wouldn't be here today. 


\section{Acknowledgements}

I would like to thank all the members of the UVA Nanoscale Heat Transfer Laboratory who helped me with this thesis. First and foremost, I would like to thank Dr. Norris for offering me a position in her lab, while providing both guidance and resources critical to my success. I was especially amazed and humbled by the caliber of her other students, working with them daily was a privilege. Specifically I would like to thank LeighAnn Larkin, Suhaib Radwan, Chris Saltonstall and Lin Qiu. Thank you LeighAnn for helping me during the development stage of this research, and most of all for your time spent answering my everyday questions. Thank you Lin, for your expertise on Raman measurements and for discussing carbon nanotubes with me. Suhaib, I am constantly amazed by your maturity and ambitions, keep up the positive spirit and passion for CNT synthesis. Chris, I could not have asked for a better person to teach me about the Raman spectroscopy system. All of you made being in this lab a wonderful experience.

Thank you Dr. Reinke, Dr. Hopkins, and Dr. Norris for agreeing to serve on my committee. I would especially like to thank Dr. Reinke for encouraging my curiosity of nanoscale materials and answering my numerous questions this year. Dr. Hopkins, it was a pleasure listening to you lecture last fall. Your passion for nanoscale heat transfer is contagious, and your class gave me an appreciation for thermal management on a broader scale. Dr. Norris, your guidance and thoughtful insight during the writing of this thesis have been invaluable.

Finally, thank you Mr. White, Mr. Thompson and Dr. Heinrich for training me on equipment and taking transmission electron microscopy images on my behalf. 


\section{Table of Contents}

List of Tables (if any, Heading 2,h2 style: TOC 2) ........................................ vii

List of Figures (if any, Heading 2,h2 style: TOC 2) ..................................... viii

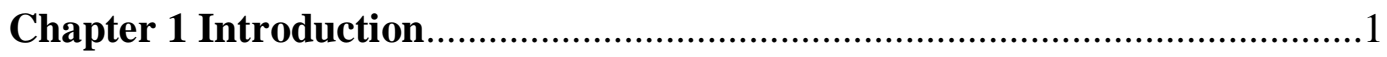

1.1 MULTIWALLED CARBON NANOTUBE ARRAYS AS TIMS (IN MICROELECTRONICS) ...................................................................

1.2 THERMAL PROBLEMS IN THE INDUSTRY WITH VERTICALLY ALIGNED MWCNT ARRAYS .................................................. 3

1.2.1 Contact Resistance ...............................................................4

1.2.2 Internal Thermal Resistance Sources ................................6

1.3 REVIEW OF THE LITERATURE ......................................... 8

1.4 OBJECTIVES OF MY RESEARCH........................................... 10

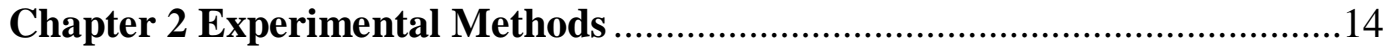

2.1 CNT GROWTH PROCEDURE .....................................................14

2.2 IMPORTANCE OF CATALYST DEPOSITION TEMPERATURE16

2.3 PREVIOUS STUDIES BY THE LAB........................................... 18

2.4 CHARACHTERIZATION METHODS ....................................21

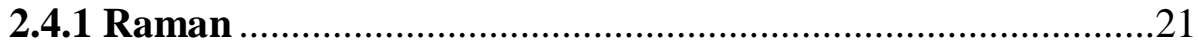

2.4.2 Scanning Electron Microscope (SEM) ...............................23

2.4.3 Transmission Electron Microscope (TEM) ........................24

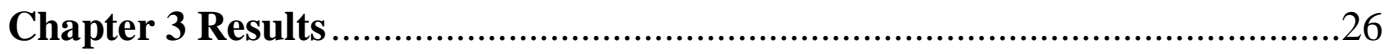

3.1 THE CATALYST IN CHEMICAL VAPOR DEPOSITION ...........26

3.2 GROWTH MECHANISM FOR MWCNTS SYNTHESIZED BY CVD

3.2.1 Vapor-Solid-Solid Model .................................................27

3.2.2 Vapor-Liquid-Solid Model ..............................................28

3.2.3 Diffusion Model for Growth ...............................................29

3.3 THE THERMAL FRAGMENTATION OF FERROCENE DURING

CVD 


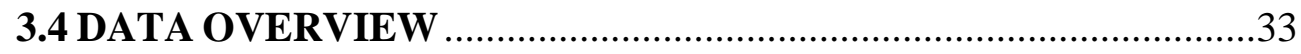

3.4.1 Scanning Electron Microscope Data ........................................33

3.4.2 Transmission Electron Microscope Data................................43

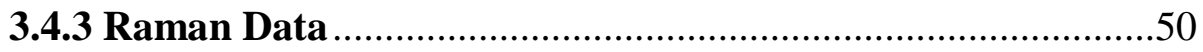

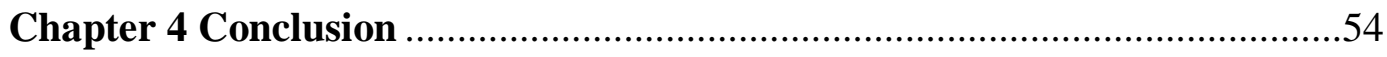

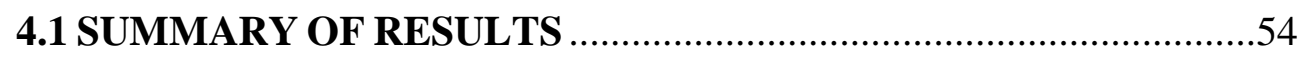

4.2 RECOMMENDATIONS FOR FURTHER STUDY ……...................58

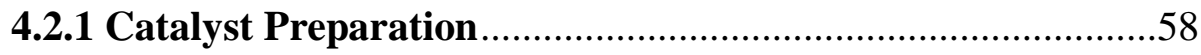

4.2.2 Hydrogen Source .....................................................................59

4.2.3 Additional Analysis ....................................................................60

4.3 CONTRIBUTIONS TO THE FIELD ……………..........................6 


\section{List of Tables}

Table 1: Thermal Conductivity Measurements of MWCNT Arrays [1] .................4

Table 2: Volume Fraction of MWCNT Arrays [2] ..............................................25

Table 3. A comparison of key experimental parameters in Bhatia's study and this

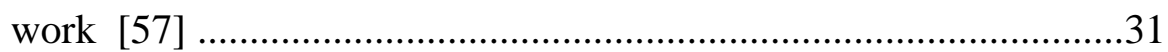

Table 4: Array Volume Fraction Calculations [2]. ............................................48 


\section{List of Figures}

Figure 1: Total thermal resistance (intrinsic and both interfacial resistances included) as a function of CNT length [1] . .......................................

Figure 2: TIM Schematic distinguishing between bulk material resistance and interfacial contact resistance [3][4][5]. .5

Figure 3: a) MWCNTs with preferable structure for thermal transport

b) MWCNT structure grown in study [6]. a) TEM image of MWCNTs overlapping b) TEM image of MWCNT with inconsistent thickness [6]. .7

Figure 4: Microprocessor with TIMs at interfaces [7][8]. .............................

Figure 5a: Schematic of common CNT defects. .12

Figure 5b: Elastic phonon mean free path vs frequency (calculated using atomistic Green's functions) [9]. ........................12

Figure 6a: Schematic of chemical vapor deposition growth equipment. .15

Figure 6b: Timing sequence of gases during CVD growth of MW VACNT

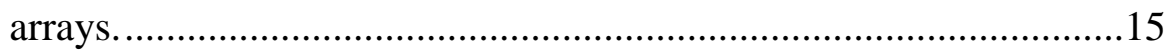

Figure 7:TEM images revealing catalyst particles inside MWCNTs [7]. ............20

Figure 8: The density of MWCNTs versus the outer diameter for different

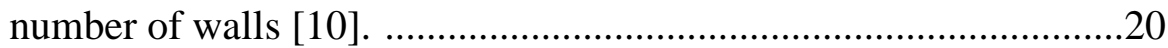

Figure 9. Carbon atoms motion in the hexagonal graphene structure of

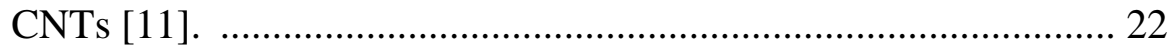

Figure 10. 785nm laser excitation wavelength Raman spectra. . .......................22

Figure 11. Schematic of electron microscope interaction with sample [12]. .......24

Figure 12. Poor dispersion (a) and proper dispersion (b) of CNTs [13]. TEM image verifying effective dispersion in toluene solution. ..............25

Figure 13. Catalytic growth processes Root Growth and Float Growth during CVD [14]. 27

Figure 14. Schematic of growth process and MWCNT TEM images at 100nm of similar structure [15]. .28 
Figure 15. Ferrocene chemical structure [16].

Figure 16. Array Height vs. Ferrocene Sublimation Temperature.

Figure 17. MW VACNTAs synthesized with a ferrocene sublimation temperature of A. $180^{\circ} \mathrm{C}$, B. $170^{\circ} \mathrm{C}, \mathrm{C} .160^{\circ} \mathrm{C}, \mathrm{D} .145^{\circ} \mathrm{C}, \mathrm{E} .140^{\circ} \mathrm{C}$, F. $137^{\circ} \mathrm{C}$. All images have a scale bar of $20 \mu \mathrm{m}$ except image $\mathrm{F}$ which has a scale bar of $10 \mu \mathrm{m}$. For additional images see Appendix 2.

Figure 18. Histograms of diameter distributions for MW VACNTAs. The temperature of ferrocene sublimation is noted in the top right of each graph i.e. $\mathrm{T} 180$ is for $180^{\circ} \mathrm{C}$.

Figure 19. Average diameter measurement versus corresponding ferrocene sublimation temperature 1) using standard deviation as the error bars and 2) using measurement uncertainty for the error. 39

Figure 20. Images with a $1 \mu \mathrm{m}$ scale bar for ferrocene sublimation at $\mathrm{A} .100^{\circ} \mathrm{C}$, B. $130^{\circ} \mathrm{C}, \mathrm{C} .140^{\circ} \mathrm{C}, \mathrm{D} 142^{\circ} \mathrm{C}$, E. $160^{\circ} \mathrm{C}, \mathrm{F} .180^{\circ} \mathrm{C}$.

Figure 21 A. Approximate density (weight change in the substrate divided by the product of the sample surface area and array height) versus ferrocene sublimation temperature.. .........................................................41

Figure 21 B. Areal density versus ferrocene temperature. 42

Figure 22. TEM images for ferrocene sublimation temperatures between $135^{\circ} \mathrm{C}-180^{\circ} \mathrm{C}$. For additional TEM images see Appendix 3. .45

Figure 23 A. Inner and outer diameter measurements from TEM and SEM images versus ferrocene sublimation temperature.

Figure 23 B. Dependence of outer diameter on inner diameter (nanowire thickness) versus ferrocene sublimation temperature

Figure 24. Measurement of MWCNT layers spacing from TEM image [17]. .....48 Figure 25. Density of MWCNTs as a function of ferrocene sublimation temperature. 49

Figure 26. MWCNTs layers of graphene at A. $140^{\circ} \mathrm{C}$ and B. $160^{\circ} \mathrm{C}$. .50

Figure 27. The $A(D) / A(G)$ ratio for varying ferrocene sublimation temperatures

A) at the respective center of the array, B) near the top of the array (side view profile), C) at the top of the array (top-down view). ......52

Figure 28. The $A(D) / A(G)$ ratio versus the normalized height of the array. ........53 


\section{Chapter 1 Introduction}

\subsection{MULTI-WALLED CARBON NANOTUBE ARRAYS AS TIMS (IN MICROELECTRONICS)}

An ideal thermal interface material (TIM) exhibits both good conductance and compliance to aid in the removal of excess heat from integrated circuits. High thermal conductivity is necessary to efficiently remove excess heat from a heat source to a heat sink and compliance is necessary to provide intimate contact at the interface of the material surfaces with different coefficients of thermal expansion [3].

Graphene exhibits excellent thermal conductivity on the order of $1,000 \mathrm{Wm}^{-1} \mathrm{~K}^{-1}-5,000$ $\mathrm{Wm}^{-1} \mathrm{~K}^{-1}$, while thermal conductivity measurements of Single Walled Carbon Nanotubes (SWCNTs) range from $1,750-5,800 \mathrm{Wm}^{-1} \mathrm{~K}^{-1}$, and thermal conductivity measurements of Multiwalled Carbon Nanotubes MWCNTs can surpass $3000 \mathrm{Wm}^{-1} \mathrm{~K}^{-1}$ [7][18]. All materials far surpass copper, a material known for its relatively high thermal conductivity, $385 \mathrm{Wm}^{-1} \mathrm{~K}^{-1}$ [7][19]. The structure of a SWCNT is simply a rolled sheet of graphene, or in the case of MWCNTs layers of concentrically rolled graphene sheets. Carbon nanotubes have the potential to transport thermal energy efficiently due to the $\mathrm{sp}^{2}$ and $\mathrm{sp}^{3}$ hybridized carbon bonds which exhibit a low phonon scattering rate [7]. The high thermal conductivity in CNTs is attributed to strong $\mathrm{sp}^{2}$ (graphite style) bonds, the hexagonal microstructure of graphene, and quasi-ballistic phonon transport [7].

Arrays of carbon nanotubes are of particular interest to researchers due to exceptional mechanical and thermal properties [8]. Asperities between surfaces in contact are the primary source for thermal contact resistance between materials [20]. In an integrated circuit device components often have different coefficients of thermal expansion which can lead to delamination of a TIM without mechanical compliance [8]. Kaur et al. noted MWCNT arrays could withstand a contact pressure of $180 \mathrm{kPa}$, limited only by the glass substrate breaking point, with no effect on CNT thermal interface resistance [21]. CNT arrays are as mechanically compliant as indium, and can displace air gaps between materials resulting in improved thermal contact conductance [20][22].

To date the thermal properties of individual carbon nanotubes are not replicable on a larger scale for composite materials or bulk arrays of carbon nanotubes [7]. The thermal 
conductivities fluctuate due to variations in defect density, tube height, and concentric tube count within the array [7].

In this study multi-walled vertically aligned carbon nanotube arrays are being synthesized for use as a TIM in microelectronic applications. Carbon nanotube films commonly refer to carbon nanotubes grown in a nonhomogeneous, randomly-oriented stack on a substrate [23]. In order to increase the thermal conductivity of carbon nanotube films, directional alignment may be accomplished using specialized techniques such as a winding drum substrate surface, or insitu injection molding into a polymer [24][25]. The multi-walled arrays in this study are naturally synthesized in a vertically aligned state by the chemical vapor deposition process. Figure 1 compares the total thermal resistance of MWCNT arrays with greases and metallic solders, both standard materials used as TIMs. Thermal greases have a low elastic modulus (good compliance), but a high thermal resistance [1]. The MWCNT arrays in Figure 1 that outperformed thermal greases had carefully deposited catalyst layers through ion beam sputtering, or selectively deposited metal catalyst thin films on grooved silicon substrates [26][27][28]. Tong et al. synthesized MWCNT arrays both above and below the grease line by thermally welding a thin indium layer between the CNT array and target surface, which lowered the interfacial resistance and increased the thermal conductance an order of magnitude [29]. Metallic solders have a higher stiffness (poor compliance), but a lower thermal resistance. If each individual CNT in a $3 \%$ volume fill fraction array has a thermal conductivity of $3,000 \mathrm{Wm}^{-1} \mathrm{~K}^{-1}$ the total thermal resistance of the MW VACNTAs will be less than that of a metallic solder [1]. The CNT array also has better compliance than a solder allowing it to withstand thermal expansion mismatch without fatigue failure [30]. Multiple research groups produced MW VACNT films in Figure 1 that outperform the total thermal resistance of greases while approaching the total thermal resistance of metallic solder. If a higher than $3 \%$ packing density of the array or higher thermal conductivity of individual CNTs is reached MW VACNTAs have the potential to outperform current greases and solders as thermal interface materials. 


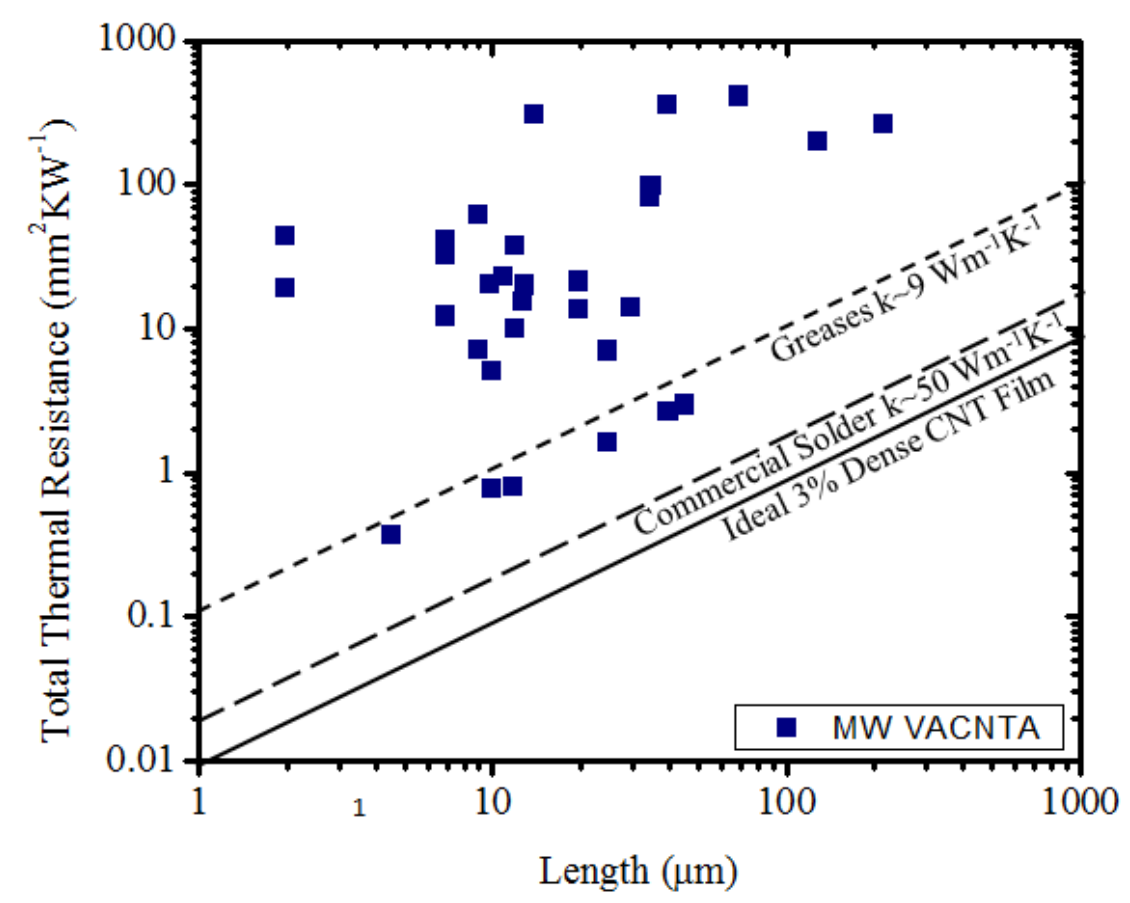

Figure 1. Total thermal resistance (intrinsic and both interfacial resistances included) as a function of CNT array length [1].

\subsection{THERMAL PROBLEMS IN THE INDUSTRY WITH VERTICALLY ALIGNED MWCNT ARRAYS}

In order for a Vertically Aligned Carbon Nanotube Array (VACNTA) to exhibit desirable properties for TIM applications both the thermal conductance and thermal conductivity need to be considered. Thermal conductance $\mathrm{G}$ is the ratio of the heat transferred in the form of flux $q$ as a result of a change in temperature $\mathrm{T}$. The thermal conductance for a given sample is a well understood parameter $\mathrm{G}=q / \Delta \mathrm{T}$. The thermal conductivity is geometrically related to the thermal conductance by $\mathrm{G}=k \mathrm{~A} / \mathrm{L}$ where $\mathrm{G}$ is thermal conductance, $k$ is thermal conductivity, $\mathrm{A}$ is the cross-sectional area, and $\mathrm{L}$ is the length of the nanotube [1]. Interface resistances, or thermal boundary resistances, are other contributors to overall thermal conductance values and cannot be neglected when drawing comparisons between various studies.

Measurement of the inner diameter of a MWCNT requires a TEM image, an experimental measurement not easily accessible to all researchers, and thus the MWCNT crosssectional areas used in thermal conductivity measurements vary. The cross sectional area of a MWCNT is approximated as a circle using diameter measurements, if TEM images are not 
available only the outer diameter is used to calculate the cross sectional area, while other studies subtract the inner hollow portion of a MWCNT using the inner diameter [1]. Table 1 demonstrates the wide distribution of thermal conductivity measurements for MWCNTs even when a uniform cross-sectional area (only outer diameter) is used in all calculations, implying additional variables need to be considered. Boundary resistance, array length, and CNT diameter distribution are additional variables which influence thermal conductivity measurements, and these factors may perhaps be more important than cross sectional area calculations when determining the compatibility of an array in a TIM application.

Table 1 Thermal Conductivity Measurements of MWCNT Arrays

\begin{tabular}{||ll|r|r|r|r||}
\hline \multicolumn{1}{||}{ Authors } & $\begin{array}{c}\text { Measurement } \\
\text { Technique }\end{array}$ & $\begin{array}{c}\text { Array } \\
\text { Length } \\
(\mu \mathrm{m})\end{array}$ & $\begin{array}{c}\text { Diameter } \\
(\mathrm{nm})\end{array}$ & $\begin{array}{c}k \\
\left(\mathrm{Wm}^{-1} \mathrm{~K}^{-1}\right)\end{array}$ & Boundary Resistance \\
\hline \hline Li et al. (2009) & Raman shift & 32 & 8.2 & 1400 & Estimated \\
\hline $\begin{array}{l}\text { Pettes \& Shi } \\
(2009)\end{array}$ & Heater sensor & 1.97 & 11.4 & 160 & Estimated \\
\hline & & 3.31 & 14 & 34 & Estimated \\
\cline { 3 - 7 } & & 3.7 & 9.8 & 2950 & Estimated \\
\hline Fujii et al. (2005) & T-type sensor & 1.89 & 16.1 & 1650 & Neglected \\
\hline & & 3.6 & 28.2 & 500 & Neglected \\
\hline Kim et al. (2001) & Heater sensor & 2.5 & 14 & 3000 & Neglected \\
\hline
\end{tabular}

(Table 1. Modified from [1].)

\subsubsection{Contact Resistance}

Thermal interface materials (TIMs) have multiple contributions to the total thermal resistance that influence the thermal conductance of the system. A contact resistance exists between the CNT array and the interface at both the heat source and heat sink material, while internal volumetric thermal resistance is present within the array. In Figure 2 both interfacial and internal thermal resistances are represented in a TIM schematic. 

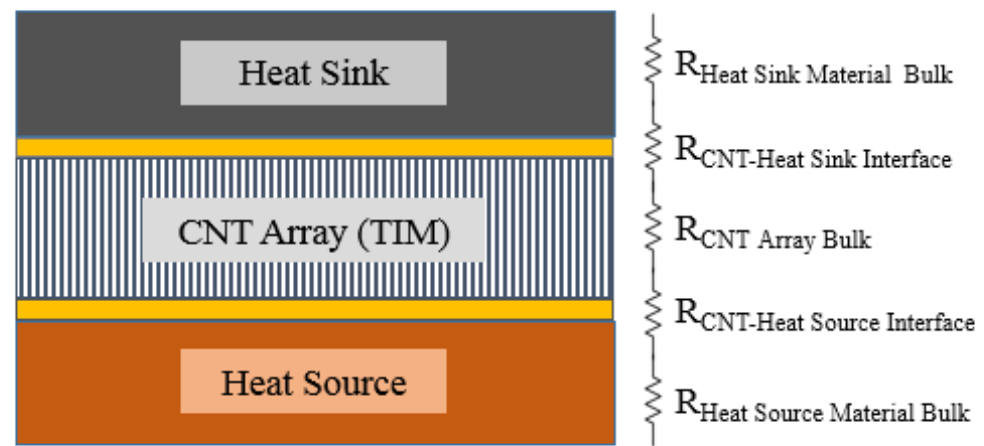

Figure 2. TIM Schematic distinguishing between bulk material resistance and interfacial contact resistance [3][4][5].

Contact resistance is dependent on the roughness at the material interface. When thermal conduction measurements are taken for a system the interfacial resistances are often a prevailing source of resistance. The contact resistance at the growth interface for MWCNTs grown on a silicon chromium substrate is $0.03 \mathrm{~mm}^{2} \mathrm{KW}^{-1}$ while the contact resistance for MWCNTs grown on $\mathrm{SiO}_{2}$ is $37 \mathrm{~mm}^{2} \mathrm{KW}^{-1}$ [6][8]. Contact resistances are taken into account when calculating the total thermal conductance of a TIM system. Silicon dioxide is used as the substrate material in this experimental study because it is an inexpensive, non-conducting material that can withstand the high furnace temperatures necessary for CNT growth [18]. A non-conducting silicon dioxide substrate would not be used to hold a CNT array for use in an electronic circuit component [7]. However, MW VACNTAs can be removed from the substrate or alternatively grown directly on a semiconducting material such as silicon.

Results of prior research in the nanotechnology community have demonstrated that creating CNT arrays with favorable thermal properties will require reducing the thermal contact resistance and increasing the percentage of CNTs contributing to heat conduction [1]. Roughness at the contact surfaces decreases the number of CNTs in the array participating in thermal transport, reducing the effective volume of the array [1]. Panzer et al. measured the effective volume fraction of SWCNT arrays participating in heat transfer using a thermoreflectance technique, a technique which monitors transients reflectivity of a metallic surface which is then related to transient temperature, and discovered that only CNTs in direct thermal contact to the 
top metal layer exhibited transient diffusion which contributed to the experimentally measured heat capacity [1][31]. The same phonon effects that influence heat capacity measurements are of importance to the thermal conductivivty of a material [1]. Panzer et al. isolated the effects of thermal boundary resistance and CNT volumetric ressistance using the thermoflectance technique [31]. As the roughness at the interface of a VACNTA increases fewer CNTs maintain the contact necessary for thermal transport contributions. Aligned arrays with uniform height are an objective in this study in order to optimize the number of CNTs contributing to heat transfer.

\subsubsection{Internal Thermal Resistance Sources}

The structural alignment of graphene layers inside of a MWCNT, and thickness uniformity of the layers impact the internal thermal resistance of the VACNTA [6][32]. Wang et al. found that individual MWCNTs exhibited a thermal conductivity of $27.3 \mathrm{Wm}^{-1} \mathrm{~K}^{-1}$, well below the maximum value of $3000 \mathrm{Wm}^{-1} \mathrm{~K}^{-1}$ reported in Table 1, due to abnormalities within the MWCNT. In Figure 3 it is apparent that Ni catalyst particles did not form around the tube as predicted experimentally and also that the thicknesses of the tubes are not consistent [6]. The planes of graphene formed did not stack perpendicular to the substrate but instead at an approximately 45 degree angle. The directionality of tubes within an array will affect the thermal conductivity. Marconnet et al. stated, "the thermal diffusivity and thermal conductivity in aligned CNT arrays is highly anisotropic, such that the axial thermal conductivity is as much as 110 times greater than the radial conductivity" [1]. The vertical alignment of CNTs in an array can be used to guide the direction of maximum thermal transport [2]. The TEM images in Figure 3 depict overlapping CNTs of non-uniform thickness. Contact between the overlapping CNTs results in additional phonon scattering, which reduces the thermal conductivity of the array. TEM images provide qualitative insight into the defects within a MWCNT while Raman measurements provide a quantitative measurement of array purity by measuring the disorder. The density of the array or volume fraction of CNTs participating in thermal properties is important, but growth defects cannot be overlooked in thermal conductivity measurements. Pettes and Shi found that thermal conductivity measurements for individual MWCNTs varied from $42 \mathrm{Wm}^{-1} \mathrm{~K}^{-1}$ to $343 \mathrm{Wm}^{-1} \mathrm{~K}^{-1}$ as the spacing between defects increased from $13 \mathrm{~nm}$ to $29 \mathrm{~nm}$ apart [33]. Defects are the most difficult factor to account for between studies due to differences 
in MWCNT diameter size, array length, and availability of both quantitative and qualitative array data.

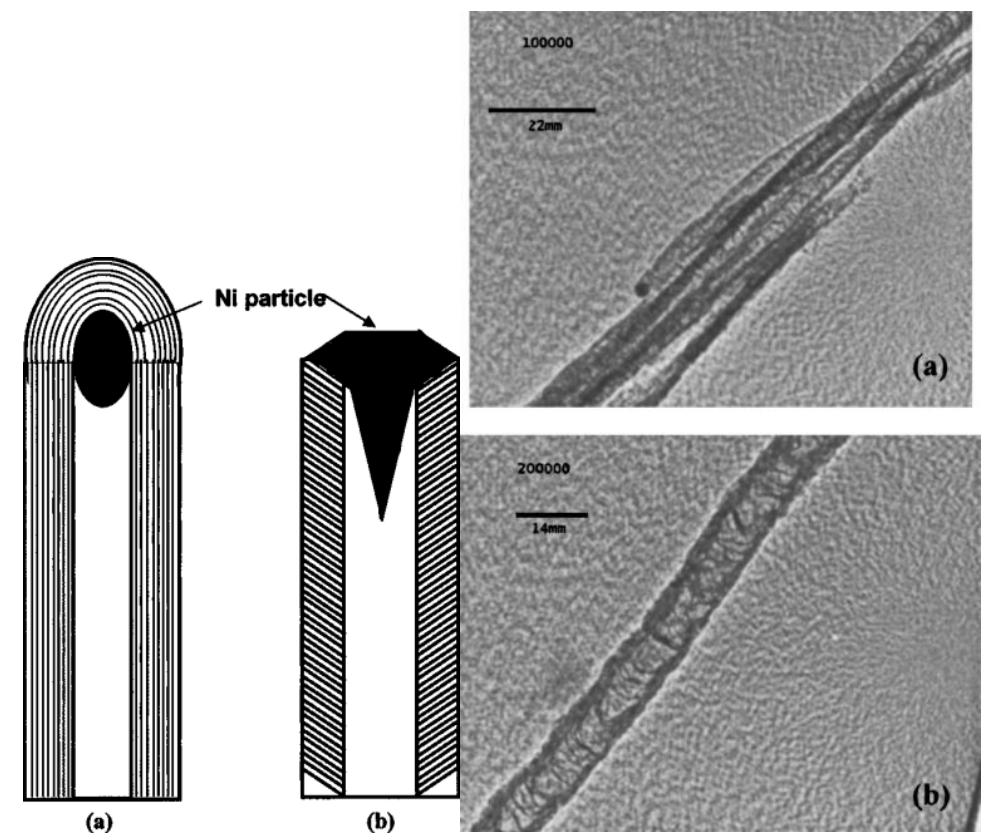

Figure 3 a) MWCNTs with preferable structure for thermal transport b) MWCNT structure grown in study [6]. a) TEM image of MWCNTs overlapping b) TEM image of MWCNT with inconsistent thickness [6]. 


\subsection{REVIEW OF THE LITERATURE}

As the power densities of microprocessors continue to increase the heat generated by the devices needs to be dissipated to prevent overheating and a shortened device lifetime [26][30][8]. To decrease interfacial resistance between the silicon chip and heat sink one or more thermal interface material (TIM) layers are used in microprocessor devices as depicted in Figure 4. Thermal greases, solders, and phase change materials currently used as TIMs in the industry have a thermal conductivity range of $0.19-8 \mathrm{Wm}^{-1} \mathrm{~K}^{-1}$, which is much lower than the materials they are transferring heat between [34][35]. Motivated by the thermal conductivity relation developed by Biercuk and Huxtable, for liquid epoxy resin filled with CNTs above a percolation threshold $\left(0.2 \%\right.$ volume fraction), $\mathrm{k}=\left(\mathrm{k}_{\mathrm{f}} \varphi\right) / 3$ where $\mathrm{k}_{\mathrm{f}}$ if the filler thermal conductivity, and $\varphi$ is the volume fraction, early research investigated carbon nanotubes dispersed in a matrix material as a potential TIM [36][37]. The relation by Biercuk and Huxtable predicts that MWCNTs with a thermal conductivity of $3,000 \mathrm{Wm}^{-1} \mathrm{~K}^{-1}$ arranged in an matrix with a volume fill fraction of only $1 \%$ would provide a thermal conductivity of $10 \mathrm{Wm}^{-1} \mathrm{~K}^{-1}$, and this exceeds current TIM materials [8]. Huxtable found CNTs dispersed in a liquid medium exhibited high interface thermal conductance between overlapping CNTs, limiting thermal conductivity measurements [37]. The CNT composite only reached an effective thermal conductivity near $1 \mathrm{Wm}^{-1} \mathrm{~K}^{-1}$ [30]. The discrepancy for CNT fillers is thought to be caused by; high boundary resistance between the CNTs and the matrix, small contact area between overlapping CNTs due to small diameters, and not all CNTs participating in heat conduction when they are randomly oriented [8].

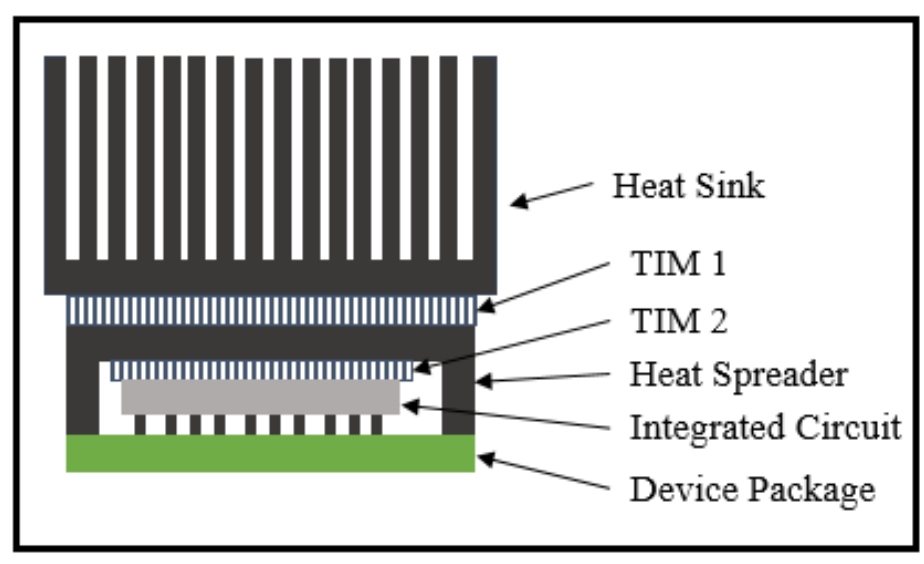

Figure 4. Microprocessor with TIMs at interfaces [7][8]. 
Aligning CNTs into vertical arrays improved the thermal conductivity of the material far more than a composite base matrix filled with transversely oriented CNTs [8]. With a higher intrinsic thermal conductivity in aligned arrays, the contact resistance at free ends remains the primary source of thermal resistance [8]. Zhao et al. discovered that by increasing volume fraction of an array from $0.87 \%$ to $1.84 \%$ the array thermal conductivity improved from $\sim 8$ $\mathrm{Wm}^{-1} \mathrm{~K}^{-1}$ to $30 \mathrm{Wm}^{-1} \mathrm{~K}^{-1}$, and the array thermal conductance increased from $0.5 \mathrm{MWm}^{-2} \mathrm{~K}^{-1}$ to 3 $\mathrm{MWm}^{-2} \mathrm{~K}^{-1}$ [30]. The MW VACNTAs were subjected to a bonding pressure which buckled the lower volume fraction arrays, creating additional boundary resistance due to CNT-CNT contact [30]. Synthesizing dense MWCNT arrays that can withstand bonding pressure without buckling is necessary to minimize interfacial resistance. Catalyst particle density and activation rate directly affect CNT array volume fraction [30]. Altering the surface topography of CNT arrays both at the substrate and top of the array changes the thermal conductance [38][26]. Transition metal catalyst particles on the substrate are covalently bonded to the MWCNTs, while weaker van der Waals interactions bond arrays to additional materials at the top surface [21]. Growing MW VACNTAs on a flat substrate with all the CNTs of similar orientation and height, is ideal for heat dissipation in microprocessor devices [38]. Considerable advancements have been made to improve MW VACNTAs thermal interfacial resistance so that heat flow is not impeded at the TIM. Improving array contact inherently reduces the interfacial resistance, however the intrinsic thermal conductivity of MWCNTs must be kept in the 3,000 $\mathrm{Wm}^{-1} \mathrm{~K}^{-1}$ range in order for the CNT array thermal conductivity to surpass other TIMs.

$\mathrm{CNT}$ array thermal transport behavior is not fully understood although certain parameters have been shown to effect the intrinsic thermal performance of arrays [30]. To improve the quality of VACNT TIMs better control over volume fraction, defects, and array height is needed [38][8]. Chemical vapor deposition (CVD) is the growth mechanism of choice to experimentally control CNT height, diameter, alignment, and adhesion to the growth substrate [23][8]. The research presented in this thesis alters the catalyst temperature during the CVD synthesis of MW VACNTAs to characterize the impact on array quality. 


\subsection{OBJECTIVES OF MY RESEARCH}

Knowledge gained from a literature review indicated that growing well aligned MW VACNTAs for TIM applications requires the following objectives; arrays aligned vertically, reducing the CNTs diameter, keeping the height close to $10 \mu \mathrm{m}$, arrays of uniform height, and minimizing the number of defects or inhomogeneity in the array [1][39][7][31][9].

Growing well aligned, straight, vertical arrays will favor the thermal conductivity transport in the axial direction. As stated previously the thermal conductivity of aligned CNT array is highly anisotropic and favors the axial over the radial direction by as much as 110 times [1]. Thermal diffusivity, a measurement of how well a material can conduct thermal energy or react to a change in temperature, varies with alignment direction as well [40][41]. Thermal diffusivity $(\alpha)$ is related to thermal conductivity by $\alpha=\mathrm{k} /(\rho \mathrm{c})$ where $\mathrm{k}$ is thermal conductivity, $\rho$ is density and $\mathrm{c}$ is specific heat [42]. The thermal diffusivity for MWCNTs along the axial alignment direction of an array is 25 times larger than across the radial direction [41]. The packing fraction of CNTs, or effective volume fraction of CNTs contributing to thermal transport, is greater for vertically aligned arrays than randomly oriented CNT films because the potential for a higher density of CNTs exists.

Individual SWCNTs outperform both double walled CNTS (DWCNTs) and MWCNTS in thermal conductance measurements [33]. Reducing the diameter of SWCNTs improves thermal conductivity, decreasing the diameter of MWCNTs is expected to cause MWCNTs to perform closer to the ideal SWCNT [39][43]. A smaller diameter will increase the internal array thermal conductivity measurements while decreasing the thermal conductance. The thermal conductance is proven to rely more heavily on boundary resistances than CNT diameter [1]. Therefore, reducing the average diameter to maximize the thermal conductivity within the array is an objective in this catalyst temperature study but it may not have an overall impact at the integrated TIM level.

Shorter CNT arrays provide higher thermal conductivities [44]. Table 1 demonstrates that for the same researchers and experimental parameters having an array only 2-3 $\mu \mathrm{m}$ longer could reduce the thermal conductivity more than $50 \%$ [1]. A length on the order of $10 \mu \mathrm{m}$ is suitable for most TIM electronic applications [3]. Growing CNT arrays outside the $10 \mu \mathrm{m}-20 \mu \mathrm{m}$ range is certainly possible with the chemical vapor deposition method used, by adding ethylene, an 
additional carbon source, or increasing the growth time, however increasing array length is not a priority for use in TIMs.

Yamamoto et al. found "CNTs [are] different from bulk materials due to [the] coexistence of ballistic and diffusive phonons" [45]. CNTs of $\mu \mathrm{m}$ length are in the quasi-ballistic thermal transport regime which allows both phonon mechanisms to coexist [45]. "In the quasiballistic regime, phonon-phonon scattering plays an essential role in thermal transport properties, and drives the system toward local thermal equilibrium" [19]. Aliev et al. found that thermal conductivity differed by a factor of four between bundled and individual MWCNT suggesting that grouping of CNTs results in a suppression of phonon modes [46]. The bundling of CNTs in the array growth process shortens the phonon mean free path, while defects and inter-tube interaction in the array can cause further phonon scattering, all events decrease array thermal conductivity [1]. The impact of CNT-CNT contact is not fully understood in the nanotechnology community, additional insight into MWCNTs structure and the resulting array thermal properties is necessary to improve thermal simulations. The capability to predict phonon scattering events as a result of abnormalities or defects within the array could close the gap between thermal conductivities experimentally observed and those calculated based on array volume fraction [1].

The impact of defects for nanotubes with similar geometrical features is not fully understood [1]. Disorder in the array can be caused by both tube structure defects and inter-tube impurities within the array. Molecular dynamic simulations have shown that low concentrations of tubular defects significantly reduce the thermal conductivity of CNTs [9]. Figure 5a provides a schematic of three common defects found in CNTs when the graphene nanotubes do not grow into the ideal hexagonal structure. While SEM images do not provide this level of detail for MWCNTs, the schematic provides useful visualization of deviations in the tube structure. In Figure $5 \mathrm{~b}$ the elastic phonon mean free path decreases with increasing levels of single vacancy defects. After modeling all three kinds of structural defects the results predicted a common thermal conductivity decrease with the reduction of the phonon mean free path [9]. Reducing the number of structural defects in the MWCNTs provides the opportunity for the volume fraction of the array to increase, due to available space on the substrate. Catalyst nanoparticle size variance is proven to impact the growth kinetics of MW VACNTAs, focusing on the catalyst could reduce 
the structural disorder and number of impurities in the array, minimize impact on the phonon mean free path and increase the thermal conductivity [17].

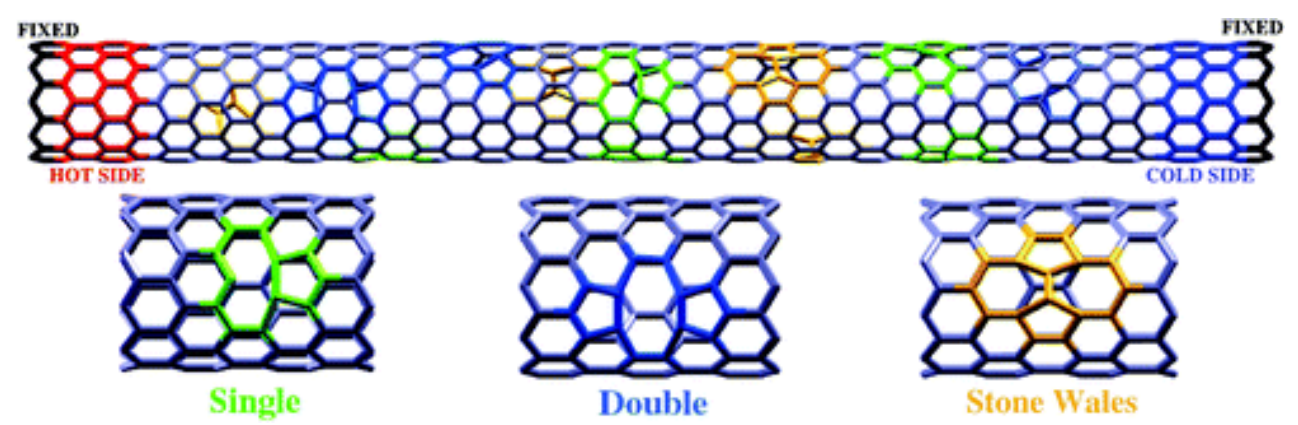

Figure 5a. Schematic of common CNT defects [9].

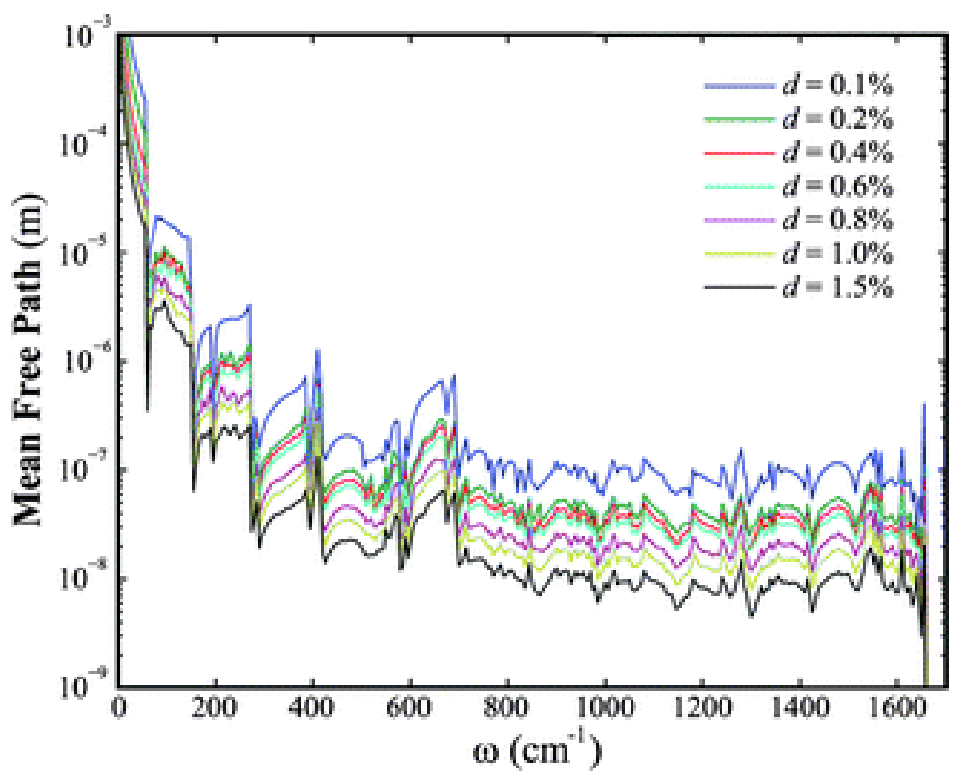

Figure 5b. Elastic phonon mean free path vs frequency (calculated using atomistic Green's functions) [9].

To improve the MW VACNTAs for TIM applications this experimental study has the following objectives; align CNTs vertically, reducing the CNTs diameter, an array height close to $10 \mu \mathrm{m}$, arrays of uniform height, and minimizing the number of defects or disorder in the array. As described in Chapter 2 a single parameter, catalyst temperature, will be investigated in this study. The motivation for this study and the variable selected were strongly influenced by 
prior work in the Nanoscale Heat Transfer Laboratory at UVA as will be described. The goal of this work is to study the effect of catalyst sublimation temperature on the growth and purity of multi-walled carbon nanotube arrays.

Briefly, Chapter 2 will discuss the chemical vapor deposition growth procedure for the CNT arrays, previous studies completed by the Nanoscale Heat Transfer Laboratory, and characterization techniques used on the samples. Chapter 3 will discuss growth mechanisms for MWCNTs and data gathered during this study. Chapter 4 provides a summary of the results section and recommendations to improve CNT growth for future studies. 


\section{Chapter 2- Experimental Methods}

\subsection{CNT GROWTH PROCEDURE}

The VACNT arrays were synthesized via chemical vapor deposition (CVD) in a tube furnace [7]. A $2.4 \mathrm{~cm}^{2}$ amorphous silicon dioxide $\left(\mathrm{SiO}_{2}\right)$ substrate is placed on a silicon wafer within a 22 $\mathrm{mm}$ inner diameter, $1 \mathrm{~m}$ long quartz tube. The silicon wafer places the silicon dioxide substrate in the vertical center of the tube to maintain a uniform gas stream and temperature. A Thermolyne tube furnace is connected to MKS mass flow controllers monitored using a MKS mass-flow power supply reader. Using a thermocouple in the center of the quartz tube and furnace zone the variation in temperature was tested within $+/-1^{\circ} \mathrm{C}$. A Fischer Scientific hotplate controls the ferrocene sublimation temperature in a zone independent to the tube furnace to an accuracy of $+/-1^{\circ} \mathrm{C}$. Measuring the ferrocene sublimation temperature zone inside the quartz tube while inert gases are flowing would increase the certainty of the temperature measurement, without this measurement the temperature error has been increased to $+/-3^{\circ} \mathrm{C}$. Ferrocene is placed into a precisely constructed aluminum foil boat inside of the tube but out of the furnace zone. Figure 6a summarizes the necessary equipment for the chamical vapor deposition growth process. In all growths a He flow of $500 \mathrm{sccm}$ is used to create an inert environment during the furnace heating and cooling. A tube furnace growth temperature of $800^{\circ} \mathrm{C}$ was selected due to previous success growing at that temperature in the Nanoscale Heat Transfer Laboratory. After stabilization of the hot plate and tube furnace at the desired temperature an argon/hydrogen blend $(0.95 / 0.05)$ at $900 \mathrm{sccm}$ carries the ferrocene particles for deposition. The argon/hydrogen blend is not thought to be reactive at room temperature, because noble gases have a stable electronic configuration, but the gaseous blend serves to maintain the inert growth environment [47]. A ferrocene heating time of 10 min allowed for the deposition of particles on the $\mathrm{SiO}_{2}$ substrate and growth of MWCNT arrays. After $10 \mathrm{~min}$ the argon/hydrogen flow is ceased and helium remains until the tube furnace cools to $200^{\circ} \mathrm{C}$. Figure $6 \mathrm{~b}$ summarizes the experimental heating and cooling times with respective gas flow rates. The cooling process takes $60 \mathrm{~min}$ and allows for minimal annealing of the sample. MWCNTs form as a result of Van der Waals adhesive forces which bind the CNTs to the substrate and each other. The forces between individual CNTs allow the CNTs to grow upwards, creating an aligned array [7]. The growth kinetics of the MW VACNT arrays is further developed in the results section. 


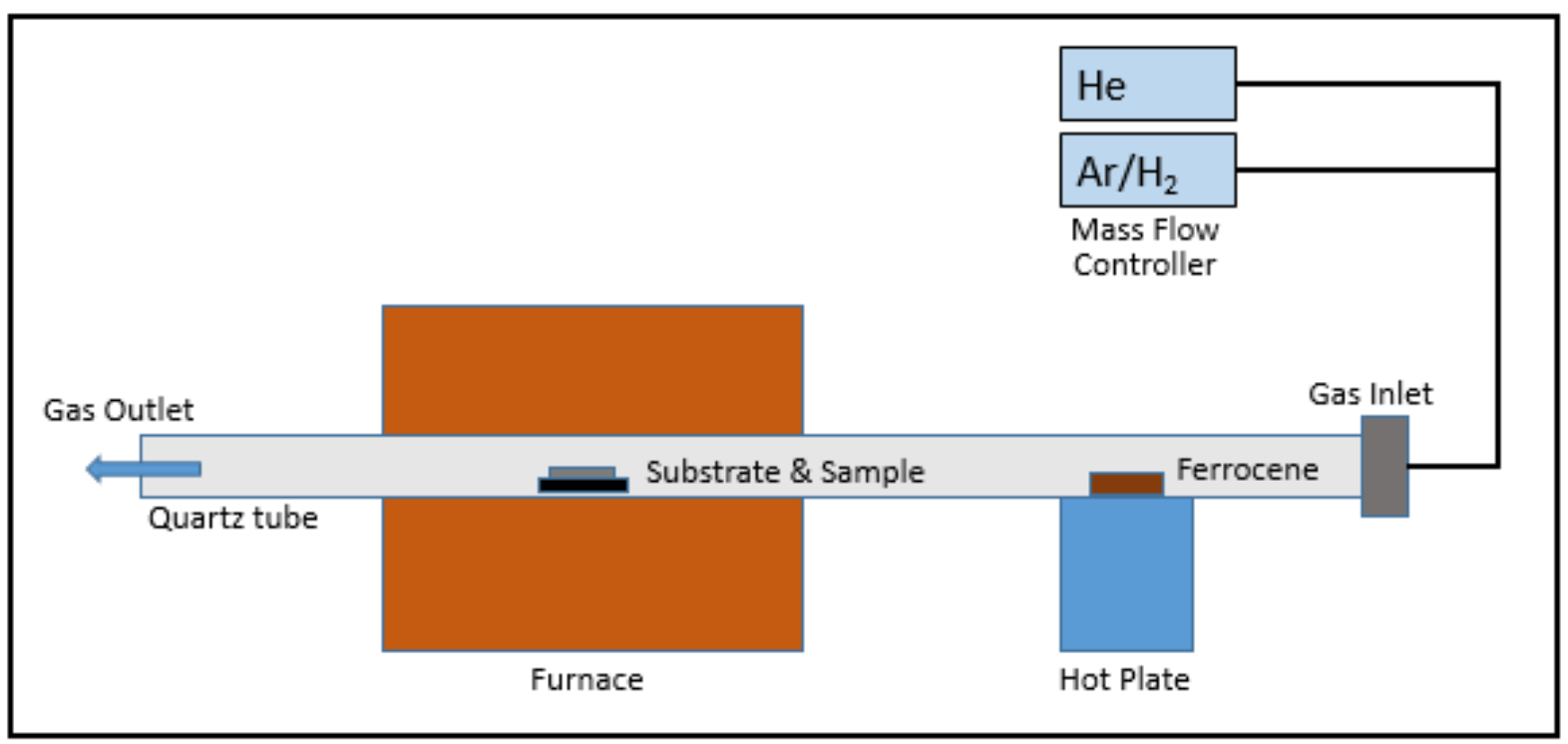

Figure 6a. Schematic of chemical vapor deposition growth equipment.

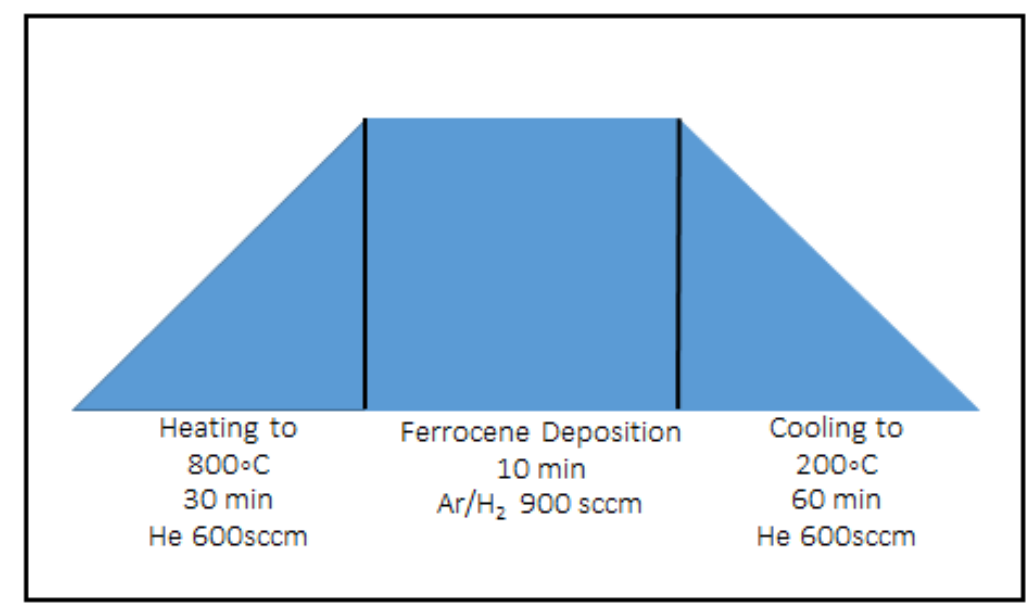

Figure 6b. Timing sequence of gases during CVD growth of MW VACNT arrays.

As explained previously, CNTs have a thermal resistance both internal to the array and at boundary interfaces. The $\mathrm{SiO}_{2}$ substrate is an inexpensive and effective substrate for our experimental growth purposes. Although the thermal boundary resistance is higher for $\mathrm{SiO}_{2}$ than pure silicon + deposited oxide layer, the same CVD techniques could easily be used on most desirable substrates for TIM applications. The difference in boundary resistance can be accounted for in thermal conductivity calculations. The contact resistance at the substrate surface 
and VACNTA base is a relatively fixed interaction based on the catalyst, CNT array and substrate selected for growth. Contact resistance at the top of the array has a greater potential for fluctuation and is therefore a focal point in this catalyst temperature study. Interfacial resistances have been found to dominate the total measured thermal resistance of a system and the interfacial resistance of MWCNTs free ends is an order of magnitude greater than at the substrate [48][1]. The prior experimental growth parameters established in the UVA Nanoscale Heat Transfer Lab resulted in a visible layer of amorphous carbon at the top of the array. Reducing the amorphous carbon layer would allow for better contact of any metal deposited, and a larger number of CNTs participating in thermal transport.

\subsection{IMPORTANCE OF CATALYST DEPOSITION TEMPERATURE}

In order to independently study the effect of catalyst sublimation temperature on VACNT arrays, growths were completed without ethylene as an additional carbon source. After sublimation of ferrocene, the catalyst, for 10 mins the silicon dioxide substrates were removed from the furnace. Independent characterization of the catalyst sublimation step had not been investigated previously in the Nanoscale Heat Transfer Laboratory, creating a necessity to examine the ferrocene nanoparticles on the substrate surface without the introduction of ethylene. This examination provides insight into the ferrocene nanoparticles size, and the possibility of drawing parallels between the catalyst nanoparticle size and MWCNT arrays grown at the same sublimation temperature. A thin orange layer of ferrocene particles were not discovered on the substrate, but instead an array of MWCNTs. In true research fashion the unexpected results led to many questions and insightful discoveries.

After the initial discovery of a MWCNT array in a growth without ethylene present the first question to be answered was whether array growth occurred on account of excess carbon in the system. The three main suspects for excess carbon in the system were; black powder remaining from pervious experiments inside the glass tube, high purity ethanol used to sterilize the equipment, and our catalyst ferrocene. A tube bake out procedure was developed which burned off the excess carbon in the tube, and this became part of our pre-experimental set-up. It was determined that at the high furnace temperatures used for growth ethanol would not exist long enough, or in high enough abundance to serve as the carbon source. Ferrocene remained the 
primary suspect for the abundance of carbon in the system. A literature search further investigating the matter revealed that multiple magnetic carbon nanostructures were formed at the Institute of Metal Research by Liu et al. using a similar CVD process to our own, including the pyrolysis of only ferrocene [17].

Liu's paper provided valuable insight into the growth mechanisms of carbon nanostructures as a function of ferrocene sublimation temperature. For the following catalyst sublimation temperatures the structures varied accordingly; $60^{\circ} \mathrm{C}-110^{\circ} \mathrm{C}$ formed ferrocene nanoparticles (NPs) adhering to SWCNTs, $110^{\circ} \mathrm{C}-140^{\circ} \mathrm{C}$ formed carbon $\mathrm{NPs}, 140^{\circ} \mathrm{C}-160^{\circ} \mathrm{C}$ formed ferrocene (Fe) nanoparticle decorated MWCNTs, and $160^{\circ} \mathrm{C}-400^{\circ} \mathrm{C}$ formed Fe-filled MWCNTs, at $280^{\circ} \mathrm{C}$ the MWCNTs began to flake off the substrate [17]. Fe nanowires within MWCNTs steadily grow in diameter with increasing sublimation temperature from $160^{\circ} \mathrm{C}-400^{\circ} \mathrm{C}$. This provided an explanation for the Fe filled MWCNTs found in the study by Bauer and indicated that further increasing the sublimation temperature above $180^{\circ} \mathrm{C}$ would not eradicate the problem. Liu also noted an amorphous unidentifiable iron carbide layer within $1 \mathrm{~nm}$ of the substrate surface, this agrees with the high level of disorder in the Raman spectra near the substrate interface for Bauer et al. [17].

It should be noted that Liu's set-up did not directly match this study, the gas flow rates were higher (2000 sccm for Argon), the quartz tube diameter is about double (40mm), the tube furnace temperature was $1100^{\circ} \mathrm{C}$ (instead of $800^{\circ} \mathrm{C}$ ), and a dual zone furnace was used as opposed to a single zone furnace with a hot plate. For these reasons the carbon nanostructures produced are not expected to replicate Liu's results, but merely used as a reference for trends. Liu's study focused on the magnetic properties of the carbon nanostructures, therefore Raman spectra gathered does not reveal the degree of disorder but instead confirms different Fe-NP structures exhibit different spectra. Additionally, the Raman collected in a single location does not reflect the uniformity of the array over the array length. The diameters of the Fe NPs are presented in the form of a histogram but not the diameters of the encompassing CNTs.

Liu et al. established that growing arrays out of ferrocene alone is possible and altering the temperature will significantly impact the final structural characteristics of the array. To better understand the quality of the MW VACNT arrays additional characterization techniques need to be utilized. Raman spectroscopy can quantify the disorder in the array, SEM will provide 
diameter and length measurements in addition to visual details of the structure, while TEM will be used to calculate the volume fraction of the CNTs.

\subsection{PREVIOUS STUDIES IN THE NANOSCALE HEAT TRANSFER LAB}

My predecessors, Matthew Bauer, Quang Pham, and Carina Lisboa in the Norris Research Group Nanoscale Heat Transfer Laboratory developed experimental techniques and procedures necessary to grow MWCNTs over the last 5+ years. The lab completed a variety of studies with the objective of increasing the thermal conductivity of MWCNT arrays while still maintaining desirable structural and mechanical material characteristics [7].

An extensive study investigating the effect of tube furnace temperature on CNT array purity, varied growth temperatures between $680^{\circ} \mathrm{C}$ and $900^{\circ} \mathrm{C}$. This study indicated that a tube furnace growth temperature between $760^{\circ} \mathrm{C}-820^{\circ} \mathrm{C}$ produced favorable MWCNTs for TIM applications, leading to our selection of an $800^{\circ} \mathrm{C}$ furnace growth temperature.

Carina implemented new gas flow rates based on an updated literature search, and an angled substrate holder or 'boat' to examine if an inclined substrate is favorable for growth conditions. The angled substrate was not found to have a noticeable impact on growth and it lacked repeatability, due to the difficulty in producing a precisely angled substrate holder. Carina's gas flow rates were used in the present study because they produced repeatable arrays, when no 'boat' was used, and utilized available gas cylinders.

A recent (2014) publication from the Nanoscale Heat Transfer Laboratory, "Thermal conductivity of vertically aligned carbon nanotube arrays: Growth conditions and tube inhomogeneity”, examined the effect of water vapor and hydrogen on CNT array growth [49]. Hata and Dutaba of A IST Tsukuba in Japan successfully grew SWCNT arrays with heights up to 2.5 millimeters by enhancing the activity and lifetime of catalysts with water-assisted chemical vapor deposition (CVD) [50]. The addition of both water vapor and increased hydrogen levels during the growth process performed by the Nanoscale Heat Transfer Laboratory improved the thermal conductivity of the sample, however a clear trend of the order in the array was not supported by Raman spectroscopy measurements (further explained in Chapter 3). TEM images (Figure 7) revealed that iron catalyst particles remained within the MWCNTs as a permanent feature in the VACNTA, influencing the structure of the tube diameter and number of 
concentric graphene layers on either side of the iron particle. Raman spectroscopy measurements along the length of the array confirmed that the degree of disorder in the VACNTA fluctuated with height. Raman revealed an increasing level of disorder at the top of the array and near the substrate. The inhomogeneity in the tubes at the substrate-array interface was hypothesized to be caused by catalyst particles "not yet formed into ordered tubes" [7].

Varying tube diameters and inhomogeneity within the arrays are problematic occurrences when growing VACNTAs for the purpose of TIM applications. Catalyst particles present inside MWCNTs influence the inner diameter of the tubes and volume fill fraction possible. Figure 8 depicts the relationship between outer diameter and achievable densities of non-bundled CNTs, with embedded catalyst particles inside the CNTs the outer diameter will increase and the density achievable in the array will decline [10]. The structural variations along the length of the array serve as defects and increase the frequency of phonon scattering events, inhibiting the MWCNT arrays from reaching their quasi-ballistic potential and limiting thermal transport [7].

Multiple variables within the chemical vapor deposition (CVD) growth process are not fully understood, providing ample research opportunities to further refine VACNTA growth for TIM applications. Bauer's TEM images confirmed catalyst particle size directly affects the MWCNT diameter dimensions, sparking an initial curiosity in catalyst deposition [7]. The Nanoscale Heat Transfer Laboratory had not yet investigated catalyst deposition, providing an ample research opportunity to explore. 

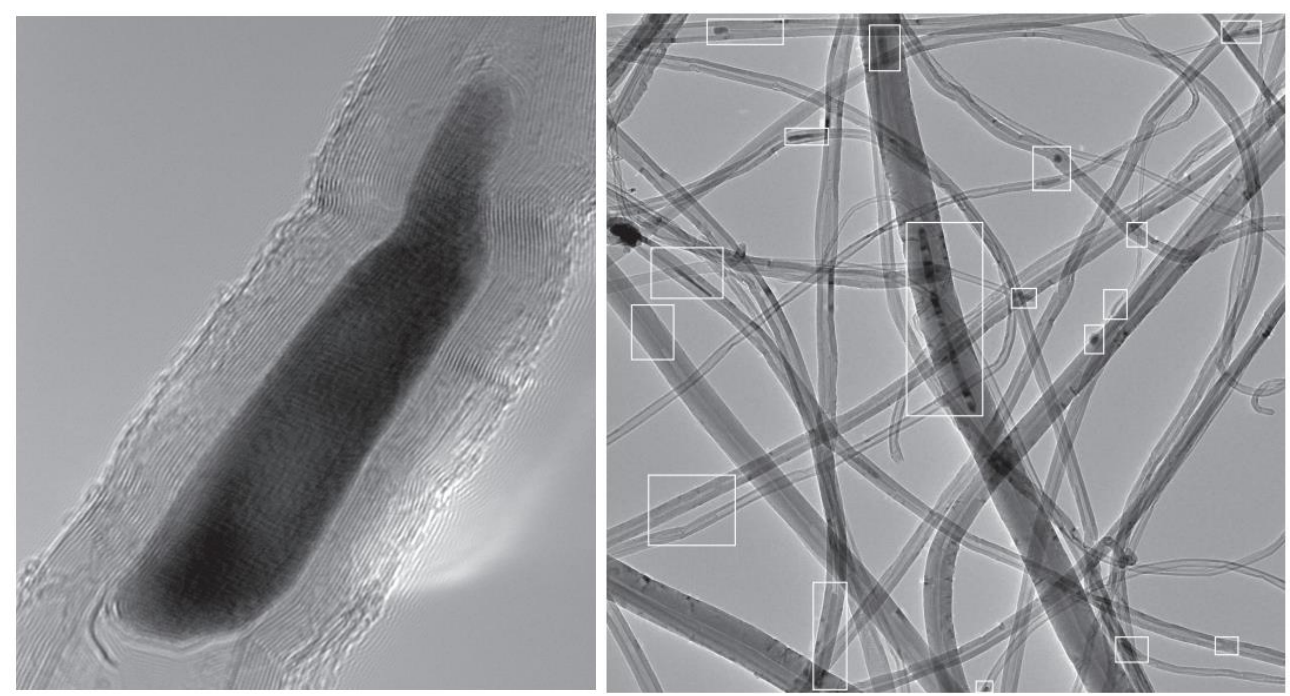

Figure 7.TEM images revealing catalyst particles inside MWCNTs [7].

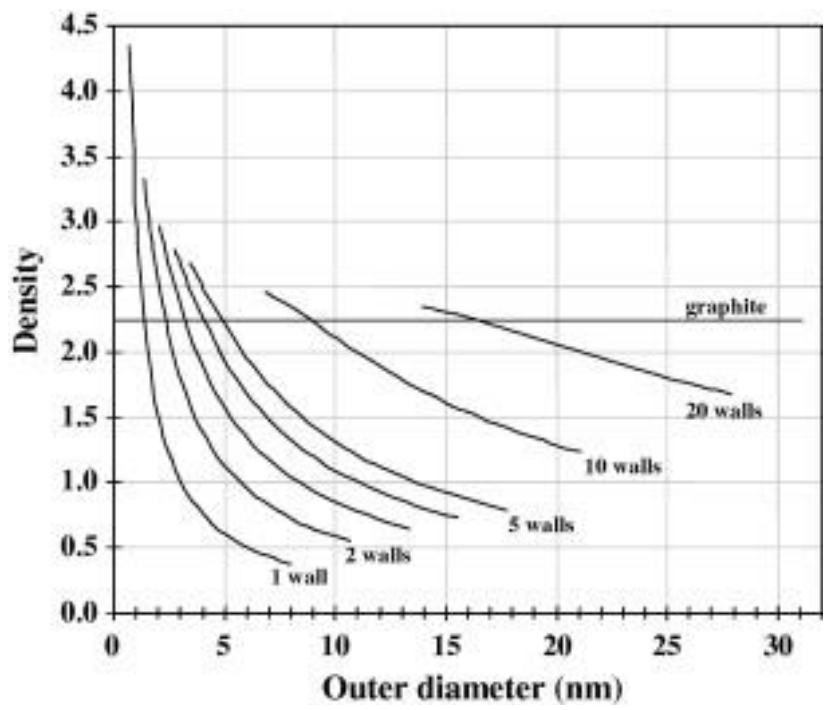

Figure 8. The density of MWCNTs versus the outer diameter for different numbers of walls [10]. 


\subsection{CHARACTERIZATION METHODS}

\subsubsection{Raman}

Raman spectroscopy involves inelastic scattering of monochromatic light originating from a laser beam [51][13]. The frequency of photons in a sample will change due to interaction with the laser beam, and the reemitted photons are measured in an optical spectrometer. The remitted photons are compared to the original monochromatic frequency, resulting in a photon frequency shift referred to as the Raman effect. Raman spectroscopy provides insight into carbon nanotubes purity, defects and tube alignment [13].

Graphene exhibits specific radial breathing modes under Raman spectroscopy which allows for the analysis of MWCNTs purity, or level of disorder, in an array using the technique. A multi-walled carbon nanotube exhibits intensity peaks on the Raman spectrum at $\sim 1360 \mathrm{~cm}^{-1}$ referred to as the $\mathrm{D}$ mode and $\sim 1600 \mathrm{~cm}^{-1}$ referred to as the $\mathrm{G}$ mode [7]. Carbon atoms that are aligned in a perfect crystalline structure form $\mathrm{sp}^{2}$ bonds, similar to graphite $\Gamma$ point vibrations, which contribute to the $\mathrm{G}$ mode or graphene mode peak intensity [16]. Amorphous or disordered carbon atoms in the array contribute to the $\mathrm{D}$ mode or disorder mode peak intensity from $\mathrm{K}$ point modes in the Brillouin Zone, which are not present in perfectly crystalline graphite [7]. The difference between these two radial breathing modes of carbon nanotubes is illustrated in Figure 9. The $\mathrm{sp}^{2}$ carbon atoms in the $\mathrm{G}$ mode are exhibiting the same movement as carbon atom chains [11]. The doublet in the D band curve displayed in Figure 10 is due to the curvature of the MWCNT [52]. 


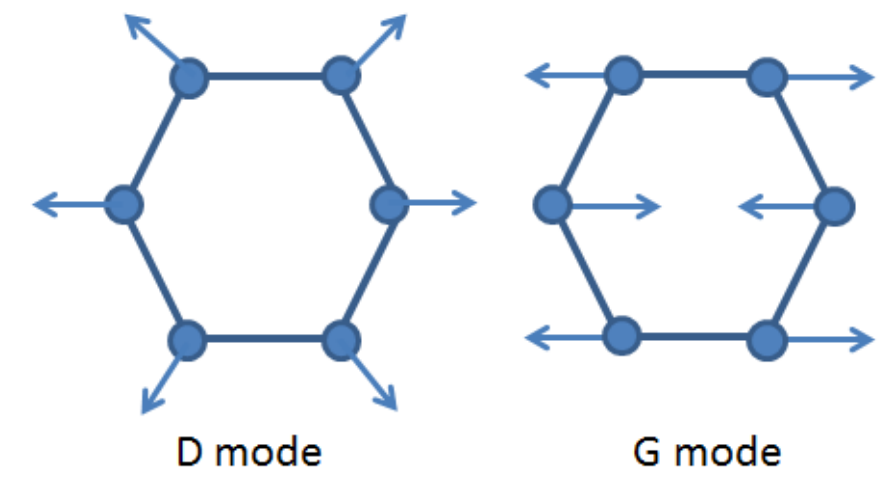

Figure 9. Carbon atoms vibrational motion in the hexagonal graphene structure of CNTs [11].

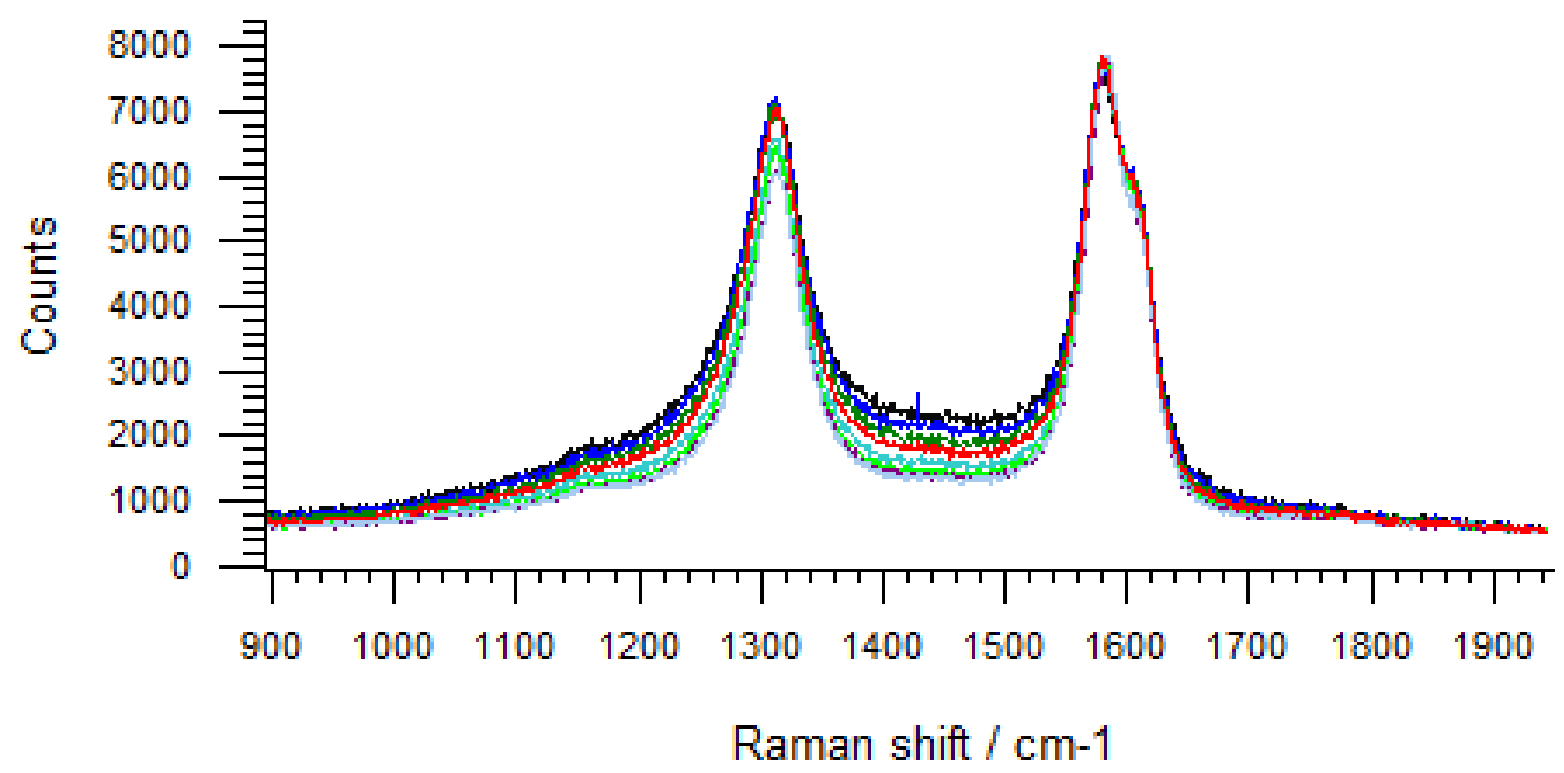

Figure 10.785nm laser excitation wavelength Raman spectra.

A common ratio quantifying the amount of disorder in the array is the $I(D) / I(G)$ ratio which is a ratio of the maximum intensity of the $D$ peak and $G$ peak. The $I(D) / I(G)$ ratio quantifies the amount of $\mathrm{sp}^{2}$ hybridized carbon versus disordered carbon atoms in the array [53]. A desirable $\mathrm{I}(\mathrm{D}) / \mathrm{I}(\mathrm{G})$ ratio for MWCNTs synthesized on a silicon substrate using a $514.5 \mathrm{~nm}$ laser is on the order of 0.8 [53]. The peak intensity curves produced for multi-walled carbon nanotubes often experience a spreading or widening of the curve which is not accounted for in 
the peak height measurement of an $\mathrm{I}(\mathrm{D}) / \mathrm{I}(\mathrm{G})$ ratio. For this reason an $\mathrm{A}(\mathrm{D}) / \mathrm{A}(\mathrm{G})$ ratio, or ratio of areas under the curve for both the D mode and $\mathrm{G}$ mode, is another mechanism used to analyze the disorder in MWCNTs [11].

A Renishaw InVia Raman spectroscopy machine with a $785 \mathrm{~nm}$ laser and a $1200 \mathrm{~g} / \mathrm{mm}$ grating was used in this study for Raman measurements, which produced a penetration depth of $48 \mathrm{~nm}$ into the array. A $514 \mathrm{~nm}$ laser could have been used however an independent study, by Costa et al., exhibited additional radial breathing modes for SWCNTs with a $785 \mathrm{~nm}$ laser [54]. Laser alignment and a silicon calibration were performed before every use. The glass substrate was cleaved with high precision tweezers in order to reveal the side-view of MW VACNT arrays. An exposure time of 120 seconds per measurement location produced minimal noise on the intensity curves and was therefore used for every scan. Raman spectra are collected in 10 positions along the length of the VACNT array with a minimum displacement of $2 \mu \mathrm{m}$, the accuracy of the Raman spectroscopy machine, up the carbon nanotubes. A mixed Gaussian and Lorentzian curve fit in WiRE Software was used to find the Raman shift curves center, width, height, and area.

\subsubsection{Scanning Electron Microscope (SEM)}

A scanning electron microscope operates by scanning an electron beam across a sample which penetrates the sample in three dimensions, providing a signal which is then picked up by several detectors to display an image or information about the sample. The selected Everhardt-Thornly Detector (ETD) measures secondary electrons (SE) for imaging specimen in a high vacuum mode [55]. Secondary electrons exhibit greater surface sensitivity compared to backscattered electrons and allow for a higher resolution image. A small spot size of 3 provided a high signal to noise ratio, allowing for high magnification images to be captured. An acceleration voltage of $5 \mathrm{kV}$ provides low penetration of the sample to minimize MWCNT array damage. High magnification images on the order of $1 \mu \mathrm{m}$ or $500 \mathrm{~nm}$ provide a qualitative assessment of the 
VACNT array structure, while MWCNT diameter measurements and array height measurements offer further characterization.

\subsubsection{Transmission Electron Microscope (TEM)}

A transmission electron microscope (TEM) operates by irradiating a sample with an electron gun. The electrons experience elastic and inelastic scattering while penetrating through the specimen and interacting with the atomic nuclei [56]. The electron intensity distribution behind the specimen is imaged with lenses providing an interior view.

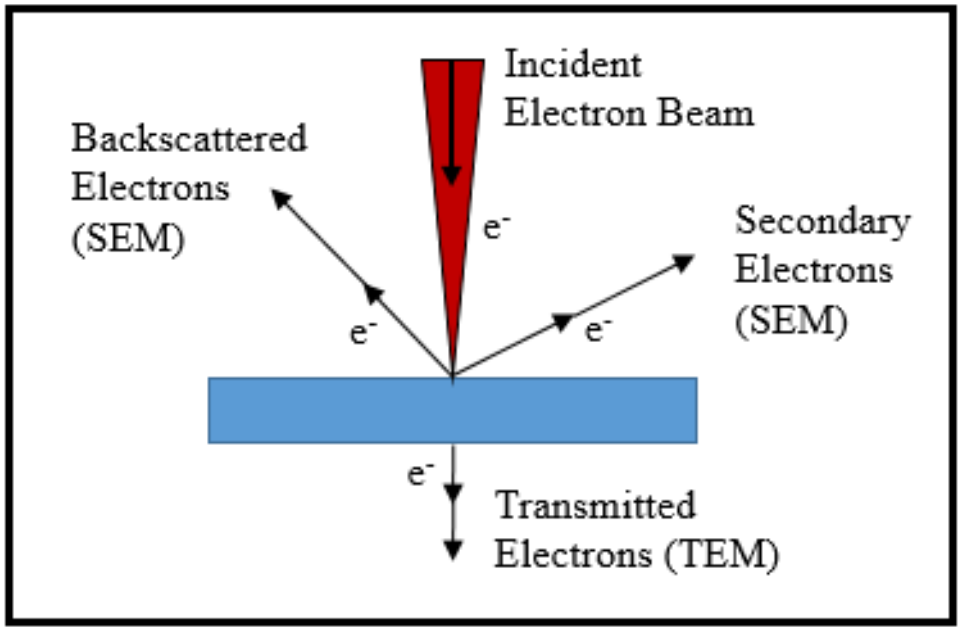

Figure 11. Schematic of electron microscope interaction with sample [12].

A specimen must be on the order of $5 \mathrm{~nm}-0.5 \mu \mathrm{m}$ thick in order to be imaged by a TEM [56]. The MW VACNT arrays far surpassed this threshold and therefore could not be imaged intact. In order to image the individual MWCNTs with the TEM the MW VACNT arrays were first scraped off the silicon dioxide substrate with a scalpel. The black CNT dust was then deposited into vials with toluene. CNTs prefer to remain in solution as agglomerate particles due to the strong Van der Waals forces between them (Figure 12), sonication is therefore necessary to allow for proper dispersion in the toluene solution [13]. A sonication duration of $25 \mathrm{~min}$ transformed the toluene solution into a uniform gray color. Mesh copper grids were then briefly dipped into the solution allowing for a single layer of MWCNTs to be imaged. 

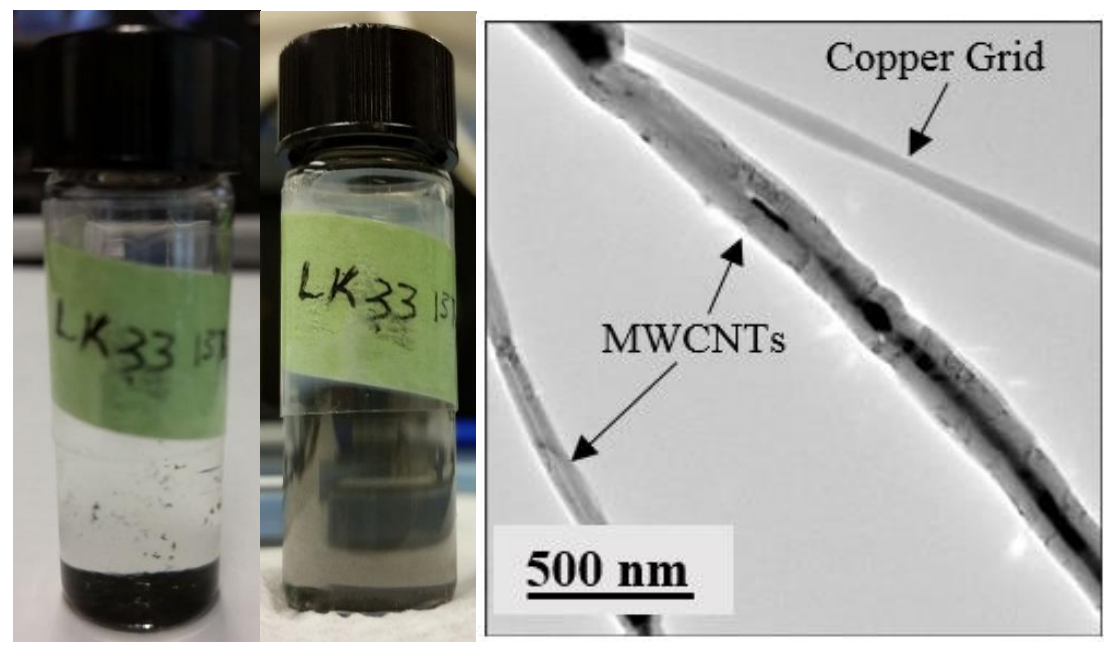

Figure 12. Poor dispersion (left) and proper dispersion (right) of CNTs [13]. TEM image verifying effective dispersion in toluene solution.

TEM images allow for structural characterization of CNTs including; determination of catalyst particles presence or absence within the tube, number of concentric rings for multiwalled carbon nanotubes, and inner/outer diameter CNT dimensions. Volume fraction for CNT arrays can be reported using the number of CNTs per unit area or estimated from a comparison of graphite density to the array density [1]. A method for volume fraction calculations using TEM diameter data and graphite's density is summarized in Table 2, and will be utilized in this study.

Table 2 Volume Fraction of MWCNT Arrays

\begin{tabular}{|c|c|c|c|}
\hline \multicolumn{2}{|c|}{ Experimentally obtained parameters } & \multirow{2}{*}{$\begin{array}{c}\text { Calculated results } \\
\text { Cross-section area of } \\
\text { hollow part }\end{array}$} & \multirow[b]{2}{*}{$\pi(2.75)^{2}=23.8 \mathrm{~nm}^{2}$} \\
\hline Inner diameter & $5.5 \mathrm{~nm}$ & & \\
\hline Number of walls & 4 & $\begin{array}{l}\text { Cross-section area of } \\
\text { whole CNT }\end{array}$ & $\pi(4.1)^{2}=53.1 \mathrm{~nm}^{2}$ \\
\hline Wall thickness & $0.34 \mathrm{~nm}$ & Wall area & $(53.1-23.8)=29.3 \mathrm{~nm}^{2}$ \\
\hline Outer diameter & $8.2 \mathrm{~nm}$ & $\begin{array}{l}\text { Volume fraction of wall } \\
\text { area in tube }\end{array}$ & area $_{\text {wall }} /$ area $_{\text {total }}=0.552$ \\
\hline Array density & $0.017 \mathrm{~g} / \mathrm{cm}^{3}$ & $\begin{array}{l}\text { Density of as-grown } \\
\text { CNT }\end{array}$ & $2.26 \mathrm{~g} / \mathrm{cm}^{3} \times 0.552=1.25 \mathrm{~g} / \mathrm{cm}^{3}$ \\
\hline graphite density & $2.26 \mathrm{~g} / \mathrm{cm}^{3}$ & $\begin{array}{l}\text { Volume fraction of } \\
\text { array }\end{array}$ & $\left(0.017 \mathrm{~g} / \mathrm{cm}^{3} / 1.25 \mathrm{~g} / \mathrm{cm}^{3}\right)^{*} 100=1.4 \%$ \\
\hline
\end{tabular}

(Table 2. Method developed by Lin et al. [2].) 


\section{Chapter 3- Results}

\subsection{THE CATALYST IN CHEMICAL VAPOR DEPOSITION}

Multi-walled carbon nanotubes are $\mathrm{sp}^{2}$ hybridized molecular structures which belong to the fullerene family [57]. Multi-walled bundles and arrays can be formed by numerous growth mechanisms including laser ablation, arc discharge, flame synthesis, high pressure carbon monoxide, electrolysis, pyrolysis, and chemical vapor deposition (CVD) [18]. Chemical vapor deposition draws fundamental knowledge from years of surface science research investigating hydrocarbons interaction with transitional metal surfaces [58]. Chemical vapor deposition is the most popular method for growing carbon nanotubes because it is low cost, can be completed in standard atmosphere in a furnace below $1000^{\circ} \mathrm{C}$, produces high quality and high yield CNTs, has the potential for direct device integration, and can be easily scaled up for industry applications [57][18]. The Nanoscale Heat Transfer Laboratory owned the necessary equipment for CVD, making it the clear choice for CNT synthesis. The most popular transition metal nanoparticles used to catalyze CNT growth are Fe, Ni, Mo and Co [59]. Catalysts beyond transition metals have been utilized in recent studies including noble metals, ceramic nanoparticles, and semiconducting nanoparticles [18]. Not all of the non-traditional catalysts attempted effectively disassociated hydrocarbons, which resulted in a new interpretation of the catalyst's role. The catalyst's nanoscale curvature and carbon absorption sites were found to control the structural formation and development of carbon nanotubes [18]. Ferrocene $\mathrm{Fe}\left(\mathrm{C}_{5} \mathrm{H}_{5}\right)_{2}$ served as both the catalyst and carbon source in this study, therefore the Fe nanoparticles curvature will influence diffusion rates. Previous studies indicated temperature greatly affects the transition metal catalyst's (Fe) nanoparticle size development in MWCNTs created using CVD [1][5]. Although the exact growth mechanics of MWCNTs formed by CVD is still being disputed by the scientific community, further elaboration of proposed growth kinetics is provided in the next subsection to create a better understanding of subsequent data analysis. 


\subsection{GROWTH MECHANISMS FOR MWCNTS SYNTHESIZED BY CVD}

Single walled carbon nanotube (SWCNT) growth kinetics are well understood at this time through in situ HRTEM studies, molecular dynamics simulations and density functional theory calculations. MWCNT growth kinetics are not universally understood, although the theory is similar to SWCNT growth, the simultaneous nucleation and growth of concentrically aligned walls causes some discrepancies [58]. Two mechanisms which are used to describe MWCNT growth are the vapor-solid solid model and vapor-liquid-solid model.

\subsubsection{Vapor-Solid-Solid Model}

According to the Vapor-Solid-Solid (VSS) model for growth hydrocarbons dissociate in the gaseous state, resulting in carbon atoms free to diffuse into the catalyst particle's surface. The carbon saturated catalyst precipitates carbon resulting in nanotube growth [58]. The catalyst particle dimension and precipitation rate determine the physical form of the carbon precipitating. Carbon nanotubes produced at temperatures below the eutectic temperature for the metal catalyst debunk the vapor-liquid-solid model as the only form of CNT synthesis [15].

The CNT growth mechanisms are further categorized between base (or root) growth and tip (or float) growth, which is differentiable based on whether the catalyst remains adhered to the substrate or is lifted off the substrate surface by the CNT formation [14].

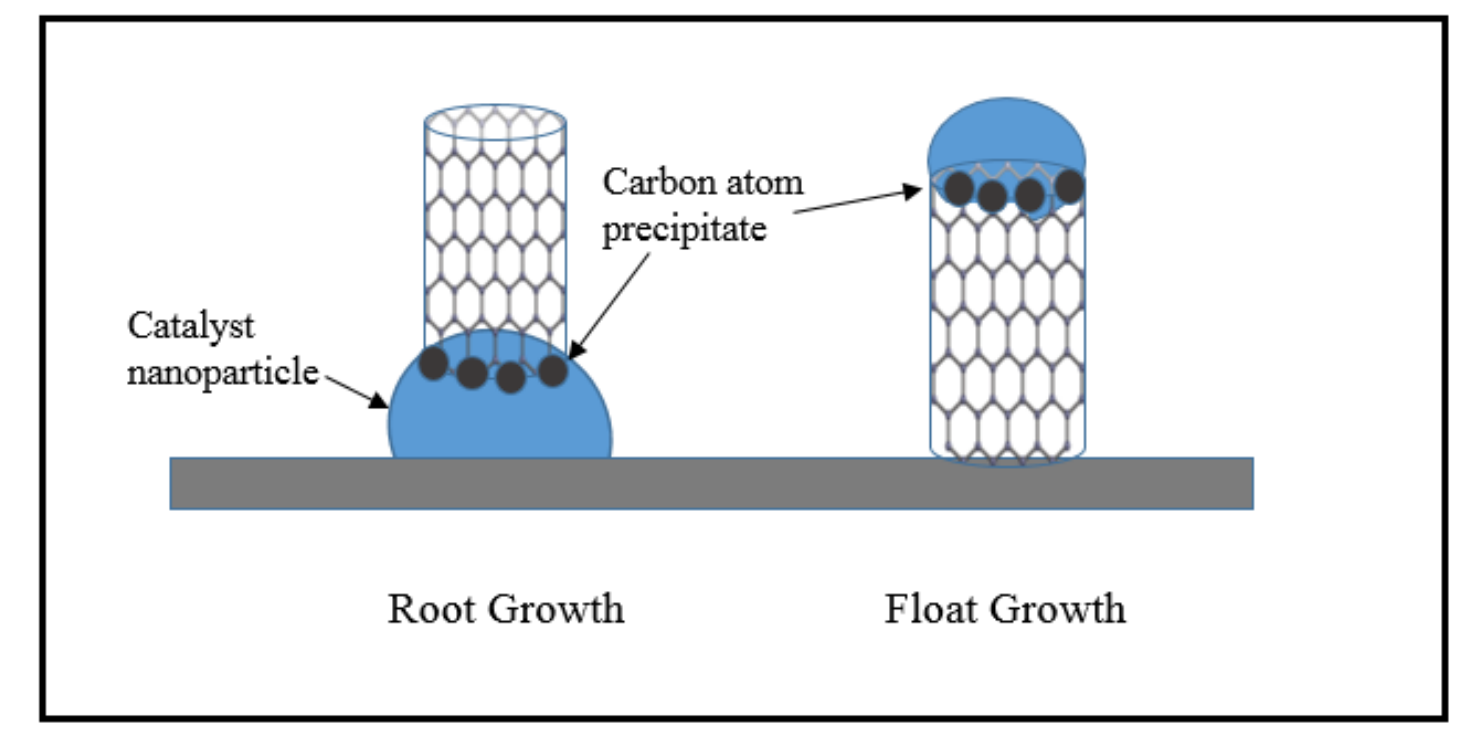

Figure 13 Catalytic growth processes, Root Growth and Float Growth during CVD [14]. 


\subsubsection{Vapor-Liquid-Solid Model}

According to the Vapor-Liquid-Solid (VLS) model a gaseous hydro-carbon absorbs and dissociates on the catalyst forming carbon atoms. The carbon atoms dissolve into the bulk of the material forming a liquid metastable carbide. The liquid metastable carbide then diffuses within the catalyst particle and the solid carbon precipitates outward creating a carbon nanotube [14][58].

The presence of a metal nanoparticle at the end of a carbon nanotube of similar diameter has been used to defend the VLS growth mechanism, although the presence of the nanoparticle at the tip in no way confirms the metal catalyst phase during growth [14]. A chemical potential and temperature gradient drive the carbon atoms to diffuse into the solid. For thermally driven CNTs synthesized via CVD the activation energy must surpass the barrier for gas decomposition (ferrocene disassociation). This differs from CNTs grown using plasma enhanced CVD, where the activation barrier is lowered, and carbon diffusion on the catalyst sub-surface limits the reaction [15].

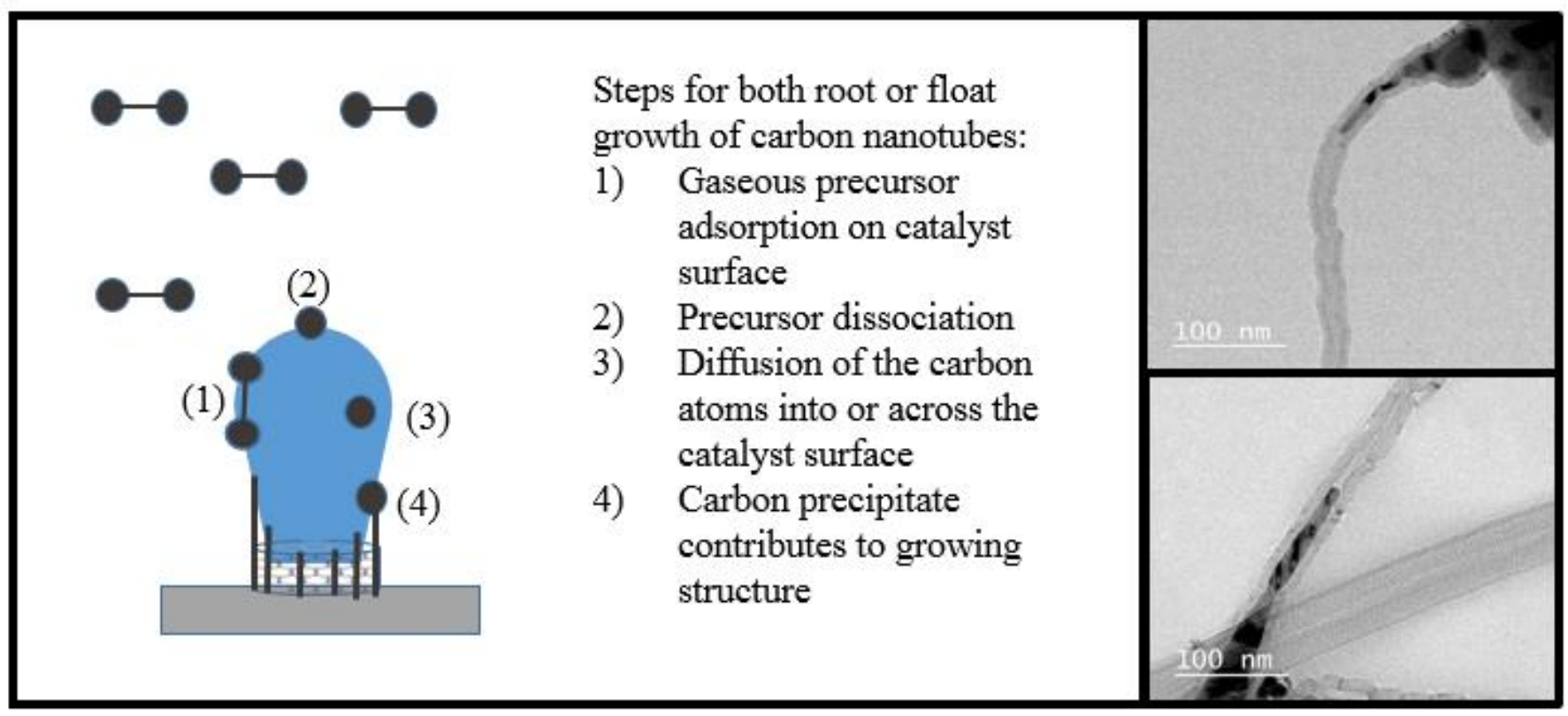

Figure 14. Schematic of growth process and MWCNT TEM images at 100nm of similar structure [15].

MWCNTs grown from ferrocene are believed to form from the VLS growth mechanism [58][17]. The carbon dissolution in the Fe catalyst particles is viewed as the rate limiting step in 
the reaction [58]. Sub-surface diffusion requires crossing a low energy barrier allowing concentrically aligned carbon walls to form. Iron carbide $\left(\mathrm{Fe}_{3} \mathrm{C}\right)$ products form during the reaction process but iron carbide is not proven to support CNT growth [60]. Iron carbide is believed to form after the CNT growth has already taken place, as the furnace temperature is lowered, or from a deactivated catalyst nanoparticle [60].

Through in situ HRTEM experiments both the VLS and VSS mechanism for growth have been observed for SWCNTs [58]. The dominant growth mechanism depends on all system parameters but primarily the materials and temperatures selected. Surface energy diffusion requires significantly less activation energy than bulk diffusion so although bulk diffusion is possible at higher temperatures it is not commonly exhibited [58]. Crystallographic orientations were experimentally altered for single walled carbon nanotubes grown from specially treated, selective area electron diffraction prepared Ni catalyst nanoparticles. The step edges exhibited around the Ni particles during growth further support sub-surface diffusion as opposed to bulk diffusion as the primary VSS mechanism [58]. Characterizing the growth mechanisms between VLS and VSS does not change the dynamics of the nanotube formation because both methods involve carbon precipitating from a supersaturated catalyst nanoparticle regardless of the nanoparticle's phase [14]. The diffusion model is driven by dependence on the catalyst particle's size and not its phase.

\subsubsection{Diffusion Model for Growth}

The carbon content is of critical importance during the growth of VACNT arrays. An abundance of carbon will result in amorphous carbon impurities which can encapsulate the catalyst particle and poison, or foul, the catalyst causing deactivation [58]. The fouling of a catalyst caused specifically by carbon may also be referred to as 'coking' in literature [61]. Insufficient carbon content will not result in high purity VACNT arrays. Gao et al. determined that an electron-beam evaporated Fe catalyst layer from 2-11nm provided dense VACNT arrays while a $20-30 \mathrm{~nm}$ catalyst film did not in a $600^{\circ} \mathrm{C}$ furnace with a carbon gas precursor present [53]. Similarly, Wei et al. found that for catalyst films deposited directly on a substrate the critical thickness to maintain CNT growth varied with temperature in a near linear relationship from $640^{\circ} \mathrm{C}-800^{\circ} \mathrm{C}$ supporting a maximum catalyst film thickness of $5 \mathrm{~nm}-60 \mathrm{~nm}$ respectively 
[23]. Both authors concluded the temperature dependence of the ideal catalyst film thicknesses discovered were a result of the diffusion model, which states that CNT formation is a result of precipitated carbon atoms from a supersaturated catalyst nanoparticle. Under the diffusion model the diffusional length of carbon atoms cannot be exceeded by the catalyst particle size in order for CNT growth to occur [53][23]. The temperature variation of the critical film thickness is credited to the temperature dependence of the carbon diffusion length [23]. With ferrocene serving as the only carbon source in this study there is no super-saturation of carbon provided from a gas precursor, an abundance of Fe creating a thickness greater than 60nm could inhibit further growth of CNTs in the $800^{\circ} \mathrm{C}$ furnace. The catalyst nanoparticle temperature during growth will effect both surface and bulk diffusion, the dissociation adsorption of carbon, and diffusion of metal atoms on the substrate [14].

The Gibbs-Thompson equation states the pressure difference across grain boundaries is proportional to the surface energy and radius of curvature of the sub-grain, or cell, pinned by the MWCNT [62]. A change in the diameter particle size effects the curvature and therefore the chemical potential driven solubility [14]. A catalyst nanoparticle that supports CNT growth will drive the incorporation of new material into the formation of a CNT at the axial growth interface by lowering the activation energy barrier [14]. It must be more energetically favorable, or requiring a lower activation energy, for the carbon material in the system to form CNTs instead of nucleating into additional amorphous islands on the substrate.

\subsection{THE THERMAL FRAGMENTATION OF FERROCENE DURING CVD}

Chemical Vapor Deposition most commonly involves a catalyst being deposited, in the form of a solution, directly on the non-conducting growth substrate and then nucleated via chemical etching or thermal annealing [18]. The catalyst coated substrate is then exposed to hydrocarbon gases and process gases for CNT growth to occur. Alternatively, the sublimation of ferrocene in this experiment creates a thin film layer of Fe, which clusters due to Volmer-Weber interactions where the $\mathrm{Fe}$ surface atoms have a stronger attraction to each other than the $\mathrm{SiO}_{2}$ substrate, creating the nucleation site for CNT formation [63]. The $\mathrm{SiO}_{2}$ substrate inhibits epitaxial growth, causing disordered Fe atoms to more readily agglomerate into nanoparticle islands as opposed to a uniformly distributed layer of Fe atoms [14]. Ostwald ripening, or the 
structural evolution over time of larger precipitate particles growing at the expense of smaller sized particles, also creates nucleation sites for growth and is accelerated by thermal annealing [64]. The interplay between Volmer-Web interactions and Ostwald ripening forces will alter the size of the Fe nanoparticle on the substrate.

A dual zone furnace set-up is rare in the community and a single zone furnace growth is even less common which makes the following study and growth kinetics suggested by Ravi Bhatia a very interesting comparison to this experiment. Bhatia et al. grew MWCNT bundles using only ferrocene in a quartz tube without a substrate at $980^{\circ} \mathrm{C}$ and $800^{\circ} \mathrm{C}$ as summarized in Table 3 below [57]. Ferrocene was the only carbon source in the experiment. Bhatia et al. attempted to perform CVD at furnace temperatures below $800^{\circ} \mathrm{C}$ which resulted in a low yield of CNTs and lumps of amorphous carbon, this aligns with Quang's findings for ideal growth temperatures [65]. Carbon diffusibility and solubility within Fe drives the resulting nucleation and growth of the MWCNTs. Bhatia found the structural development of MWCNT bundles depended on the thermal fragmentation of the ferrocene particles in the furnace. Ferrocene's sublimation point at standard atmosphere is $100^{\circ} \mathrm{C}$, melting point is $173^{\circ} \mathrm{C}$, and boiling point is $249^{\circ} \mathrm{C}$ [16]. In this experiment the catalyst temperature ranged from the minimum temperature necessary for sublimation $\left(100^{\circ} \mathrm{C}\right)$ to just beyond the melting point $\left(180^{\circ} \mathrm{C}\right)$. Vaporized ferrocene was then carried by a blended argon gas stream into the $800^{\circ} \mathrm{C}$ furnace. The ferrocene in Bhatia's study was not carried along the length of the tube by an argon gas stream and instead formed MWCNTs on the quartz tube near the original ferrocene source. Although the growth techniques vary slightly, in both cases the MWCNTs are formed by ferrocene in an inert environment above boiling point therefore the chemical decomposition of ferrocene will be similar.

\begin{tabular}{|l|l|l|}
\hline & Scheider & Bhatia \\
\hline $\begin{array}{l}\text { Furnace } \\
\text { Temperature }\end{array}$ & $800^{\circ} \mathrm{C}$ & $980^{\circ} \mathrm{C} \& 800^{\circ} \mathrm{C}$ \\
\hline $\begin{array}{l}\text { Second Zone } \\
\text { Temperature }\end{array}$ & $\begin{array}{l}135^{\circ} \mathrm{C}- \\
180^{\circ} \mathrm{C}\end{array}$ & $\begin{array}{l}\text { N/A, ferrocene placed directly in single } \\
\text { temperature zone furnace }\end{array}$ \\
\hline Growth Time & $10 \mathrm{~min}$ & 35 min \\
\hline Argon Supply & $\begin{array}{l}\text { Continuous } \\
\text { flow }\end{array}$ & $\begin{array}{l}\text { Argon gas bladder connected when } \\
\text { furnace reached growth temperature }\end{array}$ \\
\hline
\end{tabular}

(Table 3. A comparison of key experimental parameters in Bhatia's study and this work [57]) 
The ferrocene molecule is stable below $454^{\circ} \mathrm{C}$ so the ferrocene vapor particles are stable in the first temperature zone near the hot plate [66]. After reaching the furnace temperature of $800^{\circ} \mathrm{C}$ the ferrocene molecular structure begins to break in a sequence corresponding to the binding energies. Molecular dynamic simulations performed by Elihn et al. found that the ferrocene molecule undergoes complete fragmentation in $300 \mathrm{fs}$ at $1000 \mathrm{~K}\left(727^{\circ} \mathrm{C}\right)$ [67]. C-H bonds have the lowest binding energy so they disintegrate first, followed by the $\mathrm{C}-\mathrm{C}$ and $\mathrm{Fe}-\mathrm{C}$ bonds visualized in Figure 15 [57]. The hydrogen atoms with a low binding energy of 492 $\mathrm{kJ} / \mathrm{mol}$ first leave the ferrocene molecule. Next the cyclopentadienyl $\left(\mathrm{C}_{5} \mathrm{H}_{5}\right)$ ring breaks when the C-C binding energy of $602 \mathrm{~kJ} / \mathrm{mol}$ is reached, lastly the Fe-Cp bond with a binding energy of $1480 \mathrm{~kJ} / \mathrm{mol}$ disintegrates [67]. The catalyst particle is available for MWCNT formation above $454^{\circ} \mathrm{C}$, at lower temperatures thermal vibrations will be taking place but the ferrocene bonds remain intact. After the Fe nanoparticle is dispersed on the substrate it becomes covered by dimer and trimer carbon clusters [57]. The supersaturated nanoparticle precipitates out carbon in a tubular structure forming a MWCNT. Although carbon nanotubes can form in a non-inert environment they will lack alignment and have increased amorphous carbon levels. With the disintegration of ferrocene possible at temperatures above $454^{\circ} \mathrm{C}$ carbon nanotubes can be grown at lower temperatures, however the ratio of structured CNTs to amorphous carbon decreases at temperatures below $800^{\circ} \mathrm{C}$ [49][57].

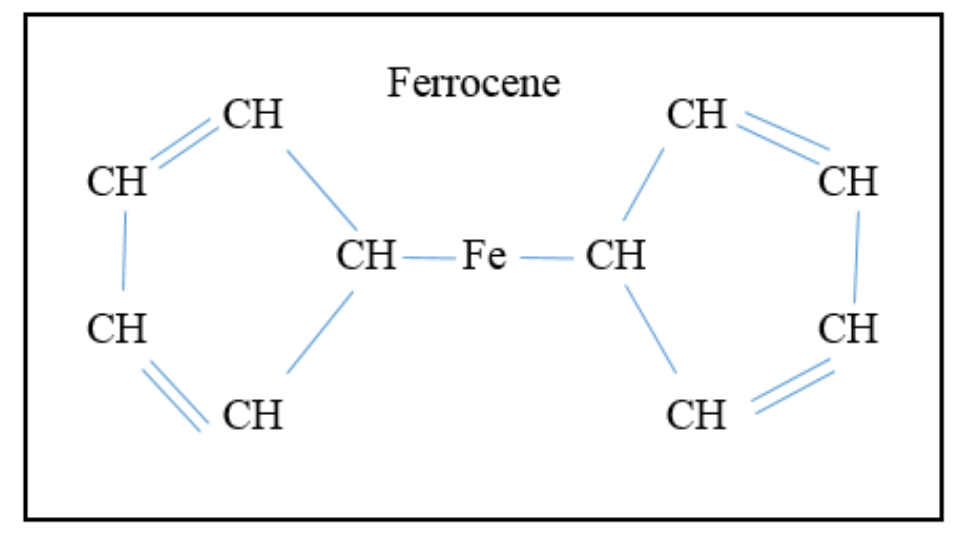

Figure 15. Ferrocene chemical structure [16]. 


\subsection{DATA OVERVIEW}

\subsubsection{Scanning Electron Microscope (SEM) Data}

SEM images provide an initial view of the MW VACNTA structure. The most notable discovery during the initial imaging of samples was that ferrocene deposition during the growth process does not produce nanoparticles that are not yet formed into ordered tubes, but MW VACNTAs. After reducing excess carbon in the experimental set-up and completing a literature search it was confirmed that ferrocene provides a high enough concentration of carbon to form CNTs. As seen in Figure 16 a distinguishable trend existed between the array height and ferrocene sublimation temperature. Thermal decomposition of ferrocene increases with temperature which allows for an increased growth rate in our experiment. At $800^{\circ} \mathrm{C} \mathrm{Kim} \mathrm{et} \mathrm{al.}$ observed a growth rate of $10 \mu \mathrm{m} / \mathrm{min}$ using an iron chloride catalyst, pretreated with ammonia, and acetylene $\left(\mathrm{C}_{2} \mathrm{H}_{2}\right)$ gas as the carbon source [68]. Using no catalyst pretreatment process and no hydrocarbon gas source it is not surprising that the growth rate is less in this experiment. The amount of carbon available to precipitate out of the catalyst limits the rate of reaction [68]. Still, the growth rate range of $0.7-3.3 \mu \mathrm{m} / \mathrm{min}$ in Figure 16 is within the same order of magnitude expected for a Fe catalyst growth. 


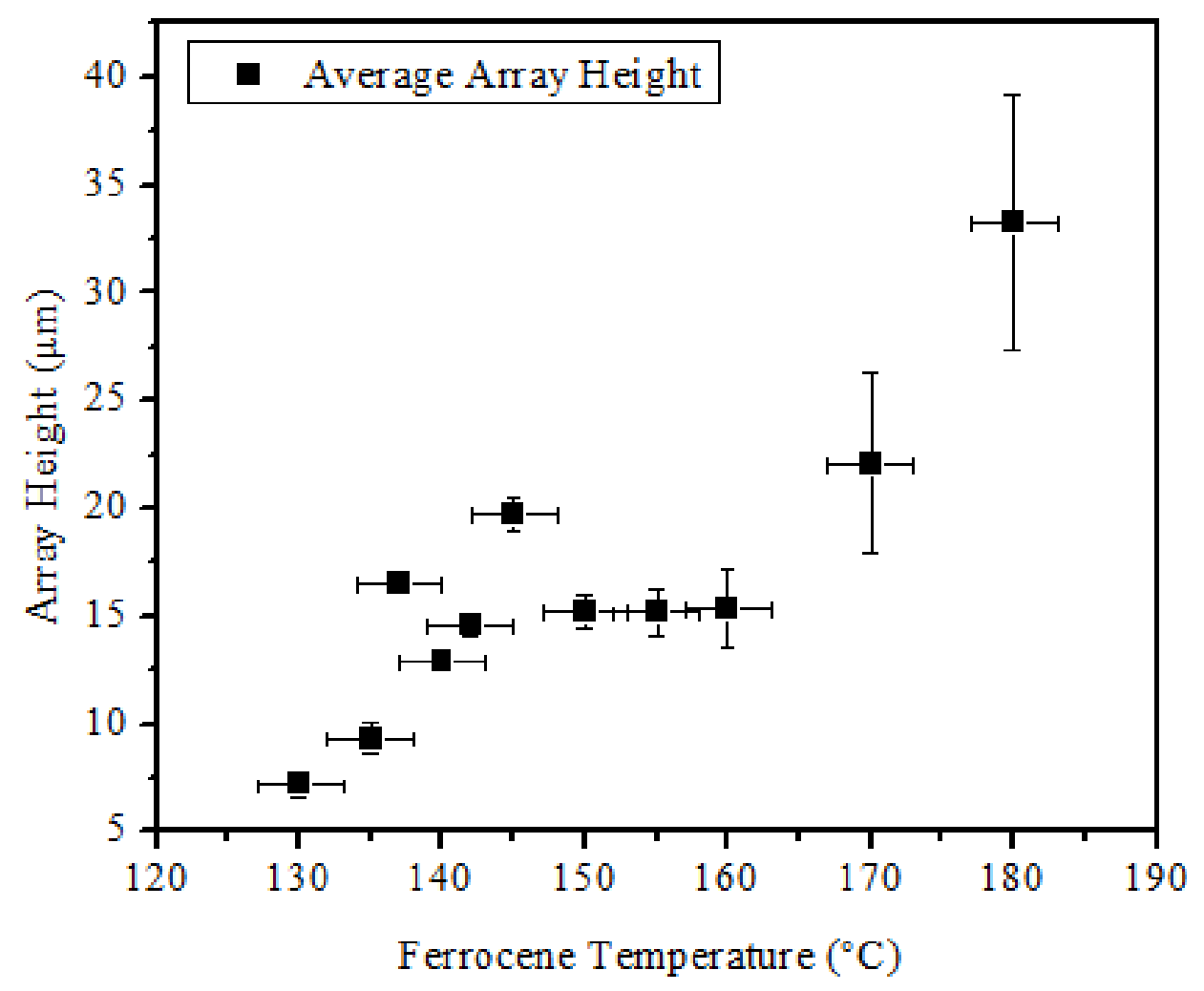

Figure 16. Array Height vs. Ferrocene Sublimation Temperature. The horizontal error bars represent $+/-3{ }^{\circ} \mathrm{C}$ temperature uncertainty, and the vertical error bars represent the standard deviation of array height measurements.

The error bars in Figure 16 depict the standard deviation from forty-five measurements of the array height taken across images at three separate locations. The deviation in height at the higher ferrocene sublimation temperatures is a result of amorphous carbon on top of the VACNTAs as illustrated in Figure 17. The original growth procedure, set by my predecessors in the Nanoscale Heat Transfer Laboratory, used a ferrocene sublimation temperature of $180^{\circ} \mathrm{C}$ which is shown in picture A. After reducing the ferrocene sublimation temperature to $140^{\circ} \mathrm{C}$ (picture E) the array height standard deviation improved from $8.6 \mu \mathrm{m}$ to $0.44 \mu \mathrm{m}$, a $94 \%$ decrease. As stated in Chapter 1, uniform array height is necessary to provide good contact for optimal thermal transport in a thermal interface material (TIM) system. Additionally, the array at $140^{\circ} \mathrm{C}$ has a length of $12.9 \mu \mathrm{m}$ which is close to the $10 \mu \mathrm{m}$ array objective for high thermal conductivity. Further reduction in sublimation temperature to $137^{\circ} \mathrm{C}$ did not improve the height uniformity of the array although the degree of disorder is similar to the $140^{\circ} \mathrm{C}$ sample. 


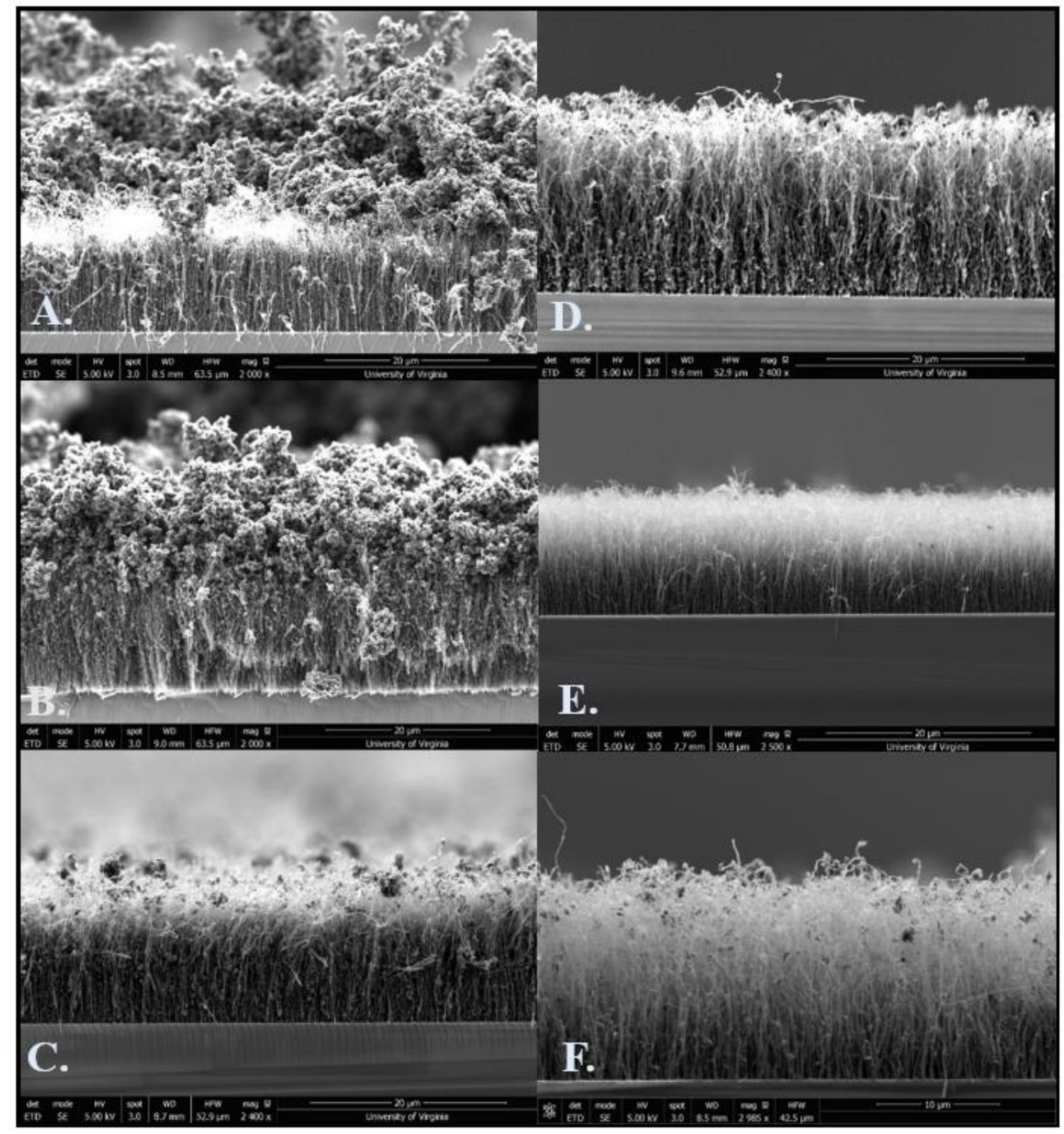

Figure 17. MW VACNTAs synthesized with a ferrocene sublimation temperature of A. $180^{\circ} \mathrm{C}$, B. $170^{\circ} \mathrm{C}, \mathrm{C} .160^{\circ} \mathrm{C}, \mathrm{D} .145^{\circ} \mathrm{C}, \mathrm{E} .140^{\circ} \mathrm{C}, \mathrm{F} .137^{\circ} \mathrm{C}$. All images have a scale bar of $20 \mu \mathrm{m}$ except image $\mathrm{F}$ which has a scale bar of $10 \mu \mathrm{m}$. For additional images see Appendix 2.

After the ferrocene particle is thermally decomposed the remaining Fe particles on the substrate form a dense mat and cluster together creating surfaces for CNT growth upon further heating [23]. The thickness of the nanoparticles size is of critical importance. When the catalyst 
nanoparticle is larger than the diffusion length of the carbon atoms the catalyst particle does not support growth [23]. As pictured in Figure 14 of the Growth Mechanisms section the carbon atoms must be able to diffuse to the backside of the catalyst agglomerate in order to form CNTs, this is not possible if the catalyst film thickness becomes larger than the diffusion length [23]. The outermost CNT diameter is determined by the catalyst particle size which makes finding a means to control the catalyst particle size an attractive opportunity [23][69]. A study on SWCNTs found multiple ways to decrease SWCNT diameters including; decreasing catalyst particle diameters, changing the catalyst particles elemental composition to alter the adhesion of carbon atoms, and decreasing the reaction temperature in order to grow CNTs on only the smallest particles [58]. Altering the furnace temperature or reaction temperature was already investigated independently by the Nanoscale Heat Transfer Laboratory which did not provide MWCNT arrays of desirable purity. Altering the sublimation temperature of ferrocene did have an effect on MWCNT diameters as summarized in Figure 18 histograms. For a full representation of the histograms across the growth temperatures see Appendix 1. Measuring 150210 diameters (depending on how many MWCNTs were clearly divisible in the SEM images) provided a sampling of the diameter dispersion within the arrays. A distinct shift in the diameters measured exists between the original sublimation temperature of $180^{\circ} \mathrm{C}$ and sublimation temperatures near $140^{\circ} \mathrm{C}$. It is very difficult to control the nucleation of transition metal particles from a gaseous phase [58]. At higher temperatures the Fe nanoparticle size distribution is less uniform which causes the widespread range of diameters measured. The range of diameter for the $180^{\circ} \mathrm{C}$ sample is from $18-250 \mathrm{~nm}$ with a difference of $232 \mathrm{~nm}$, while the $140^{\circ} \mathrm{C}$ sample range in diameters is $14-95 \mathrm{~nm}$ with a difference of $81 \mathrm{~nm}$. Smaller and more uniform catalyst particles at $137^{\circ} \mathrm{C}$ and $140^{\circ} \mathrm{C}$ allow for a more concentrated average diameter on the order of 50nm [23]. An increased average diameter of $65 \mathrm{~nm}$, for the $180^{\circ} \mathrm{C}$ sample, is due to larger Fe nanoparticles clusters that remain within the nanotubes. Further analysis of the Fe particles in the array and along the lengths of the tubes is provided in the TEM section. The heat capacity of MWCNTs is a function of diameter and number of concentric tubes [70]. SWCNTs differ from MWCNTs because their thermal conductivity can change on account of chirality and curvature [71]. Although SWCNTs and DWCNTs have higher thermal conductivity than MWCNTs diameter alone cannot determine if the thermal conductivity of the $140^{\circ} \mathrm{C}$ sample will be better than the 
$180^{\circ} \mathrm{C}$ sample. The purity of the array and alignment must also be taken into consideration because inter-tube coupling and a high defect density will impact phonons flow [28].

The ImageJ software used to measure the SEM images has a pixel size of $0.98 \mathrm{~nm}$ per pixel. Individual pixels are distinguishable when the images are enlarged for measurement. The measurement uncertainty is therefore on the order of $0.98 \mathrm{~nm}$ neglecting any microscope calibration uncertainty. The Quanta 650 SEM is frequently calibrated and inspected by technicians providing a high level of measurement certainty. Figure 19 depicts the average diameter measurement with error bars from standard deviation and measurement uncertainty. 

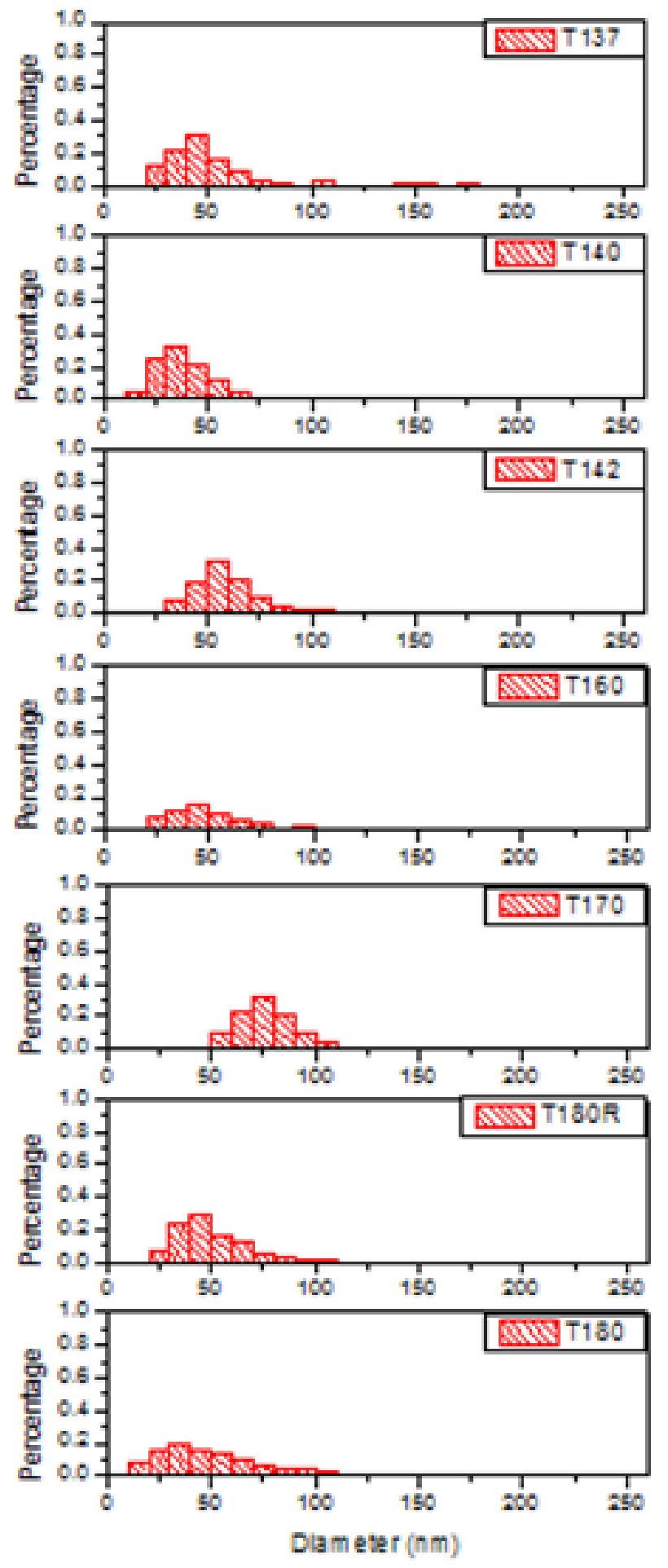

Figure 18. Histograms of outer diameter distributions for MW VACNTAs. The temperature of ferrocene sublimation is noted in the top right of each graph i.e. T180 is for $180^{\circ} \mathrm{C}$. 

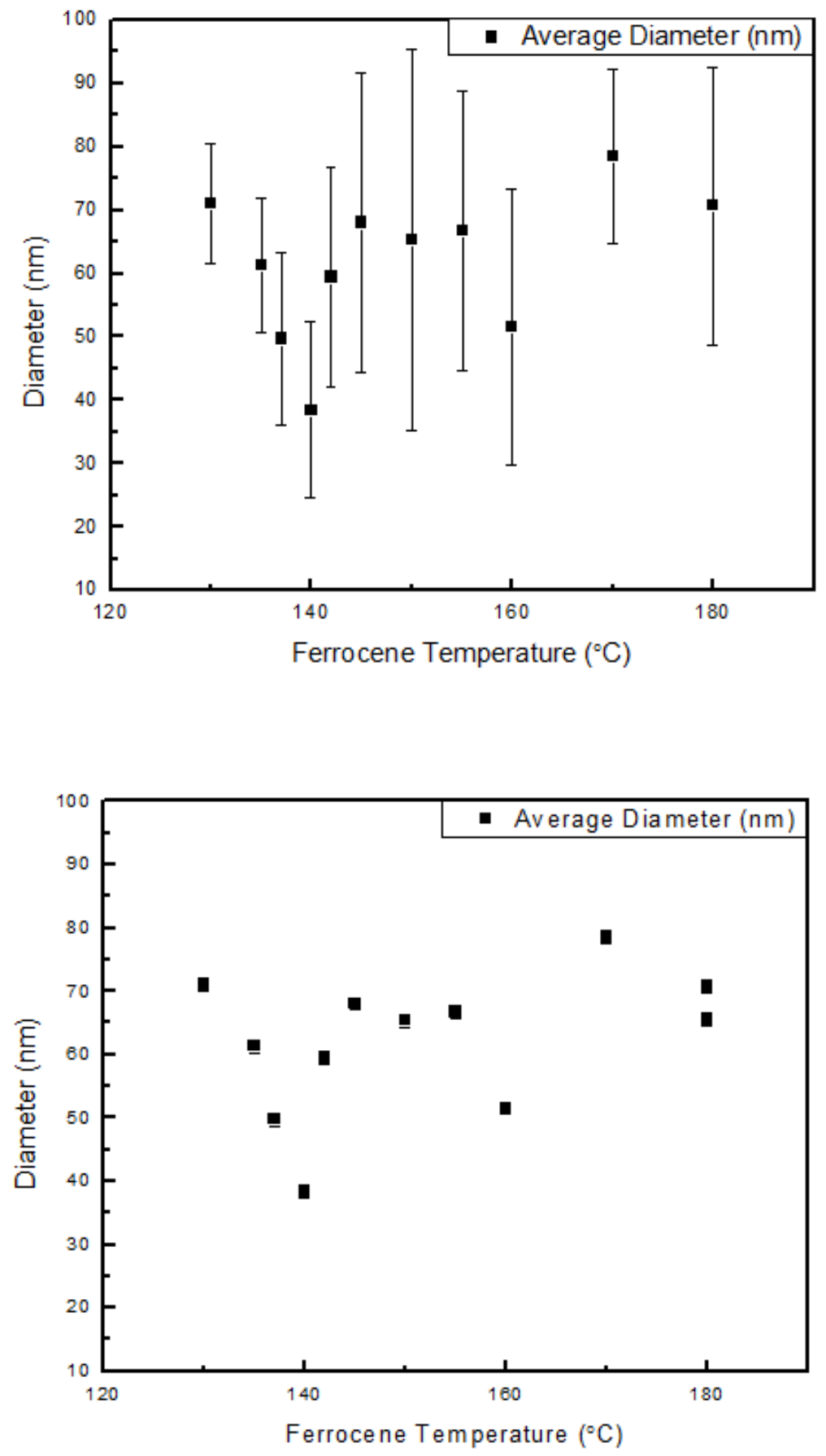

Figure 19. Average diameter measurement versus corresponding ferrocene sublimation temperature 1) using standard deviation as the error bars and 2) using measurement uncertainty for the error. 
A reduction in the average diameter can be seen in Figure 19 for the samples grown between $137^{\circ} \mathrm{C}-142^{\circ} \mathrm{C}$ and $160^{\circ} \mathrm{C}$. Several proposed theories exist to explain the interactions that determine catalytic particle size including Ostwald ripening, Volmer-Web interactions, and incorporation of carbon atoms but no in situ HRTEM experiments have been completed for MWCNTs [72][64][14]. Growth of a single carbon nanotube will differ from simultaneous growth of concentrically aligned tubes which makes structural growth observations significant. The diameter trends in this experiment coincide with the findings of Liu et al. where ferrocene sublimation above $160^{\circ} \mathrm{C}$ produced larger diameter MWCNTs filled with $\mathrm{Fe}$ nanowires. Ferrocene pyrolysis between $140^{\circ} \mathrm{C}-160^{\circ} \mathrm{C}$ produced Fe nanoparticle decorated MWCNTs and samples between $110^{\circ} \mathrm{C}-140^{\circ} \mathrm{C}$ created carbon nanoparticles with a few CNTs [17]. Higher magnification images in Figure 20 reveal similar structural trends.

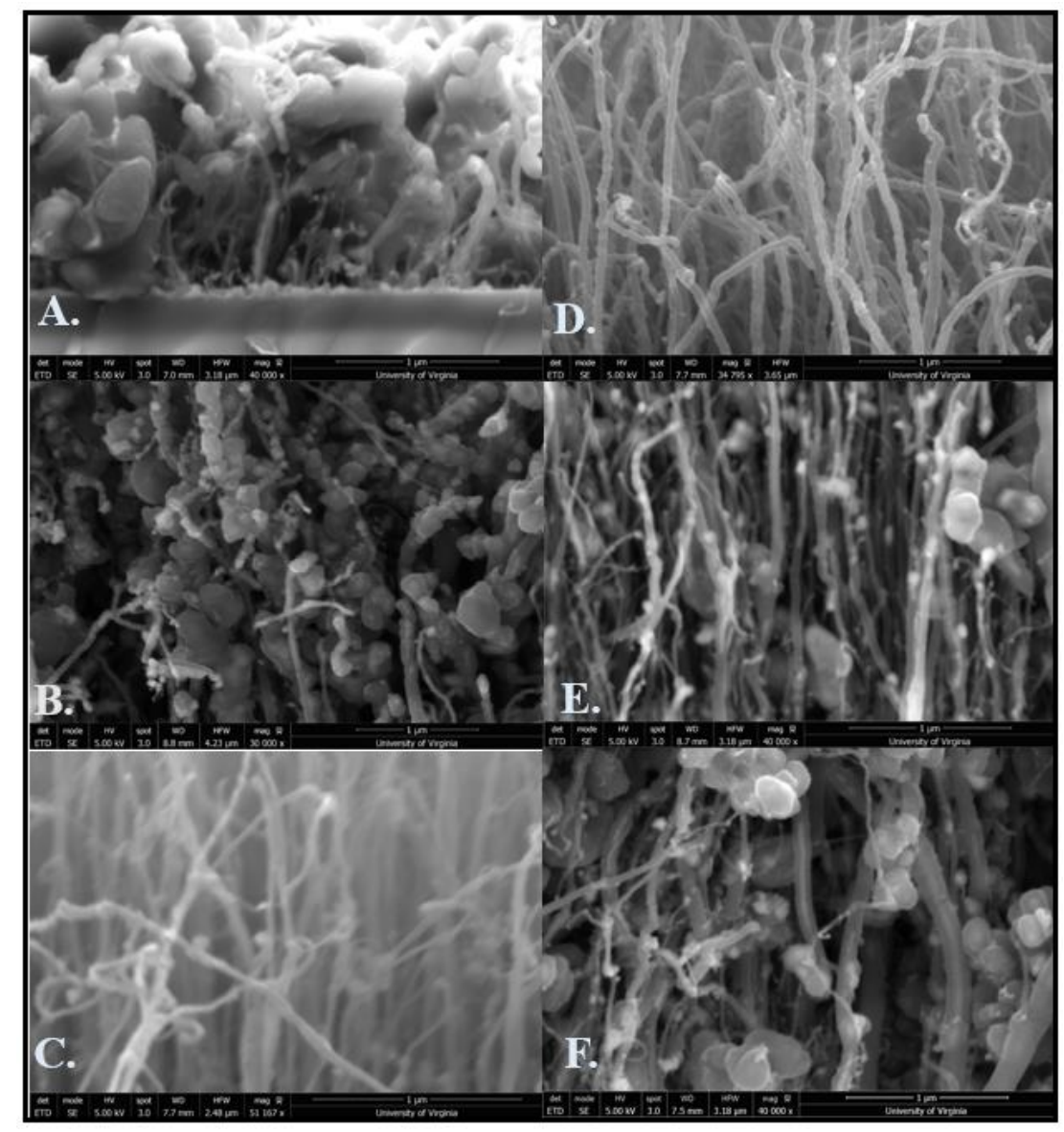

Figure 20. Images with a $1 \mu \mathrm{m}$ scale bar for ferrocene sublimation at A. $100^{\circ} \mathrm{C}, \mathrm{B} .130^{\circ} \mathrm{C}, \mathrm{C}$. $140^{\circ} \mathrm{C}, \mathrm{D} 142^{\circ} \mathrm{C}, \mathrm{E} .160^{\circ} \mathrm{C}, \mathrm{F} .180^{\circ} \mathrm{C}$. 
Measuring the density of CNT arrays is a difficult challenge because they are on the microscale and incredibly lightweight. For a $2.4 \mathrm{~cm}^{2}$ glass substrate the change in weight before and after CNT growth was on the order of one ten-thousandth of a gram. Measurements of the density as change in mass per substrate area and average array height product are in Figure $21 \mathrm{~A}$. This is an approximate density calculation because samples with higher ferrocene sublimation temperature had higher levels of amorphous carbon, which weighs more than hollow CNTs, and the scale used to measure the silicon dioxide substrate was not always stable to ten-thousandth of a gram. Figure $21 \mathrm{~A}$ is provided as a point of reference but it does not hold a high degree of accuracy.

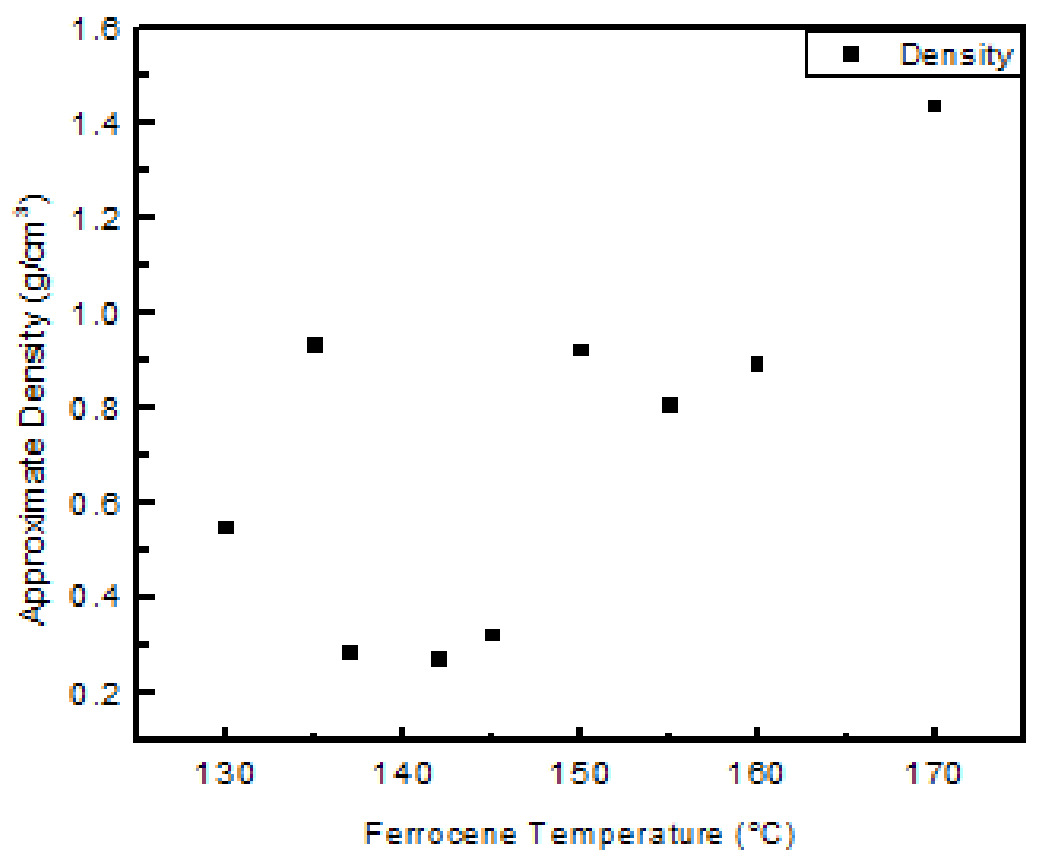

Figure 21 A. Approximate density (weight change in the substrate divided by the product of the sample surface area and array height) versus ferrocene sublimation temperature. 


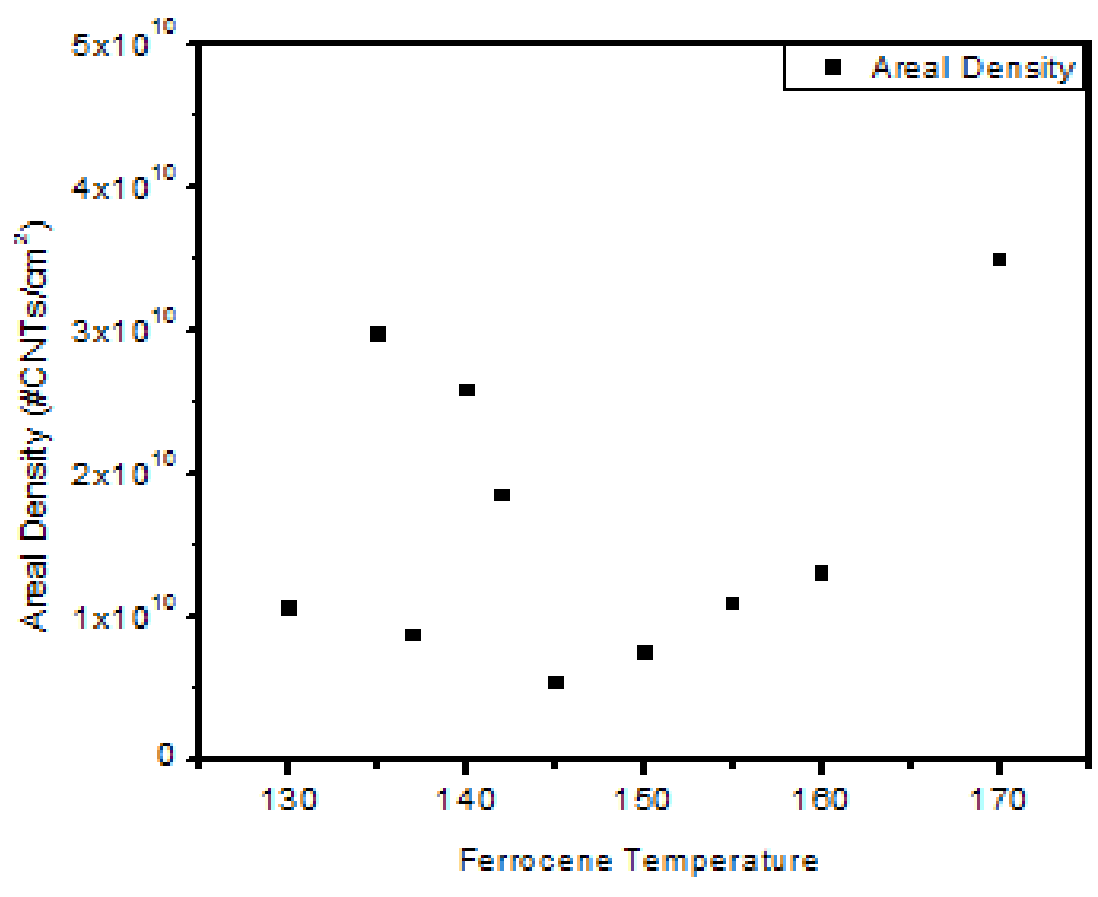

Figure 21 B. Areal density versus ferrocene temperature.

Areal density calculations are common in literature because they can be found from SEM images and do not require an extremely accurate scale [72]. Duke University developed a method under Dr. Jeffery Glass which uses the gray scale peaks of an SEM image line scan to count the number of CNTs in an image. The number of CNTs per a given length squared is the areal density. Following the same procedure but developing an independent MATLAB script to read the line scan the areal density was calculated for all ferrocene sublimation temperatures. The penetration depth of SEM images is impacted by the atomic material of the sample and accelerating voltage of the electron beam [55]. The penetration depth is not accounted for in Figure $21 \mathrm{~B}$ measurements although, based on the composition of the array, at $5 \mathrm{kV}$ it is on the order of $0.4 \mu \mathrm{m}$ (carbon)- $0.5 \mu \mathrm{m}$ (iron) [55]. The areal density results ranging from $3.5 \times 10^{10}$ $\mathrm{CNTs} / \mathrm{cm}^{2}$ at $170^{\circ} \mathrm{C}$ to $5.3 \times 10^{9} \mathrm{CNTs} / \mathrm{cm}^{2}$ at $145^{\circ} \mathrm{C}$ coincide with those reported in literature. Hinds et al. measured an areal density of $6( \pm 3) \times 10^{10} \mathrm{CNTs} / \mathrm{cm}^{2}$ on SEM images for MW 
VACNTAs grown using a plasma enhanced process [72]. Tong et al. reported areal densities on the order of $10 \times 10^{10} \mathrm{CNTs} / \mathrm{cm}^{2}$ although the method used to calculate the areal density is not distinguished [26]. Duke University's Nanomaterials and Thin Films Lab had an average areal

density of $4.2 \times 10^{8} \mathrm{CNTs} / \mathrm{cm}^{2}$, which they concurred is a low value via email correspondence, and noted that plasma enhanced CVD does not always produce a higher density array. The areal density calculations gain a greater level of certainty if mass of an average CNT (estimated using TEM images), film volume (estimated using SEM images), and film mass (measured with a high accuracy scale) are used in calculations [73].

\subsubsection{Transmission Electron Microscope (TEM) Data}

TEM images have rapidly advanced nanotechnology by providing the capability for an internal, structural view of CNTs [58]. Although useful, TEM images are costly and not always easy to attain. MWCNTs in this experiment shifted during imaging on account of magnetization of the interior Fe nanoparticles, increasing the difficulty of imaging a large number of carbon nanotubes [57]. A sampling of five MWCNT TEM images per sample provides the data for this section. Emphasis was given to selecting carbon nanotubes of similar outer diameter to the averages found from the SEM images, because a sampling of five does not provide as true a trend as 150-210 CNTs. TEM images are beneficial in this experiment for gaining insight into the number of concentrically aligned graphene layers in the MWCNTs, and observing characteristics of Fe NPs.

Kim et al. found that carbon nanotubes encapsulated the catalytic Fe particle at the base or tip of the substrate, and catalytic particles were also located throughout the length of the CNT [68]. TEM images in this experiment clearly reveal ferrocene nanoparticles (Fe NPs) within the multi-walled carbon nanotubes at the base, dispersed along the length, and at the tip. Catalytic particles in all three locations are provided in Figure 22 for $180^{\circ} \mathrm{C}, 150^{\circ} \mathrm{C}$, and $142^{\circ} \mathrm{C}$ samples respectively. The Fe NPs at the base or tip of the tube are a result of the iron metal catalyst depositing onto the silicon dioxide substrate which then creates a surface for CNT growth. The Fe NPs dispersed along the length of the tube are believed to be a result of Fe nanowires reacting with carbon at a low enough surface tension to be filling the MWCNTs by capillarity [17]. 
Bhatia noted CNTs grown in a single zone furnace at $800^{\circ} \mathrm{C}$ had rod-like Fe NPs within, while CNTs grown in a furnace at $980^{\circ} \mathrm{C}$ had spherical Fe NPs [57]. Liu et al. found that changing the ferrocene sublimation temperature varied the size of metal catalyst particles. When the sublimation temperature was in the $110^{\circ} \mathrm{C}-130^{\circ} \mathrm{C}$ range $\mathrm{Fe}-\mathrm{NPs}$ around $20 \mathrm{~nm}$ were formed which were too large to support SWCNTs, but not too large for MWCNTS [17]. At the low temperatures the carbon concentration was not sufficient to form MWCNTs causing Fe NPs to cluster instead. For a sublimation temperature of $150^{\circ} \mathrm{C}$ enough carbon is present to form MWCNTs and Fe nanoparticles around 10nm decorate the CNT surface [17]. As the ferrocene pyrolysis temperature is further increased to $160^{\circ} \mathrm{C}$ the increased number of iron clusters agglomerate into nanowires. Further increasing the sublimation temperature above $160^{\circ} \mathrm{C}$ results in MWCNTs with larger NP clusters and longer nanowires [17]. This study produced results which differ from those of Liu as seen in Figure 22. Nanowires existed within the entire $135^{\circ} \mathrm{C}$ $180^{\circ} \mathrm{C}$ ferrocene sublimation temperature range, not exclusively at temperatures above $160^{\circ} \mathrm{C}$ as Liu noted. The presence of small Fe NPs heavily decorating MWCNTs exterior around $150^{\circ} \mathrm{C}$ is in agreement. The wicking of iron nanowires inside the carbon nanotubes tubes at a lower sublimation temperature is likely due to experimental setup differences decreasing the activation energy. This experiment utilized a lower argon flow rate of $900 \mathrm{sccm}$ instead of $2000 \mathrm{sccm}$ which could allow gaseous Fe particles to more easily attach onto forming tubes and become pulled within by capillary forces. Additionally a slower growth rate for a furnace temperature of $800^{\circ} \mathrm{C}$ versus $1100^{\circ} \mathrm{C}$ could increase the amount of $\mathrm{Fe}$ on the forming nanotubes [68]. Fe NP clusters retain larger sizes at lower temperatures [57]. 


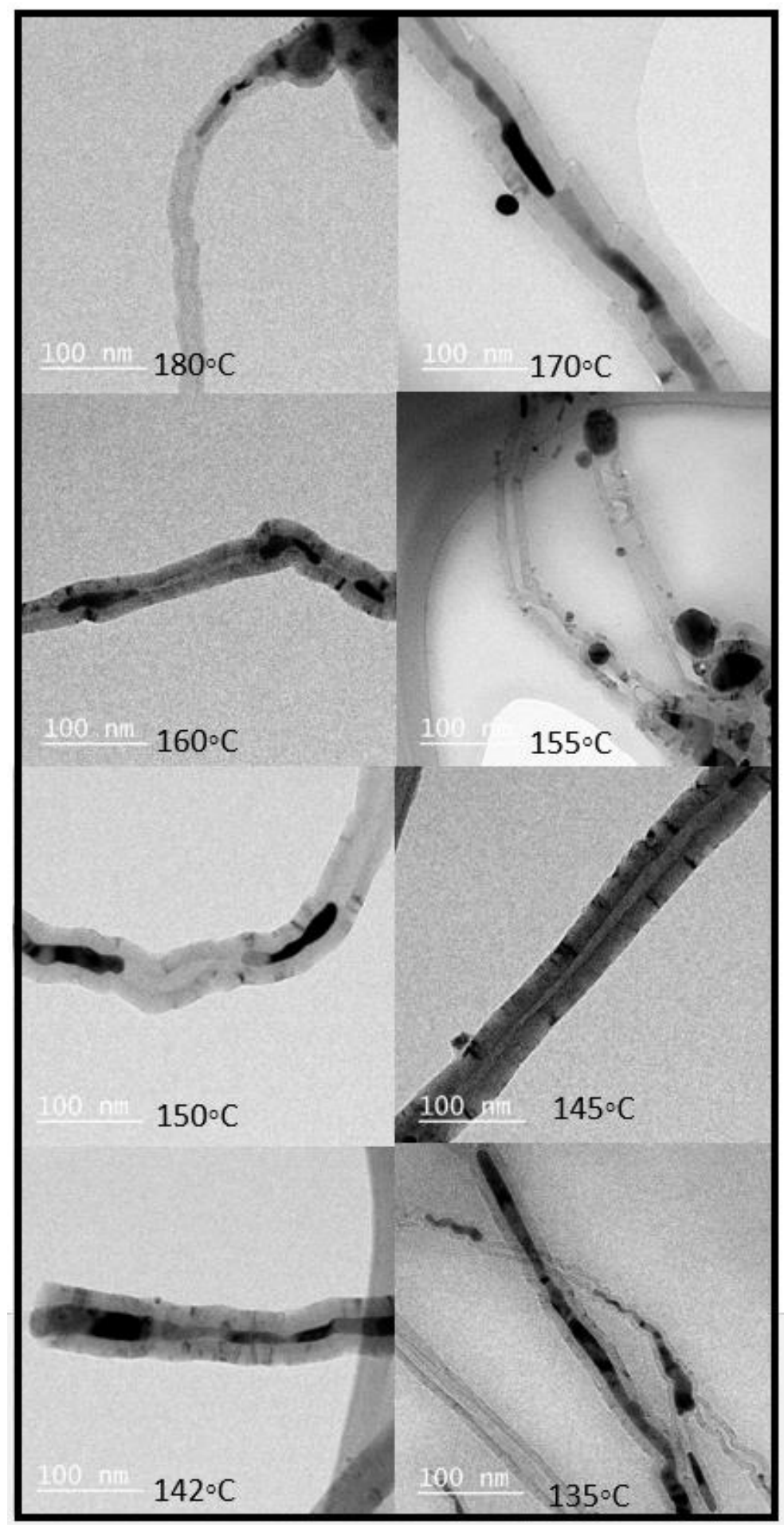

Figure 22. TEM images for ferrocene sublimation temperatures between $135^{\circ} \mathrm{C}-180^{\circ} \mathrm{C}$. For additional TEM images see Appendix 3. 
Correlations between the inner diameters, which is often identical to the Fe nanowire thickness, and outer diameters are presented in Figure 23. The largest average outer diameter sample had a sublimation temperature of $170^{\circ} \mathrm{C}$ and the largest inner diameter is the $180^{\circ} \mathrm{C}$ sample. This supports the trend Liu noted of increasing nanowire thickness with increasing temperature. The outer diameter does increase with the inner diameter thickness although both diameters fluctuate heavily within the ferrocene temperature range of $135^{\circ} \mathrm{C}-180^{\circ} \mathrm{C}$. With smaller diameters in the $137^{\circ} \mathrm{C}-145^{\circ} \mathrm{C}$ range the internal $\mathrm{Fe}$ nanowires thicknesses are narrower but still present and unpredictable in length. Increasing the reaction temperature could reduce both the Fe nanowire thickness and outer diameter according to Bhatia, however higher furnace temperatures resulted in less ordered arrays for previous studies completed by the Nanoscale Heat Transfer Laboratory [57]. With ferrocene as a catalyst there does not appear to be a consistent way to reduce the incorporation of iron in the carbon nanotubes.

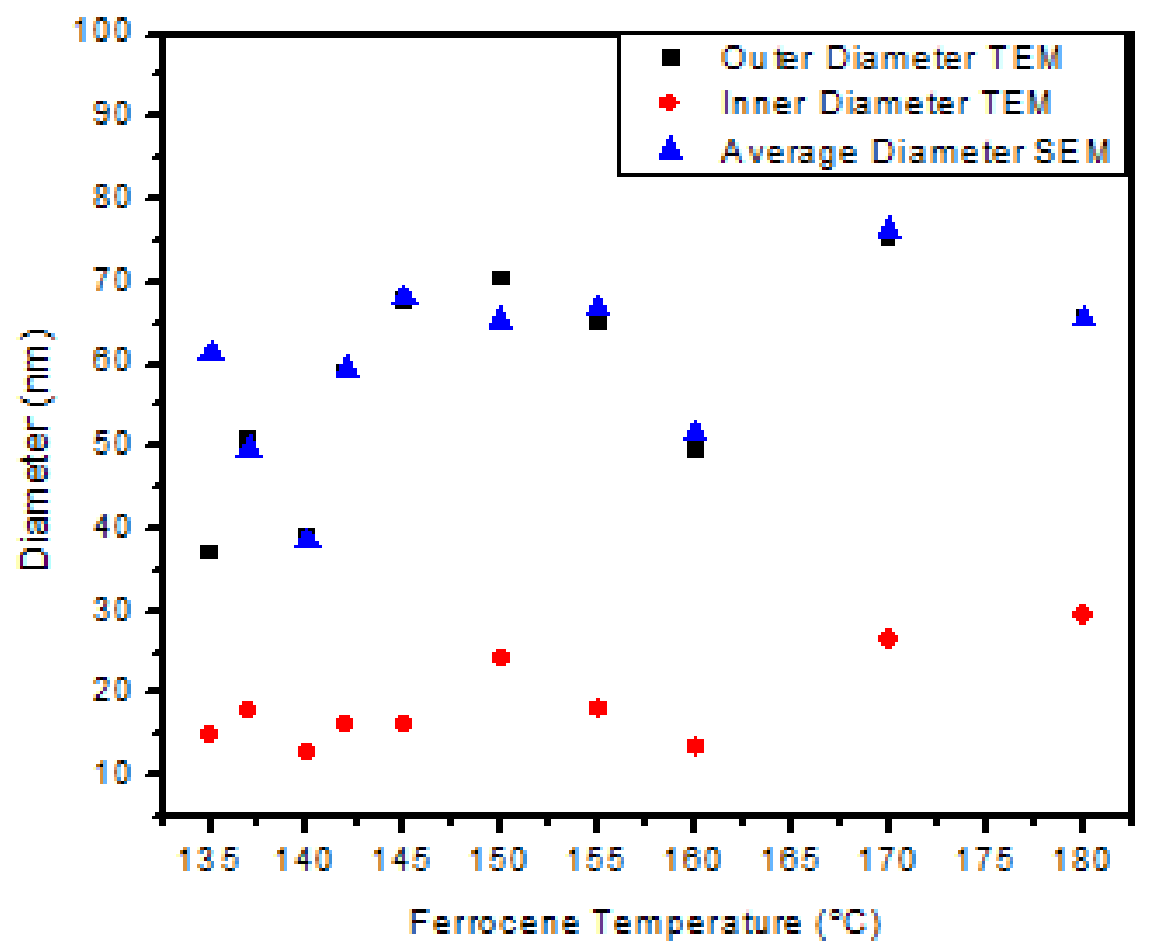

Figure 23 A. Inner and outer diameter measurements from TEM and SEM images versus ferrocene sublimation temperature. 


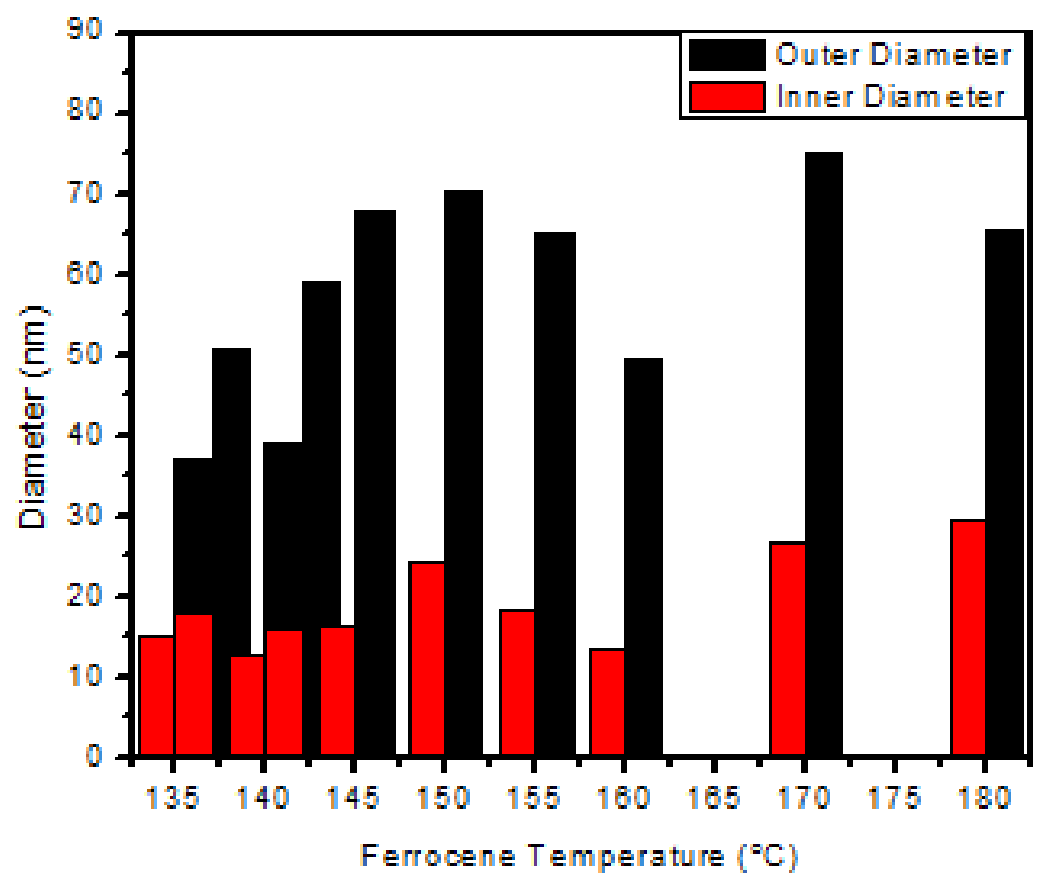

Figure 23 B. Dependence of outer diameter on inner diameter (nanowire thickness) versus ferrocene sublimation temperature.

As mentioned in Chapter 2 the MW VACNTAs were scraped into a toluene solution for proper dispersion prior to imaging. Liu et al. pretreated their samples with nitric acid and sonicated in ethanol [17]. Even after hours of sonication in ethanol the Fe NPs both inside the MWCNT and adhered to the surface remained intact. The Fe NPs are well anchored onto the MWCNT and will not be easily removed by processing post growth. Son et al. discovered that imperfect contact between VACNTAs and a substrate due to the presence of a catalyst layer may cause higher interfacial thermal resistance measurements [40]. The presence of Fe catalyst remains may not be desired for VACNTA applications that do not require magnetism. MWCNTs have been grown off different catalysts to include $\mathrm{NaCl}$ which can be washed away with water post growth, however, $\mathrm{NaCl}$ does not produce as high yield of CNTs [18][58]. Nevertheless, if the objective is to create MWCNTs without catalyst particle remains other catalyst materials should be considered.

Using the method developed by Lin et al. the inner and outer diameter measurements of the MWCNTs can be used to find the density of MWCNTs on each sample and the volume fill fraction of the array [2]. The calculation method is summarized in Table 3 and the densities of 
the as-grown CNTs are presented in Figure 25. The wall thickness measured in TEM images confirms a spacing of $0.34 \mathrm{~nm}$ which is the same spacing as graphite, making the use of graphite density in MWCNT calculations an appropriate value [57][74]. The catalyst spacing of $0.20 \mathrm{~nm}$ matches the (110) plane of $\alpha-\mathrm{Fe}$ crystal [17]. The approximate density measurements in Figure 21A gave an unrealistic volume fill fraction of $13 \%-50 \%$ which could be a result of the low accuracy scale used, or more likely the presence of iron in the sample not being accounted for. Iron carbide has a density of $4.93 \mathrm{~g} / \mathrm{cm}^{3}$ which is much greater than the density of graphite 2.266 $\mathrm{g} / \mathrm{cm}^{3}$ [75][2]. Zhao et al. stated that the average mass density and array volume fraction increase as catalyst density increases [30]. The amount of iron in the MWCNTs will artificially increase density calculations based on array weight. Calculating the volume fill fraction with a standard literature value for density of a CNT array, $0.017 \mathrm{~g} / \mathrm{cm}^{3}$, the volume fill fraction of arrays in this study ranged from $0.79 \%-0.94 \%$, comparable to values of $0.87 \%-1.84 \%$ found in literature [2][76][30].

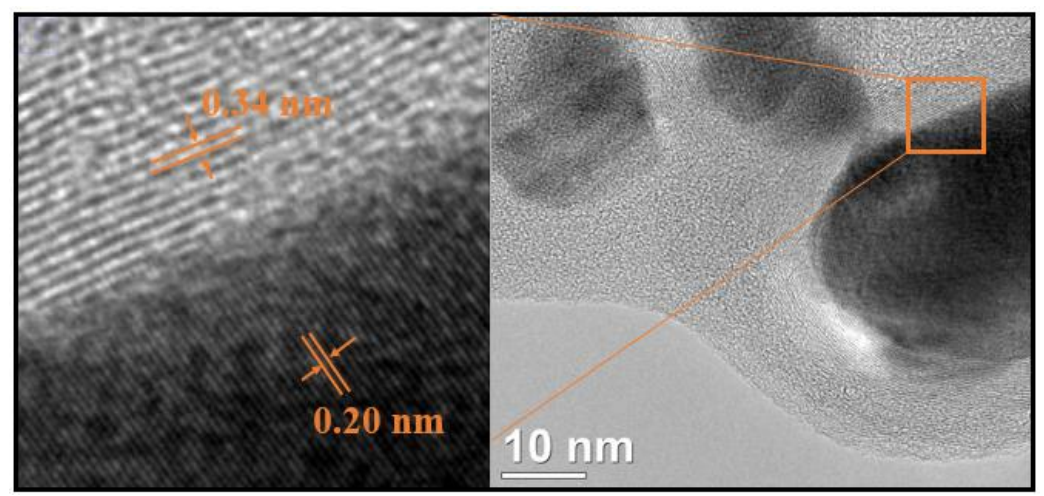

Figure 24. Measurement of MWCNT layers spacing from TEM image [17].

Table 4 Array Volume Fraction Calculations

\begin{tabular}{|c|c|c|c|}
\hline Wall thickness & $0.34 \mathrm{~nm}$ & CNT wall area & $\mathrm{a}_{\mathrm{w}}=\mathrm{a}_{\mathrm{OD}}-\mathrm{a}_{\mathrm{ID}}$ \\
\hline $\begin{array}{l}\text { Array density (from } \\
\text { literature) }\end{array}$ & $0.017 \mathrm{~g} / \mathrm{cm}^{3}$ & $\begin{array}{l}\text { Volume fraction of wall } \\
\text { area in CNT }\end{array}$ & $\mathrm{V}_{\mathrm{fw}}=\mathrm{a}_{\mathrm{w}} / \mathrm{a}_{\mathrm{OD}}$ \\
\hline Graphite density & $2.266 \mathrm{~g} / \mathrm{cm}^{3}$ & $\begin{array}{l}\text { Density of as-grown } \\
\text { CNT }\end{array}$ & $\mathrm{d}_{\mathrm{CNT}}=2.266 \mathrm{~g} / \mathrm{cm}^{3} \times \mathrm{V}_{\mathrm{fw}}$ \\
\hline $\begin{array}{c}\text { Cross-sectional area of } \\
\text { hollow portion }\end{array}$ & $\mathrm{a}_{\mathrm{ID}}=\pi\left(\mathrm{r}_{\mathrm{ID}}\right)^{2}$ & \multirow{2}{*}{ Volume fraction of array } & \multirow{2}{*}{$\begin{array}{l}\mathrm{V}_{\text {farray }}=\left(0.017 \mathrm{~g} / \mathrm{cm}^{3} / \mathrm{d}_{\mathrm{CNT}}\right) \\
* 100\end{array}$} \\
\hline $\begin{array}{c}\text { Cross-sectional area of } \\
\text { entire CNT }\end{array}$ & $\mathrm{a}_{\mathrm{OD}}=\pi\left(\mathrm{r}_{\mathrm{OD}}\right)^{2}$ & & \\
\hline
\end{tabular}

(Table 4. Modified from [2]. OD stands for outer diameter, and ID stands for inner diameter.) 


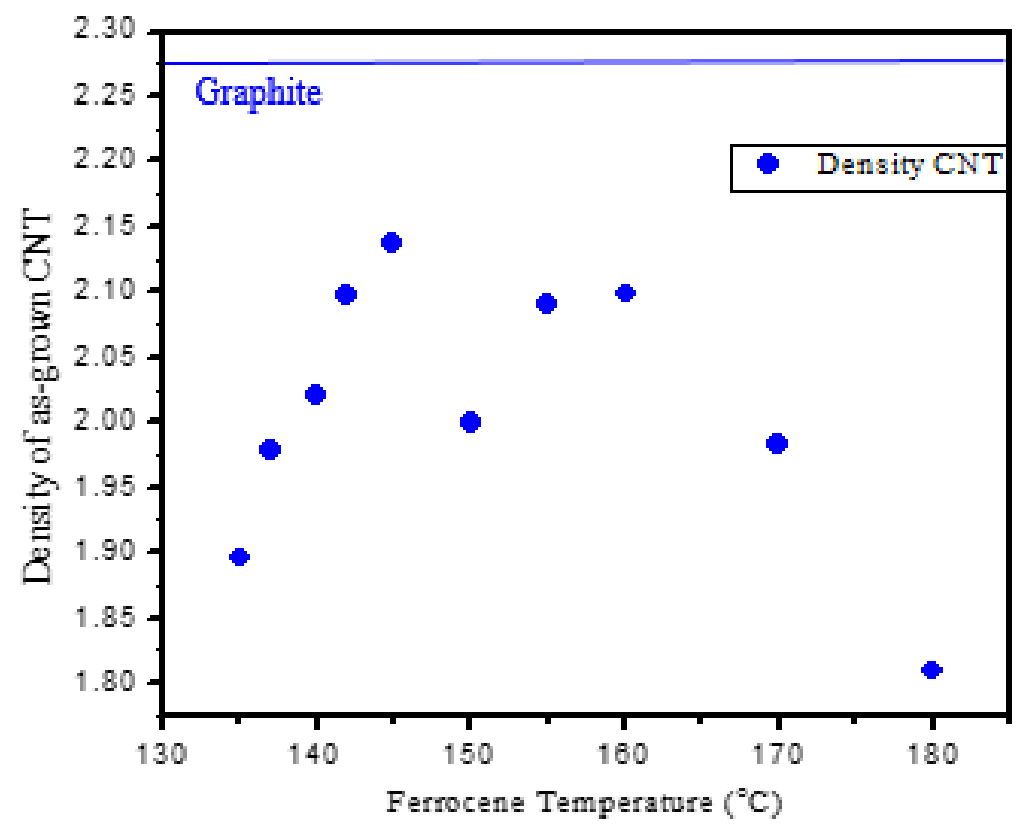

Figure 25. Density of MWCNTs as a function of ferrocene sublimation temperature.

No clear trend exists for MWCNT density in relation to ferrocene sublimation temperature in Figure 25. Figure 23B reveals that as the inner diameter of the MWCNT increased, the outer diameter increased proportionally. The density of the MWCNTS in the array remained relatively consistent as a result because both the hollow cross-sectional area and total cross sectional area of each MWCNT increases simultaneously. The number of concentrically aligned graphene layers in MWCNTs can vary anywhere from two layers to greater than one hundred layers [18]. Previous growths in the Nanoscale Heat Transfer Laboratory noted dozens of layers present in MWCNT arrays [7]. Figure 26 shows the wide variation of graphene layers comprising the MWCNTS in this study varying from $8-95$ layers. The growth mechanism section in Chapter 4 suggests that the ample supply of Fe catalyst supports the wide variation in diameters. 


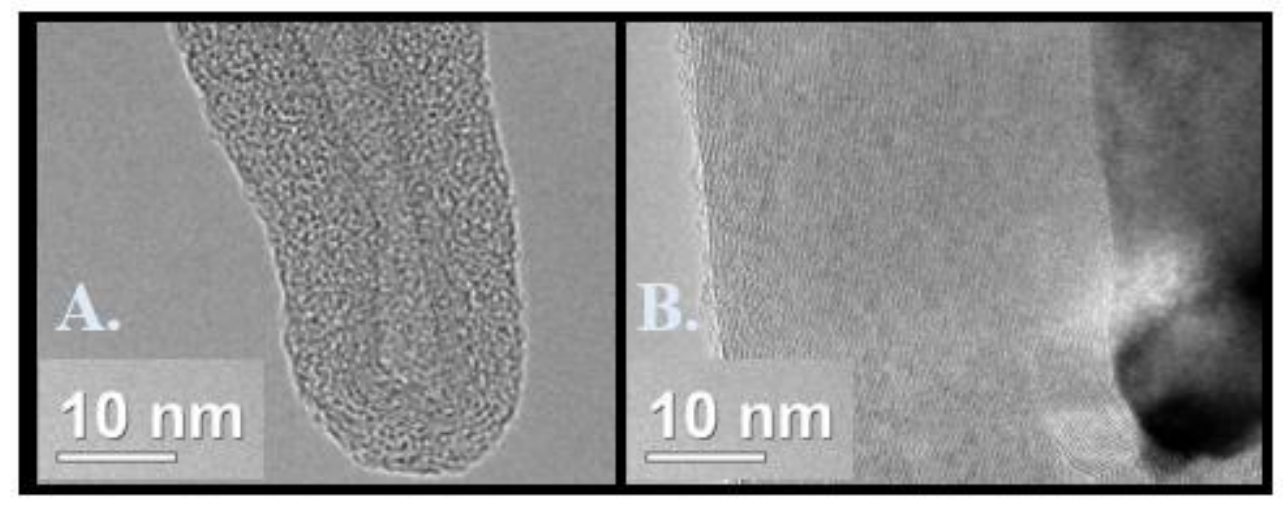

Figure 26. MWCNTs layers of graphene at A. $140^{\circ} \mathrm{C}$ and B. $160^{\circ} \mathrm{C}$.

\subsubsection{Raman Spectroscopy Data}

Raman spectroscopy is used to quantify the purity of the MW VACNTAs. When the term purity is used in terms of a carbon nanotube array it refers to the amount of crystalline $\mathrm{sp}^{2}$ hybridized carbon measured in the $\mathrm{G}$ peak compared to the amount of disordered or amorphous carbon measured in the D peak [7]. Kim et al. varied the furnace temperature for MWCNTs grown using $\mathrm{CVD}$ from $600^{\circ} \mathrm{C}$ to $800^{\circ} \mathrm{C}$ linearly decreasing the $\mathrm{I}(\mathrm{D}) / \mathrm{I}(\mathrm{G})$ wave number peak intensity ratio from 0.87 to 0.44 , and improving long-range crystallinity of the array [68]. The results verified that CNTs can be controlled by growth parameters including; the source of carbon and furnace temperature [68]. This experiment confirmed that the purity of VACNTAs will fluctuate on account of ferrocene sublimation temperature and MWCNT structure. Raman spectra resulting in two distinguishable graphene peaks at $1350 \mathrm{~cm}^{-1}$ and $1580 \mathrm{~cm}^{-1}$ can be fitted by multiple functions although a Gaussian and Lorentzian fit are the most common. Ferrari et al. noted that there is no particular fit to the spectrum that will always work best so discerning the best fit should be based on observation of the curves [11]. A Lorentzian fit is commonly selected for crystals with a finite lifetime broadening, and disordered graphite [11]. A Gaussian line shape reflects randomly dispersed phonon lifetimes of disordered materials [11]. A mixed Gaussian and Lorentzian fit was selected in the WiRE software to fit the curve distribution of the Raman Spectra. For a Lorentzian fit the $\mathrm{I}(\mathrm{D}) / \mathrm{I}(\mathrm{G})$ ratio provides a reasonable approximation of the 
disorder in graphite because the graphene peaks are narrow allowing peak height intensity to be a close fit. Amorphous carbon clusters of different dimensions create a widening of the wave number intensity spectra from distortion of the aromatic ring structure [11]. Gaussian curves account for profile width of the wave number intensity spectra. Measuring purity with an integrated area ratio $\mathrm{A}(\mathrm{D}) / \mathrm{A}(\mathrm{G})$ from a mixed Gaussian and Lorentzian fit accounts for both peak height and width fluctuations. Goudec et al. stated that area ratios well represent the crystallinity of a CNT [77].

A decrease in the $A(D) / A(G)$ ratio is seen for ferrocene sublimation temperatures between $137^{\circ} \mathrm{C}-142^{\circ} \mathrm{C}$. The lower $\mathrm{A}(\mathrm{D}) / \mathrm{A}(\mathrm{G})$ ratio is likely caused by the decrease in average diameter size for this temperature range. The MW VACNTAs heavily decorated in Fe NPs at temperatures above $150^{\circ} \mathrm{C}$ experience a decrease in carbon nanotube crystallinity. As the amount of Fe NPs decreased Fe nanowires within the carbon nanotubes expanded in diameter and length, maintaining a consistent level of disorder in the array. The D band is a reflection of lattice distortions or structural defects, therefore, an increase in the $A(D) / A(G)$ ratio in image $B$ for samples above $170^{\circ} \mathrm{C}$ represents increased levels of amorphous carbon [78]. MW VACNTAs grown via $C V D$ have an $A(D) / A(G)$ ratio in literature between 0.3 and 3.3 [32]. Shi et al. found an average $A(D) / A(G)$ ratio of 0.89 decreased to 0.64 for MWCNTs in solution treated with hydrogen chloride [78]. The furnace temperature variation study by Quang et al. resulted in an $A(D) / A(G)$ ratios between 0.8-2.2 [65]. Lowering the ferrocene sublimation temperature from $180^{\circ} \mathrm{C}$ to $142^{\circ} \mathrm{C}$ reduced the $\mathrm{A}(\mathrm{D}) / \mathrm{A}(\mathrm{G})$ ratio from 1.34 to 0.84 . Taking the average of all three Raman location measurements, this $\mathrm{A}(\mathrm{D}) / \mathrm{A}(\mathrm{G})$ ratio reduction is a $37 \%$ decrease. Growing $\mathrm{MW}$ VACNTAs at a lower catalyst sublimation temperature enhanced the purity of the array by improving the crystallinity of the carbon nanotubes. Figure 27 confirms the uniformity of the $A(D) / A(G)$ ratio along the height of the array improved for ferrocene sublimation temperatures 
between $137^{\circ} \mathrm{C}-142^{\circ} \mathrm{C}$. The disorder at the array base and maximum height is reduced as well which improves array contact resistance.
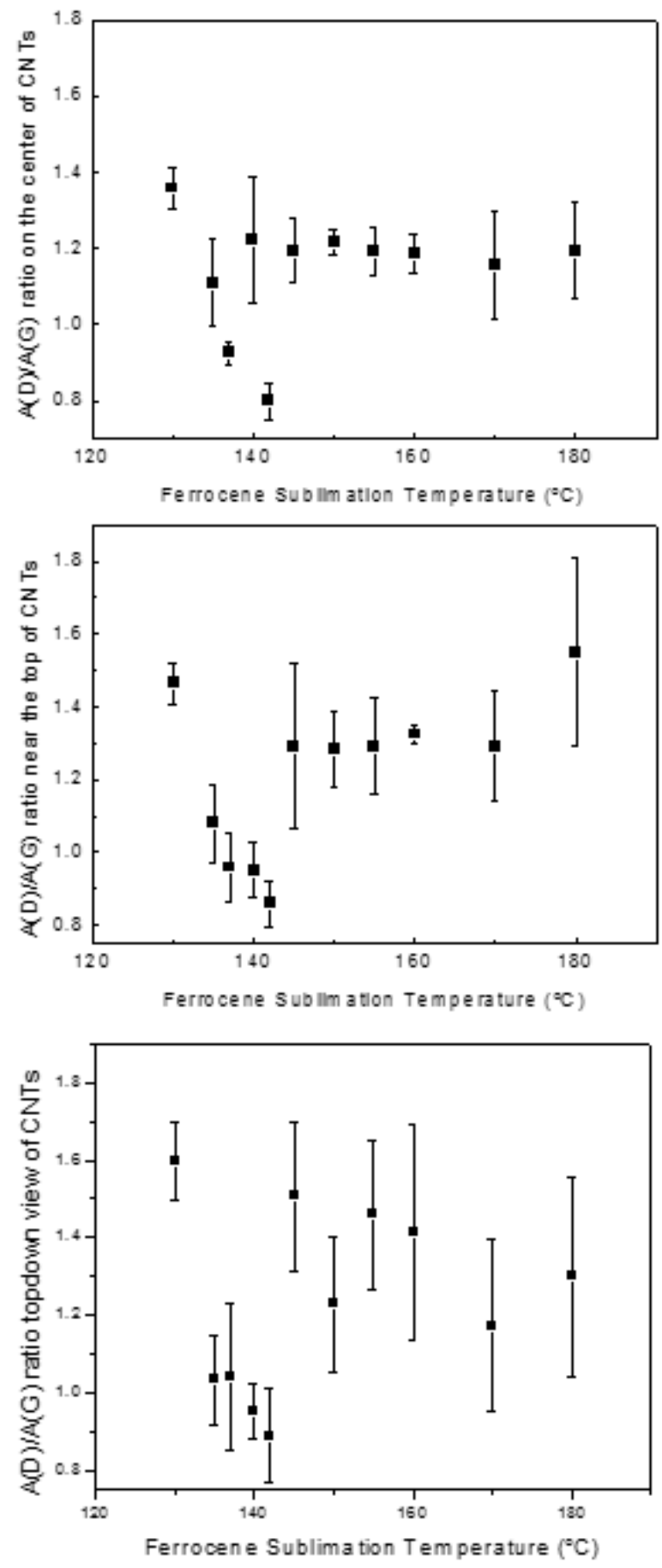

Figure 27. The $A(D) / A(G)$ ratio for varying ferrocene sublimation temperatures $A)$ at the respective center of the array, B) near the top of the array (side view profile), C) at the top of the array (top-down view). 


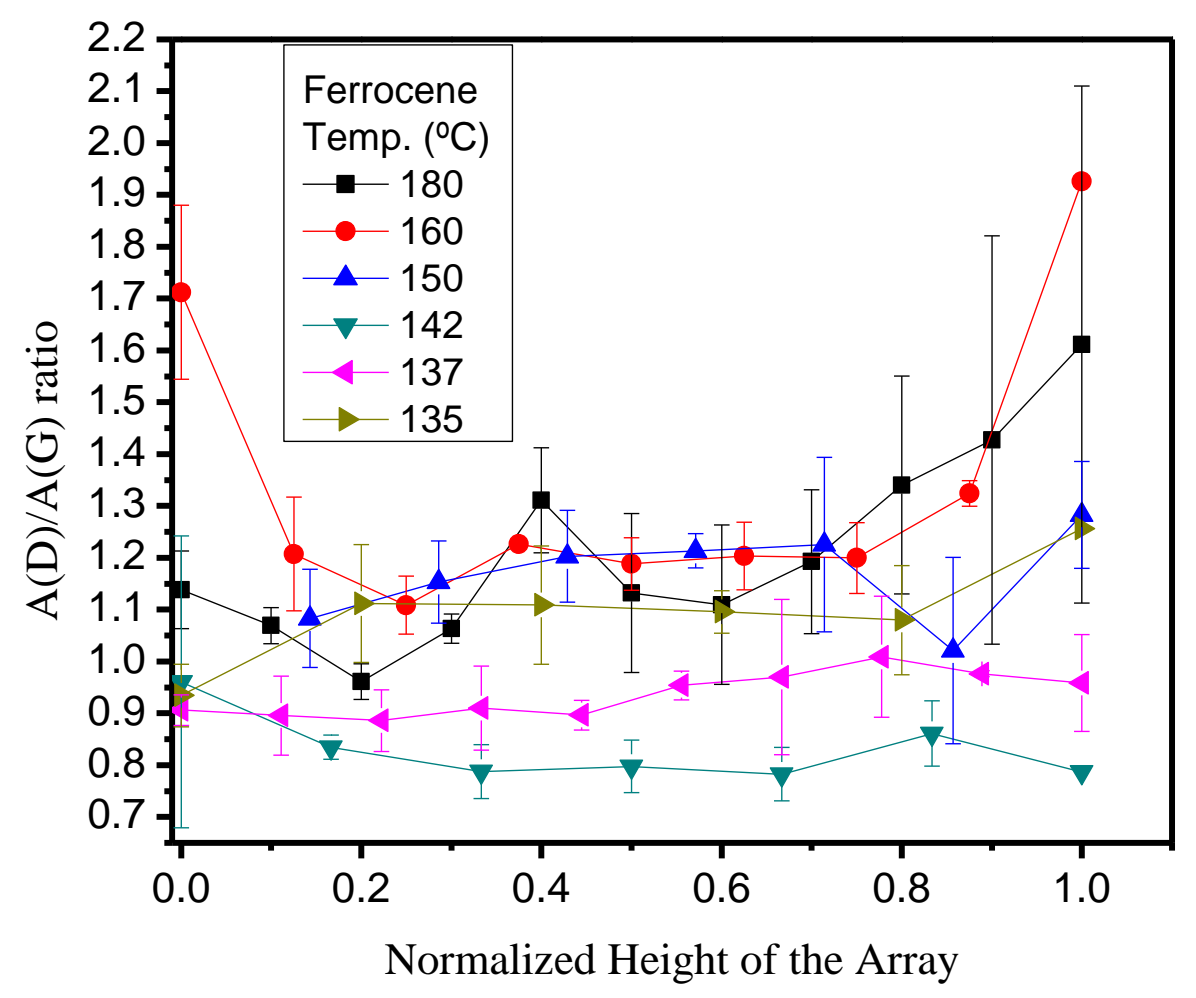

Figure 28. The $A(D) / A(G)$ ratio versus the normalized height of the array. 


\section{CHAPTER 4 CONCLUSION}

\subsection{SUMMARY OF RESULTS}

Thermal interface materials (TIMs) are used in microprocessors to improve the thermal transport between a silicon chip and heat spreader or heat sink (see Section 1.3). Vertically aligned carbon nanotube arrays (VACNTAs) have exceptional mechanical and thermal properties, with the potential for better compliance and conductance than commercially available TIMs. Due to the anisotropic properties of carbon nanotubes vertical alignment is best for thermal transport [41]. Additionally, to control the thermal properties of VACNTAs optimization of the diameter, wall structure, and areal density is necessary [73].

The growth mechanism of multiwalled carbon nanotubes has not been observed through in-situ TEM techniques at this time, which leads to uncertainty in the exact growth mechanism. Chemical vapor deposition (CVD) synthesis of VACNTAs is the most common growth technique in the field because it is inexpensive, can be scaled up for industry applications, and allows easy manipulation and study of a single process parameter. In the CVD process transition metal catalyst nanoparticles (NPs) are deposited on a substrate to lower the activation energy for nucleation and provide a surface for gaseous carbon to diffuse [14]. At the appropriate carbon concentration ratio and temperature carbon precipitates out of the metal catalyst in the form of structured carbon nanotubes. CNT growth is therefore fed out of the catalyst particle interface, which is why the catalyst dictates the diameter of individual carbon nanotubes, and structural formation of the array [79]. In the research presented in this thesis, ferrocene catalyst sublimation temperature was varied. The effect of catalyst temperature on array purity, density and diameter size was investigated through SEM images, TEM images, and Raman spectroscopy.

During this ferrocene $\left(\mathrm{Fe}\left(\mathrm{C}_{5} \mathrm{H}_{5}\right)_{2}\right)$ sublimation study the first notable discovery was that an additional hydrocarbon source is not necessary to produce well aligned multi-walled carbon nanotube arrays. As ferrocene decomposed in the $800^{\circ} \mathrm{C}$ furnace iron served as the metal catalyst, hydrogen helped 'etch' the metal into nanoparticle agglomerates, and carbon provided the material for nanotube structures [73][67]. Reducing the catalyst sublimation temperature from $180^{\circ} \mathrm{C}$ proved successful in improving the MW VACNTAs for TIM applications. The temperature range of $137^{\circ} \mathrm{C}-142^{\circ} \mathrm{C}$ produced the highest quality aligned arrays, by reducing the 
average CNT diameter, growing an array height close to $10 \mu \mathrm{m}$, and minimizing the number of defects or disorder in the array.

Single walled CNTs (SWCNT), and double walled CNTs have internal thermal conductivity values larger than multiwalled CNTs [1]. By reducing the average diameter of the tubes in the array the CNTs contributing to thermal transport may perform closer to the ideal SWCNT. The average diameter of the tubes in the array decreased $24.6 \%$ from $65 \mathrm{~nm}$ at $180^{\circ} \mathrm{C}$ to an average of $49 \mathrm{~nm}$ in the reduced temperature range explored in this work, while the standard deviation decreased from $28.0 \mathrm{~nm}$ to $14.9 \mathrm{~nm}$. In addition to a reduction in average diameter, the range of diameters also decreased from $232 \mathrm{~nm}$ to $81 \mathrm{~nm}$. Fe nanowires present within the inner diameter of most MWCNTs seemed to inhibit further reduction in the average outer CNT diameter.

Reducing the ferrocene sublimation temperature to $140^{\circ} \mathrm{C}$ limited the array height standard deviation from $8.6 \mu \mathrm{m}$ to $0.44 \mu \mathrm{m}$, a $94 \%$ decrease. Having a more uniform height will improve thermal contact conductance for the VACNTA in TIM applications. The array height of $12.9 \mu \mathrm{m}$, for the $140^{\circ} \mathrm{C}$ sample produced here, closely resembles the desired array height of 10 $\mu \mathrm{m}$. Only CNTs in direct contact to the top metal layer at a thermal interface contribute to thermal transport, therefore both uniform array height and the number of CNTs (areal density) are important factors to minimize thermal resistance in an array [1]. An average areal density of $1.8 \times 10^{10} \mathrm{CNTs} / \mathrm{cm}^{2}$ for the $137^{\circ} \mathrm{C}-142^{\circ} \mathrm{C}$ ferrocene sublimation temperature is lower than the maximum areal density in this work of $3.5 \times 10^{10} \mathrm{CNTs} / \mathrm{cm}^{2}$ at $170^{\circ} \mathrm{C}$. Although the areal density decreased at lower catalyst temperatures, the layer of amorphous carbon on top of the array declined and the purity of the array improved. Lowering the ferrocene sublimation temperature decreased the $\mathrm{A}(\mathrm{D}) / \mathrm{A}(\mathrm{G})$ ratio, a measure of amorphous carbon present, from 1.34 to 0.84 , a $37 \%$ decline in Raman measurements taken along the length of the array. A decrease in $\mathrm{A}(\mathrm{D}) / \mathrm{A}(\mathrm{G})$ ratio signifies less disordered or amorphous carbon, and more crystalline $\mathrm{sp}^{2}$ hybridized carbon of graphitic structure [7]. Array samples with smaller average diameters correlated to smaller $A(D) / A(G)$ ratios which is not unexpected because TEM images reveal that iron nanowires can cause a nearby bulge or kink in the CNT diameter which results in a disruption of the CNT crystallinity. 
The Fe nanowires and nanoparticles in the TEM images of the array provided insight into the growth mechanism characteristics of the array. Iron clusters within the MWCNTs at the base, tip, and along the length of the array support the vapor-liquid-solid growth mechanism. It is difficult to determine exactly how much influence the catalyst particle size has on the overall tube structure because the catalyst particle is in a liquid state, and additional $\mathrm{Fe}$ joins the nanotube during growth as a result of capillarity [17]. Iron nanowires were present for growth over the entire $135^{\circ} \mathrm{C}-180^{\circ} \mathrm{C}$ range, which differs from the MWCNTs grown by Liu et al. which only yielded ferrocene nanowires at growth temperatures above $160^{\circ} \mathrm{C}$ [17]. The growth of $\mathrm{Fe}$ nanowires at lower catalyst sublimation temperatures is likely a result of different gas flow rates and furnace temperatures altering the activation energy barrier. Iron NPs heavily decorated the MWCNTs grown around $150^{\circ} \mathrm{C}$, which is in agreement with Liu's results. The Fe NPs are well anchored into the structure of the CNT, impacting the crystallinity and increasing the $A(D) / A(G)$ ratio. Chemical treatments post growth have not proven successful in removing Fe NPs from MWCNTs [17]. Trends in literature between catalyst particle size and outer diameter suggest that the Fe clusters need to be shrunk on the substrate for narrower CNTs to be produced. Amorphous carbon on top of the arrays at temperatures above $170^{\circ} \mathrm{C}$ resulted in the highest level of disorder measured by Raman spectroscopy. While ferrocene is used as the catalyst source, there does not appear to be a consistent way to remove iron impurities in the array. Lowering the catalyst sublimation temperature improved the crystallinity of the array by reducing the amount of Fe in the MWCNTs, but excess iron was not eliminated.

Literature indicates that Fe nanoparticles remaining along the length of the array will inhibit phonon transport in a single direction, which can decrease the thermal conductivity of the array. Axial conductivity can be up to 110 times greater than radial conductivity [1]. Bulk CNT samples with inner-tube coupling and a high defect density concentration experienced a decrease in thermal conductivity resulting from phonon scattering [28]. A high density array with less inter-air gaps between tubes will have less heat loss than an individual CNT [28]. The substrate catalyst layer increases interface thermal resistance impacting overall thermal conductivity of the array more than array height [40]. Catalyst deposition is strongly correlated to vertical alignment, density, diameter distribution, and purity of the array [58]. Varying the sublimation temperature of ferrocene met the objectives for improving the array properties for TIM applications. 
However, to further improve the crystallinity of the array, adjustments to the CVD synthesis process need to be considered. The next section includes recommendations that could improve growth without altering the current tube furnace set-up.

\subsection{RECOMMENDATIONS FOR FURTHER STUDY}

\subsubsection{Catalyst Preparation}

The Fe catalyst nanoparticles and nanowires within the MWCNTs have the capability of increasing phonon scattering events and decreasing array thermal conductivity. Improving the purity of the array will require depositing the catalyst nanoparticles by a technique other than sublimation, and decreasing the catalyst particle size [14][73]. The three most commonly used methods for catalyst deposition on a substrate are CVD, electron beam (e-beam) evaporation, and aqueous solution deposition.

Chemical vapor deposition of ferrocene resulted in VACNTAs with Fe nanoparticles and nanowires. To reduce the amount of iron in the system the growth procedure could be altered. Removing the ferrocene source after a shorter duration and continuing with CNT synthesis using a hydrocarbon gas would limit the supply of iron, however, ceasing the inert environment to remove the ferrocene supply could have an adverse effect on the deposited Fe. There is also no guarantee that MW VACNTAs will not have already formed by the time the tube has cooled enough to safely remove the ferrocene source. Plasma enhanced CVD is another popular method of catalyst deposition but it would require purchasing additional bulky equipment while other techniques do not. Deposition techniques outside CVD should be evaluated.

E-beam evaporation allows for the deposition of a metal catalyst film layer of precise thickness on a substrate [23][53][15][80]. E-beam evaporation was used previously by the Nanoscale Heat Transfer Laboratory to deposit metal layers on the substrate or on top of the

array for TDTR measurements but it has not been used as a catalyst deposition technique [3]. If the e-beam evaporation equipment and facilities are still available for use, depositing the catalyst layer by this method would allow for greater control of catalyst nanoparticle thickness. Additionally, depositing a Fe film layer prior to growth limits the amount of $\mathrm{Fe}$ in the reaction, and prevents the abundance of iron produced by the decomposition of ferrocene, reducing the concentration of iron available for nanowire formation. 
Deposition of an aqueous catalyst solution directly onto the substrate has proven successful in growing vertically aligned dense arrays of CNTs [4][3][72]. An iron nitrate and aluminum nitrate solution mixed in deionized water (preheated to $85^{\circ} \mathrm{C}$ ) was deposited by pipette onto a preheated substrate in the 2012 UVA MURI report [3]. Complications associated with this catalyst deposition technique, and the rationale for switching to ferrocene sublimation, was not documented. Zhang et al. spin coated at $60 \mathrm{rpm}$ an aluminum substrate with an iron nitrate, ethanol, and deionized water solution [4]. The aluminum substrate required additional smoothing techniques to reduce the surface roughness, but spin coating proved a highly effective means of creating an even catalyst layer for high density arrays.

If the deposition technique is not altered, treatments post catalyst layer deposition are an alternative method for reducing nanoparticle size. Zhang et al. found that annealing a substrate before and after a nickel catalyst particle layer was deposited improved VACNTA growth [1]. Annealing VACNTAs at $980^{\circ} \mathrm{C}$ for two hours post growth reduced the number of defects within the nanotubes in an experiment by Lin et al. [80]. Additionally, VACNTAs grown with acetylene improved after being annealed at $600^{\circ} \mathrm{C}$ for an additional $30 \mathrm{~min}$ before returning the furnace to room temperature [4]. The MW VACNTAs in this experiment are already annealed indirectly during the hour long furnace cooling duration, therefore, additional annealing of the samples post CNT synthesis is not expected to significantly remove or reduce iron nanoparticles but may reduce the defect density. Annealing for multiple hours without a means to trap inert gases in the furnace was deemed an unnecessary waste of gases in this experiment. If a plug that can withstand high temperatures and fit the quartz tube apparatus is found, annealing should be considered.

\subsubsection{Hydrocarbon Source}

Ethylene $\left(\mathrm{C}_{2} \mathrm{H}_{4}\right)$ is the hydrocarbon gas utilized by the Nanoscale Heat Transfer Laboratory to serve as an additional carbon source during CNT synthesis. Methane and acetylene are two additional hydrocarbon gases commonly used in CNT production for the CVD technique. Thermochemical decomposition of hydrocarbons or pyrolysis depends on the reactivity of the hydrocarbon, and therefore, the Gibbs free energy [58]. Methane is thermodynamically stable at temperatures below $600^{\circ} \mathrm{C}$ (pressure dependent) [58]. Ethylene, acetylene and benzene have a negative Gibbs free energy above $200^{\circ} \mathrm{C}$ (pressure dependent), 
which allows for spontaneous decomposition of the gas molecules [58]. Reaction temperatures for catalyst CVD vary with the hydrocarbon gas selected. Standard furnace temperature ranges of $500^{\circ} \mathrm{C}-750^{\circ} \mathrm{C}, 650^{\circ} \mathrm{C}-850^{\circ} \mathrm{C}$, and $850^{\circ} \mathrm{C}+$ correspond to acetylene, ethylene, and methane, respectively [58].

Methane remains the most stable of the hydrocarbons up to $1030^{\circ} \mathrm{C}$, where it can then transform into acetylene $\left(1200^{\circ} \mathrm{C}\right)$ and ethylene $\left(1300^{\circ} \mathrm{C}\right)$ [81]. Acetylene is more stable above $1230^{\circ} \mathrm{C}$ so it dominates methane transformation at higher temperatures [81]. Methane produces high quality carbon nanotubes in conjunction with aluminum and nickel thin film catalysts, although this does not guarantee methane will produce the same with an iron catalyst [1]. Given methane's high thermodynamic stability, the furnace quartz tube maximum temperature of $1200^{\circ} \mathrm{C}$ may pose a limitation. Methane is not recommended as a replacement for ethylene.

Acetylene $\left(\mathrm{C}_{2} \mathrm{H}_{2}\right)$ is the most commonly used hydrocarbon gas source and should be considered as a substitute for ethylene [23][61][68][60][50][82]. Carbon dioxide $\left(\mathrm{CO}_{2}\right)$ and acetylene have produced high quality MWCNTs in controlled stoichiometric amounts because the oxygen in $\mathrm{CO}_{2}$ thermodynamically favors solid carbon formation by oxidative dehydrogenation [58]. Acetylene can also be used without the addition of carbon dioxide, which results in decomposition by increased temperature or pyrolysis [58]. Xue et al. confirmed by paper reviews and statistical analysis that methane and ethylene require a thermal conversion process to acetylene prior to providing carbon precursors for growth [83]. Acetylene does not require energy for thermal conversion but can instead act directly as the CNT precursor [83]. Hydrogen is therefore necessary for thermal conversion of methane and ethylene but only serves to reduce catalyst size for acetylene [83]. The growth rate of ethylene and acetylene can be comparable depending on experimental parameters selected. Acetylene had a carbon efficiency $32 \%$ higher than ethylene in a SWCNT experiment [84]. An excessive decomposition rate of acetylene can lead to amorphous carbon growth on the catalyst layer [82]. If the flow rate of 50 sccm (flow rate previously used for ethylene) results in an amorphous carbon layer, equilibrium is not being achieved between carbon diffusion and precipitation from the catalyst, thus the flow rate should be reduced [82]. Acetylene gas should be considered for reduced catalyst temperature and furnace temperature synthesis due to the low thermochemical decomposition energy. Depositing $\mathrm{Fe}$ in an aqueous solution or by e-beam evaporation with acetylene $\left(750^{\circ} \mathrm{C}\right.$ tube 
furnace temperature [82]) as the hydrocarbon gas source is recommended for future CNT synthesis experiments based on the current laboratory set-up.

\subsubsection{Additional Analysis}

Provided more time there are additional forms of analysis that could benefit the growth of MW VACNTAs in the Nanoscale Heat Transfer Laboratory. The number of variables in the growth process provides numerous sources for uncertainty. The temperature uncertainty both in the growth furnace and at the hot plate location need to be considered. Using a thermocouple the center of the tube furnace and hot plate were found to be within $+/-1^{\circ} \mathrm{C}$. Measuring the interior of the tube furnace while inert gases are flowing at the hot plate location would provide a more accurate depiction of sublimation temperature fluctuations.

Raman spectroscopy can provide more information than a ratio of the $\mathrm{D}$ and $\mathrm{G}$ band peak intensities or areas. Further analysis involving Raman spectroscopy in the Nanoscale Heat Transfer Laboratory could provide better characterization and insight into the MWCNT array structure. Raman spectroscopy can be used for area mapping, depth profiling, and diameter determination [54]. Kataura plots can be generated when both a $514 \mathrm{~nm}$ and $785 \mathrm{~nm}$ laser are used, which provides resonance excitations for both metallic and semiconducting tubes dependent upon the signal obtained by the respective lasers [54]. Lower Raman spectra shifts in the $150 \mathrm{~cm}^{-1}$ to $350 \mathrm{~cm}^{-1}$ range provide distinct excitations for SWCNTs, DWCNTs, and MWCNTs [54]. Increasing laser excitation energy levels from $1 \%$ up to $100 \%$ can determine whether heat effects due to laser irradiation influence the purity measurements of the CNT array [85]. Multiple publications by Andrea Ferrari use Raman spectroscopy to analyze graphite, including analysis of how $\mathrm{G}$ and 2D Raman peaks shape, position, and relative intensity change with the number of graphene layers [86]. Raman spectroscopy is a powerful tool that can provide additional forms of analysis for MWCNTs.

\subsection{CONTRIBUTIONS TO THE FIELD}

By controlling the ferrocene sublimation temperature in a fixed chemical vapor deposition process the structural characteristics of vertically aligned carbon nanotube arrays were dramatically altered. Typically chemical vapor deposition growths are composed of two main steps: 1) the formation and deposition of catalyst nanoparticles, and 2) nucleation and growth of 
carbon nanotubes on the catalyst particles due to the introduction of a hydrocarbon gas [73]. This study is unique in that the carbon source and catalyst for growth are provided at the same time in a fixed ratio through the use of ferrocene. The MW VACNTA's structure is strongly correlated to the catalyst morphology and temperature dependent vapor-liquid-solid growth mechanism. Providing further evidence that supports the vapor-liquid-solid growth mechanism aids in the development of kinetic models by confirming carbon dissolution is likely the rate limiting step [87]. By completing MW VACNTA growths in an $800^{\circ} \mathrm{C}$ furnace with a $100-180^{\circ} \mathrm{C}$ ferrocene sublimation temperature range the presence of iron nanowires and iron nanoparticles and their effect on array purity, density and diameter size is documented it is believed for the first time, supplementing existing literature. Quantifying the effect of structural abnormalities within MWCNT arrays can aid in CVD growth efficiency during future synthesis of arrays. If the objective was to grow magnetic carbon nanotubes for biomedicine, magnetic storage devices or magnetic force microscopy applications, then iron nanowires and nanoparticles present within the array, altering the naturally occurring diamagnetic state of CNTs, would be advantageous [17]. The residual magnetization of MWCNTs has been found to increase with the concentration and size of interior iron nanowires [57].

Matt Bauer suggested that better isolation of growth conditions by fabricators would promote optimization of CNT arrays thermal performance [7]. The research in this thesis provides influence data necessary to fine tune the inner and outer diameter of MWCNTs, while simultaneously altering the iron concentration in the array. Collecting data through multiple characterization techniques quantified the effect of sublimation temperature on structural characteristics in MWCNT arrays, which benefits further structural processing in the thermal interface material community. Iron impurities in the arrays present additional defect sources, increasing phonon scattering events and likely decreasing array thermal conductivity, which is not desirable for TIMs. The presence of iron impurities throughout all sublimation temperature growths provides solid grounds for altering the current growth procedure in the Nanoscale Heat Transfer Laboratory and incorporating the recommendations provided in the previous section. If thermal conductivity measurements are completed for these arrays, it is my hope that the thermal CVD growth process can be optimized for thermal applications. 
Appendix 1. Histograms of diameter distributions for MW VACNTAs. The temperature of ferrocene sublimation is noted in the top right of each graph i.e. T180 is for $180^{\circ} \mathrm{C}$. ' $\mathrm{R}$ ' denotes a repeated sample.
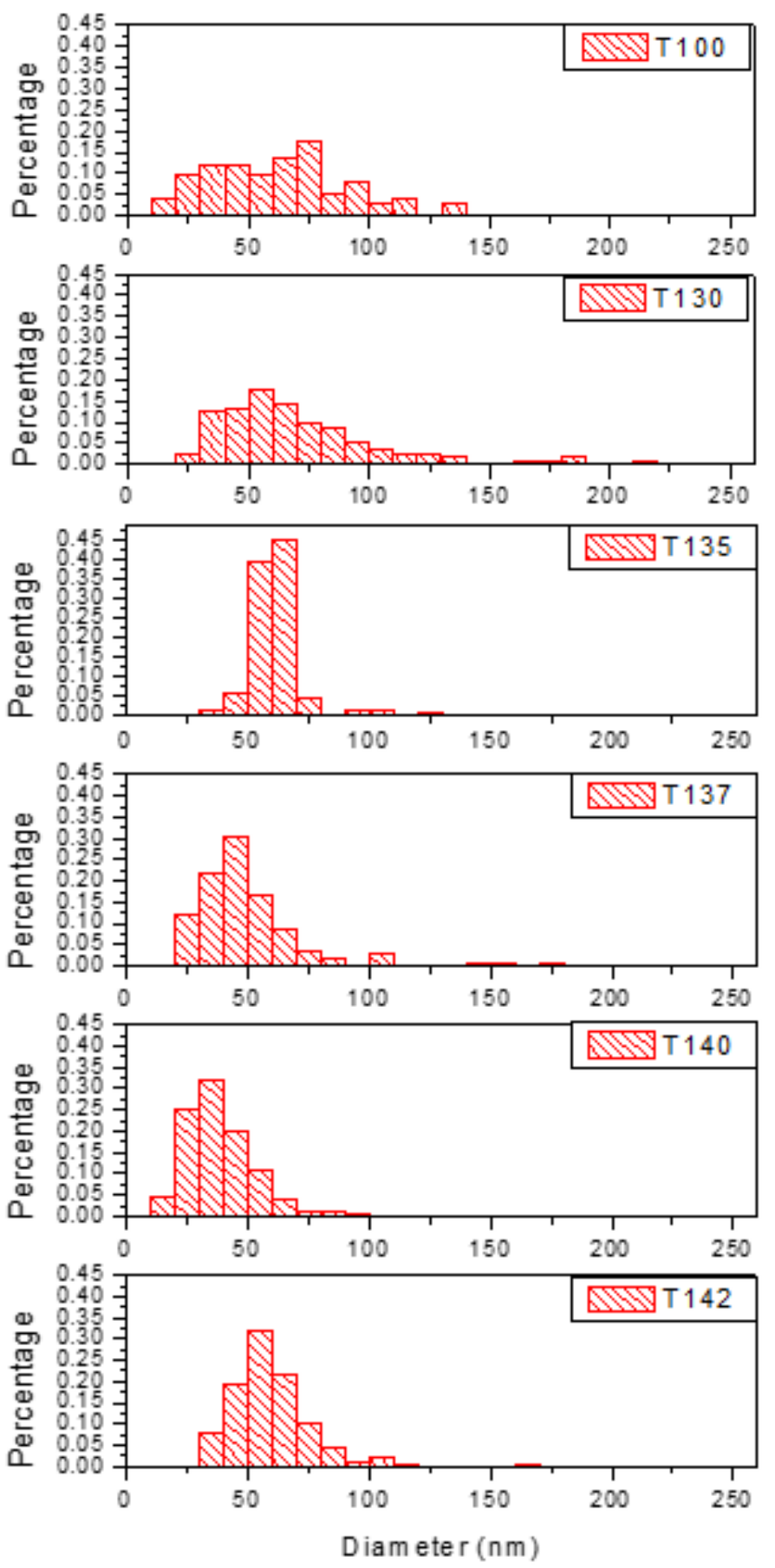

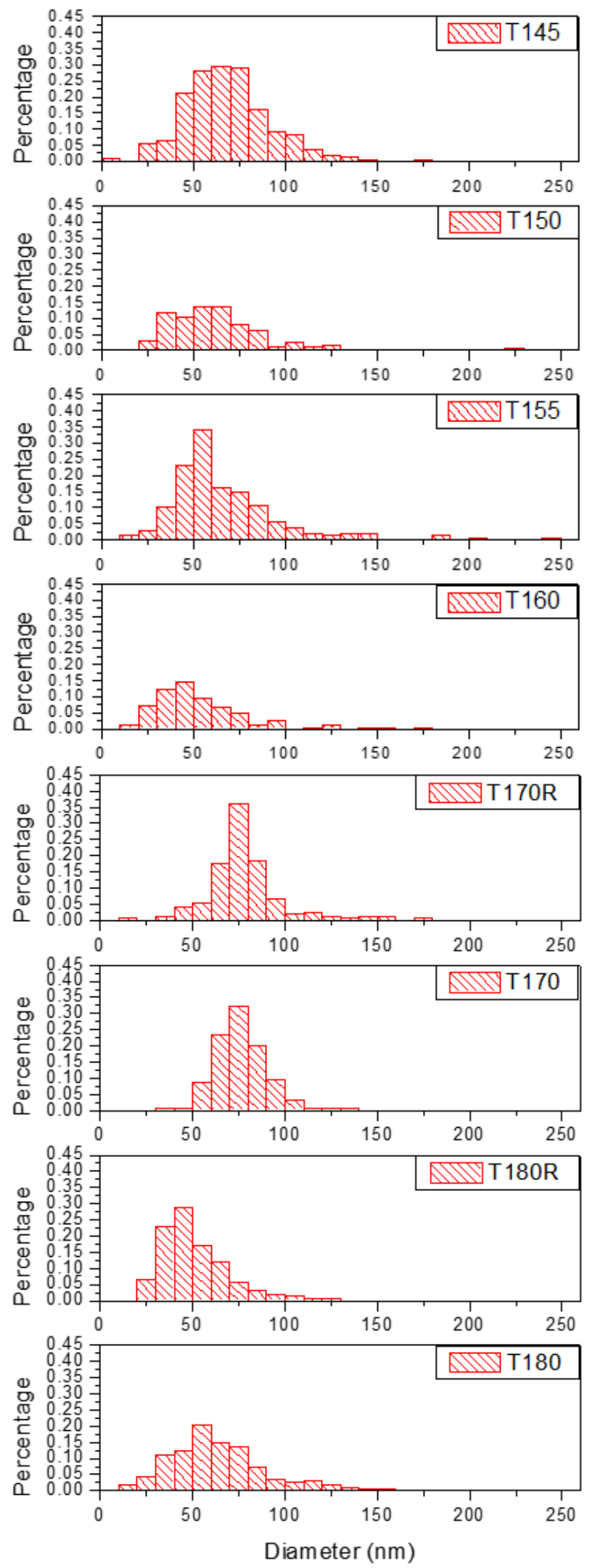

63 
Appendix 2. Multiwalled Vertically Aligned Carbon Nanotube Array Images for Ferrocene Sublimation. The array heights of two separate locations are pictured with the ferrocene sublimation temperature provided in the top left. An additional measurement is provided for samples with thick amorphous carbon layers to better depict the height variation.

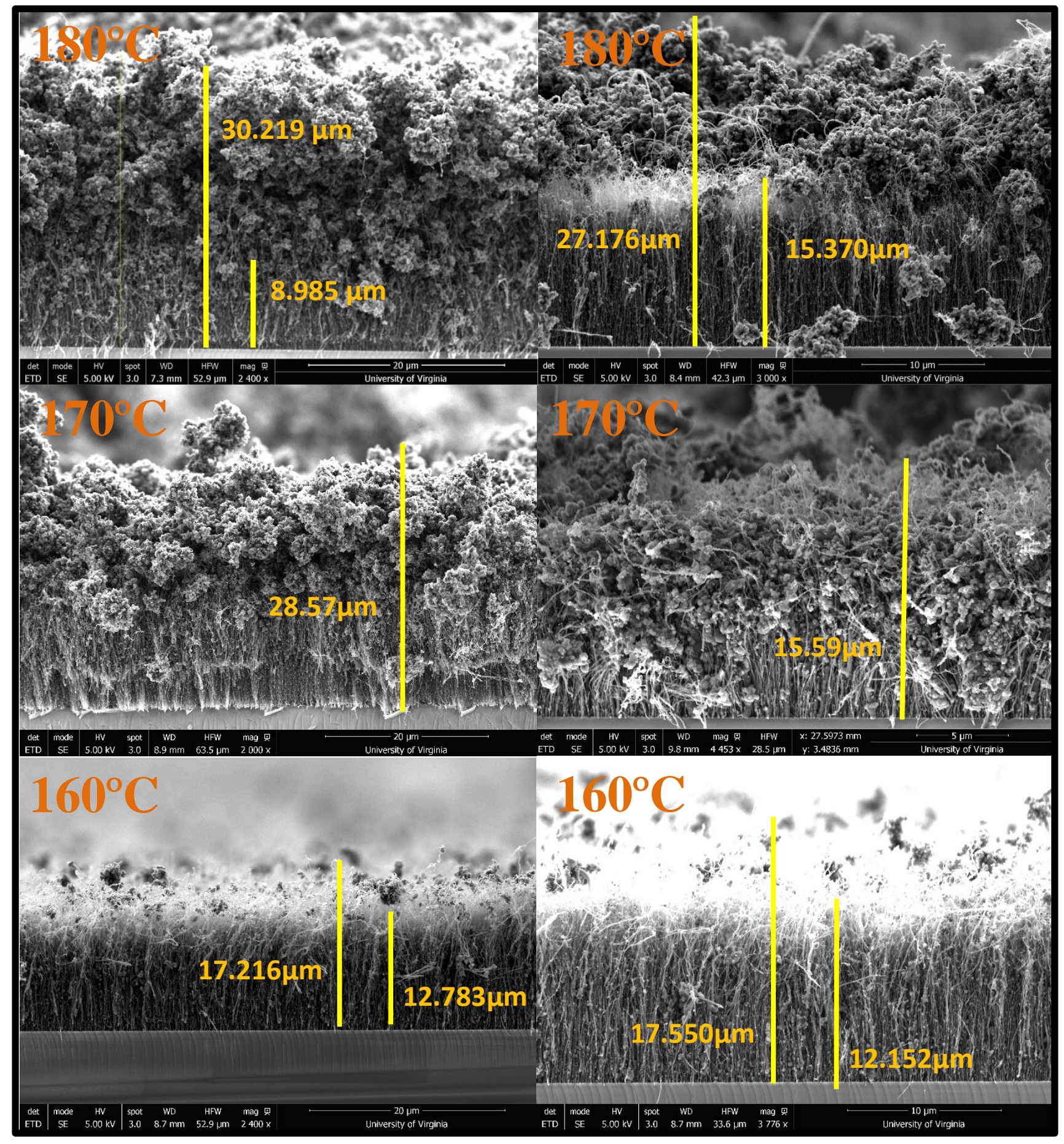




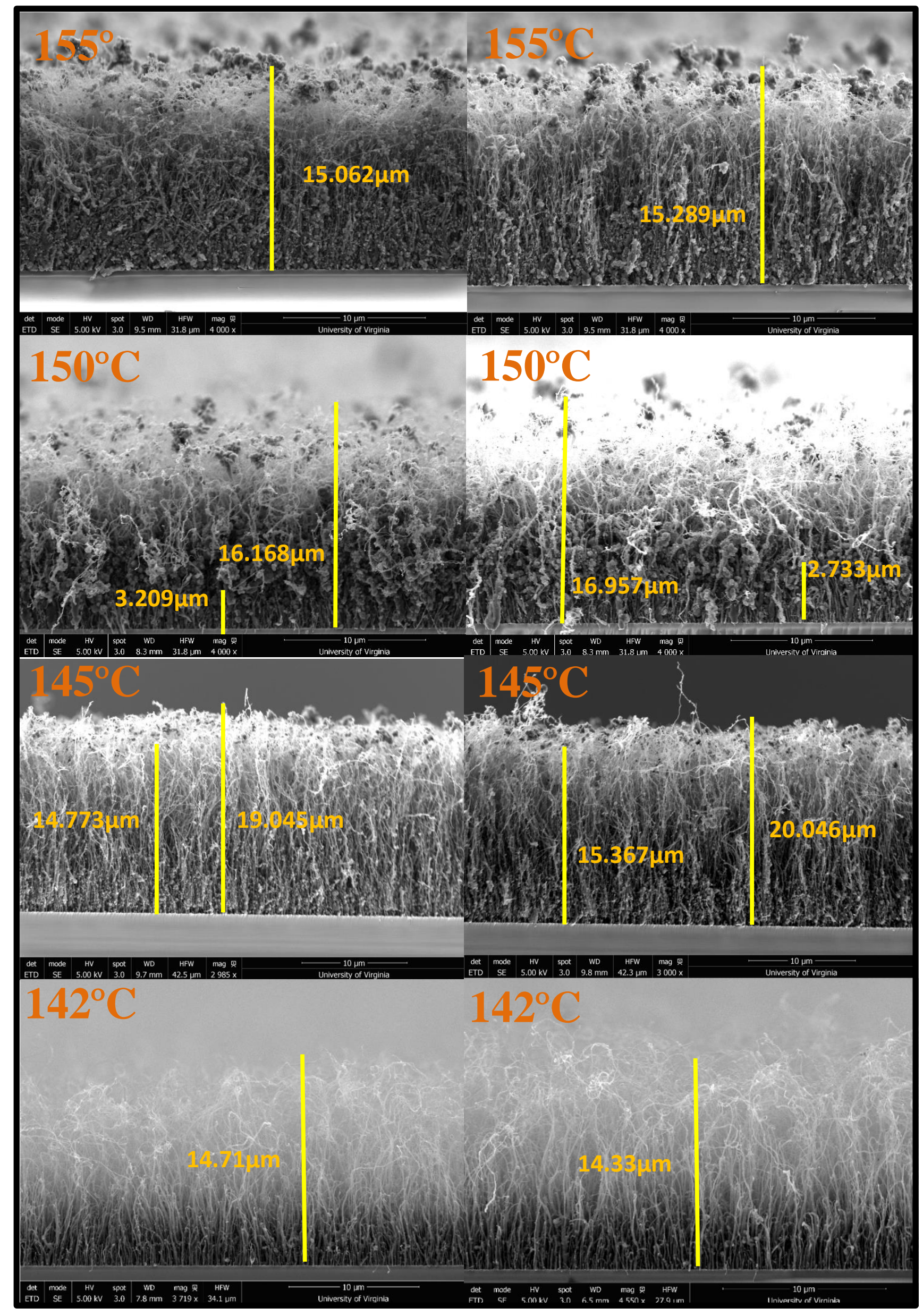




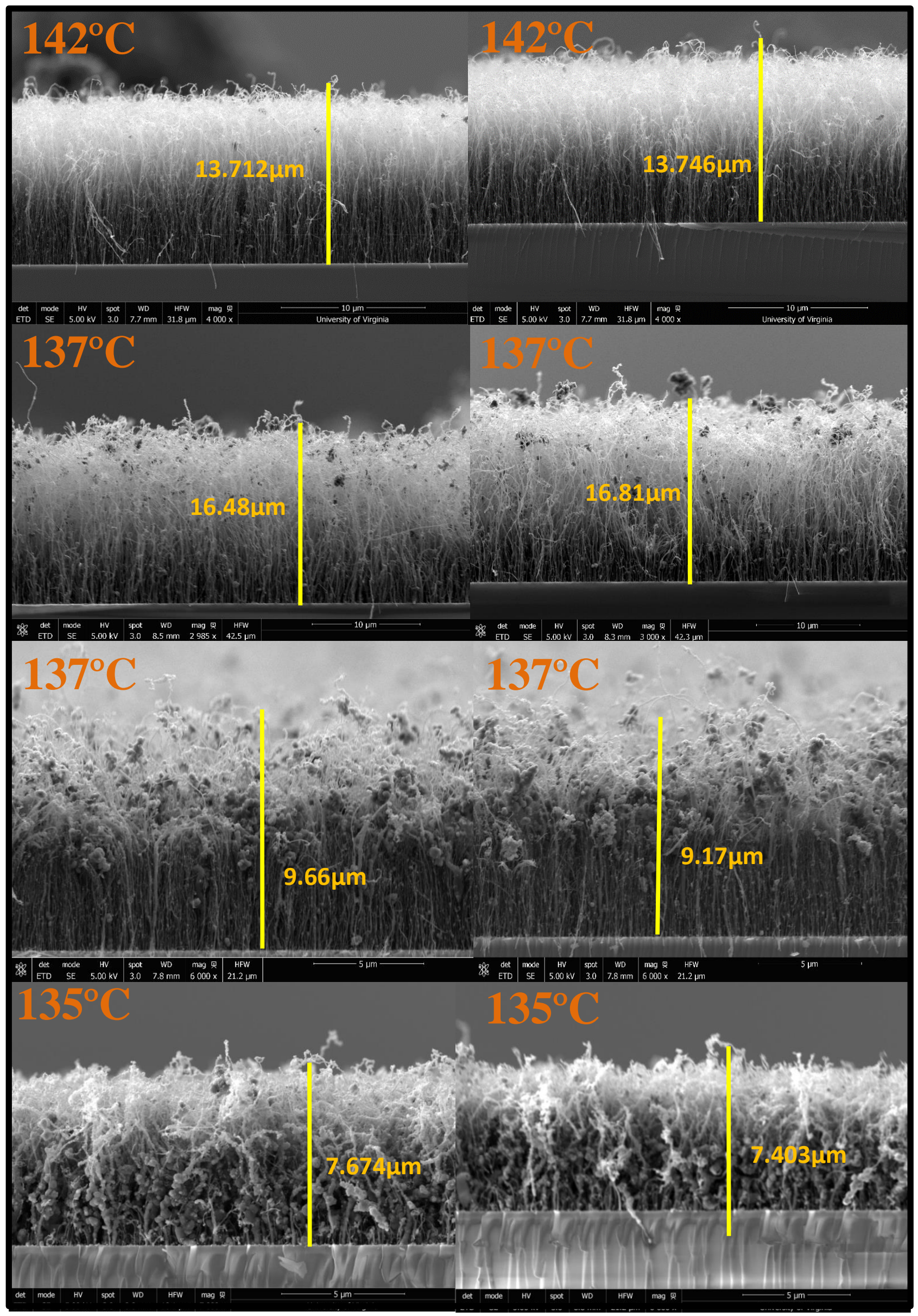


Appendix 3. TEM Images at 50kx of 100kx magnification (scale bars either 100nm or 50nm).

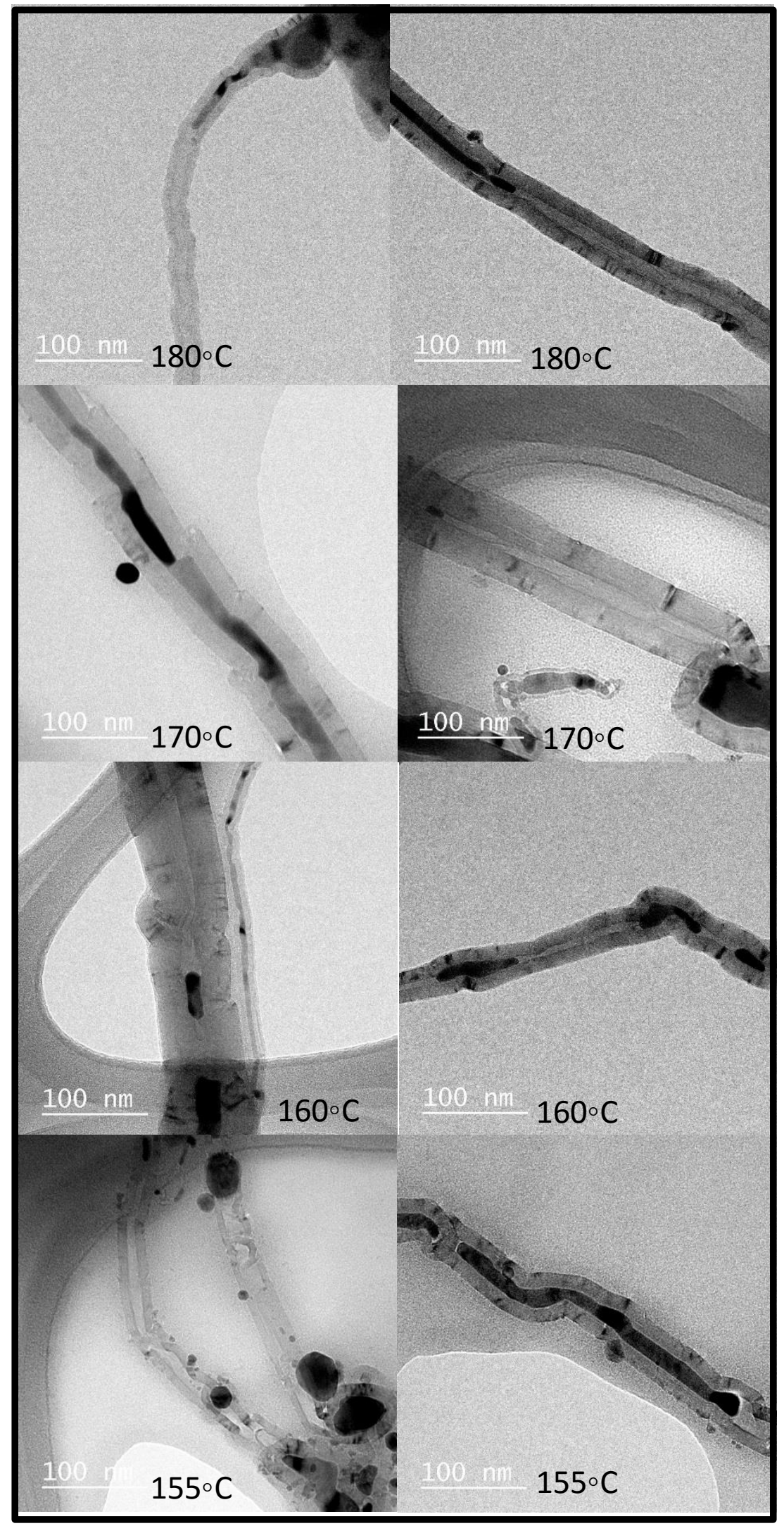




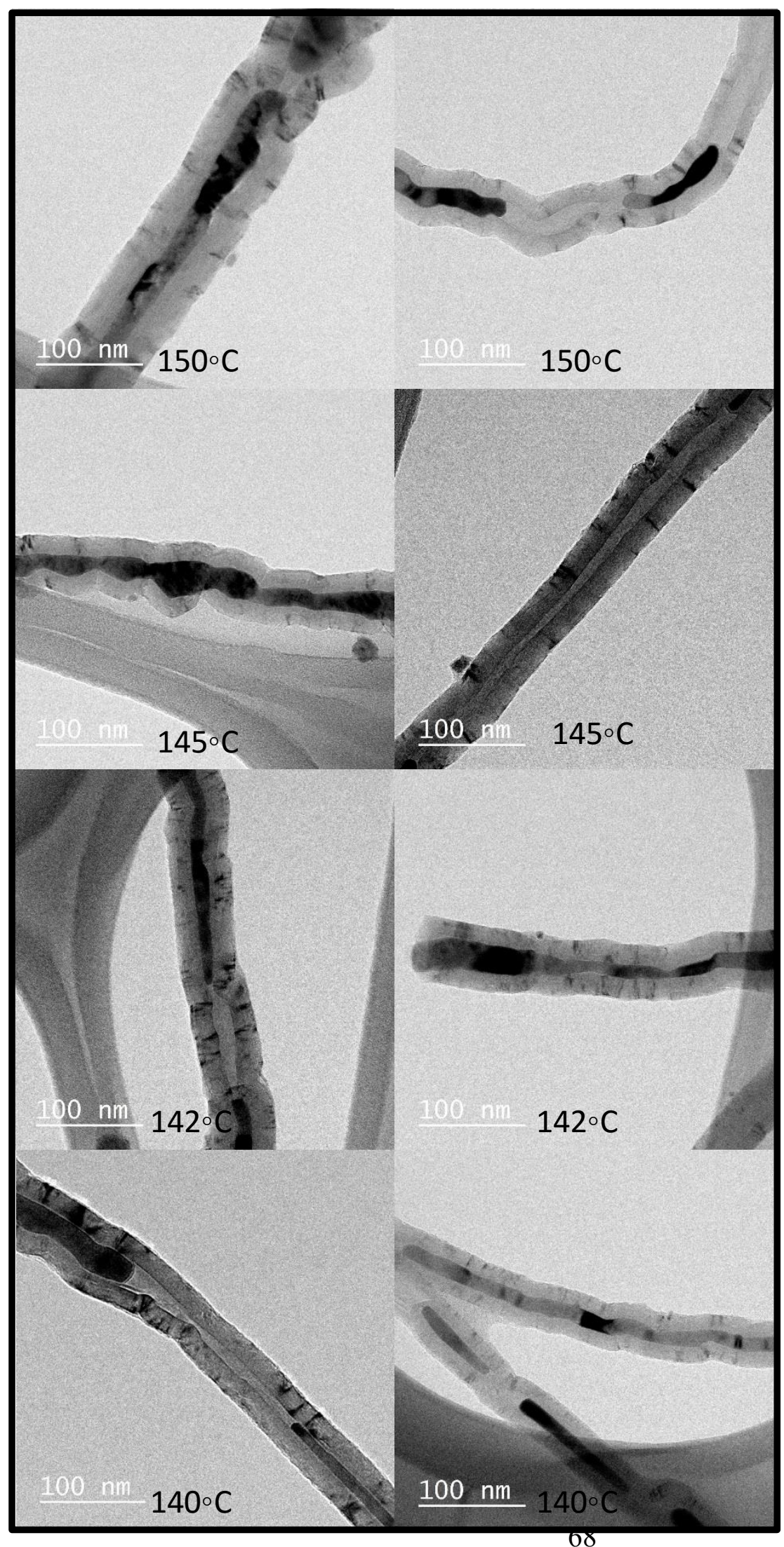




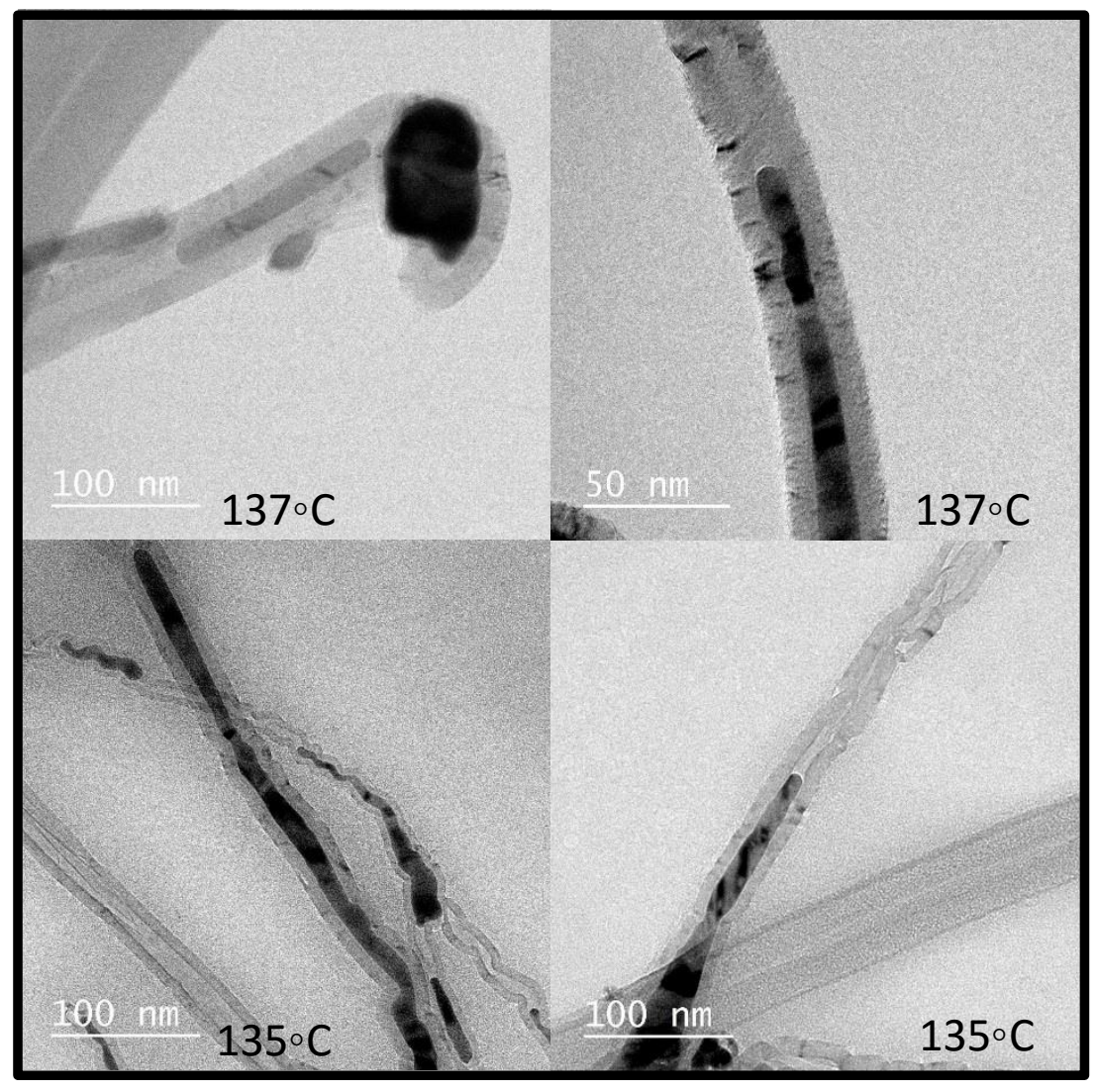


Appendix 4. Multiwalled Vertically Aligned Carbon Nanotube Array Data with the Addition of Ethylene. Hydrocarbon gas recommendations are provided in section 4.2.2. Ethylene did not improve the quality of the MW VACNTAs which led to the recommendation to pursue Acetylene as a future hydrocarbon source.
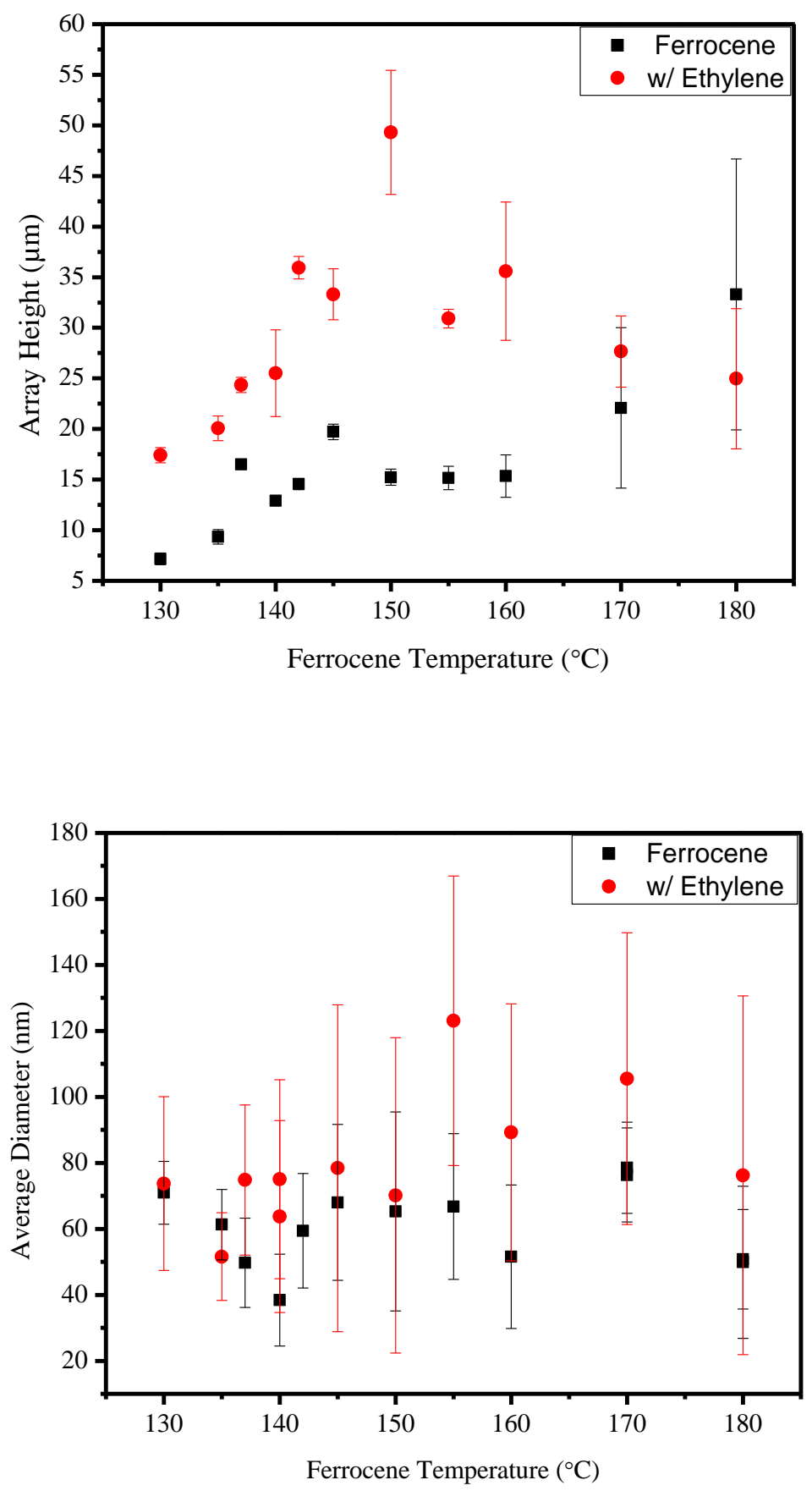

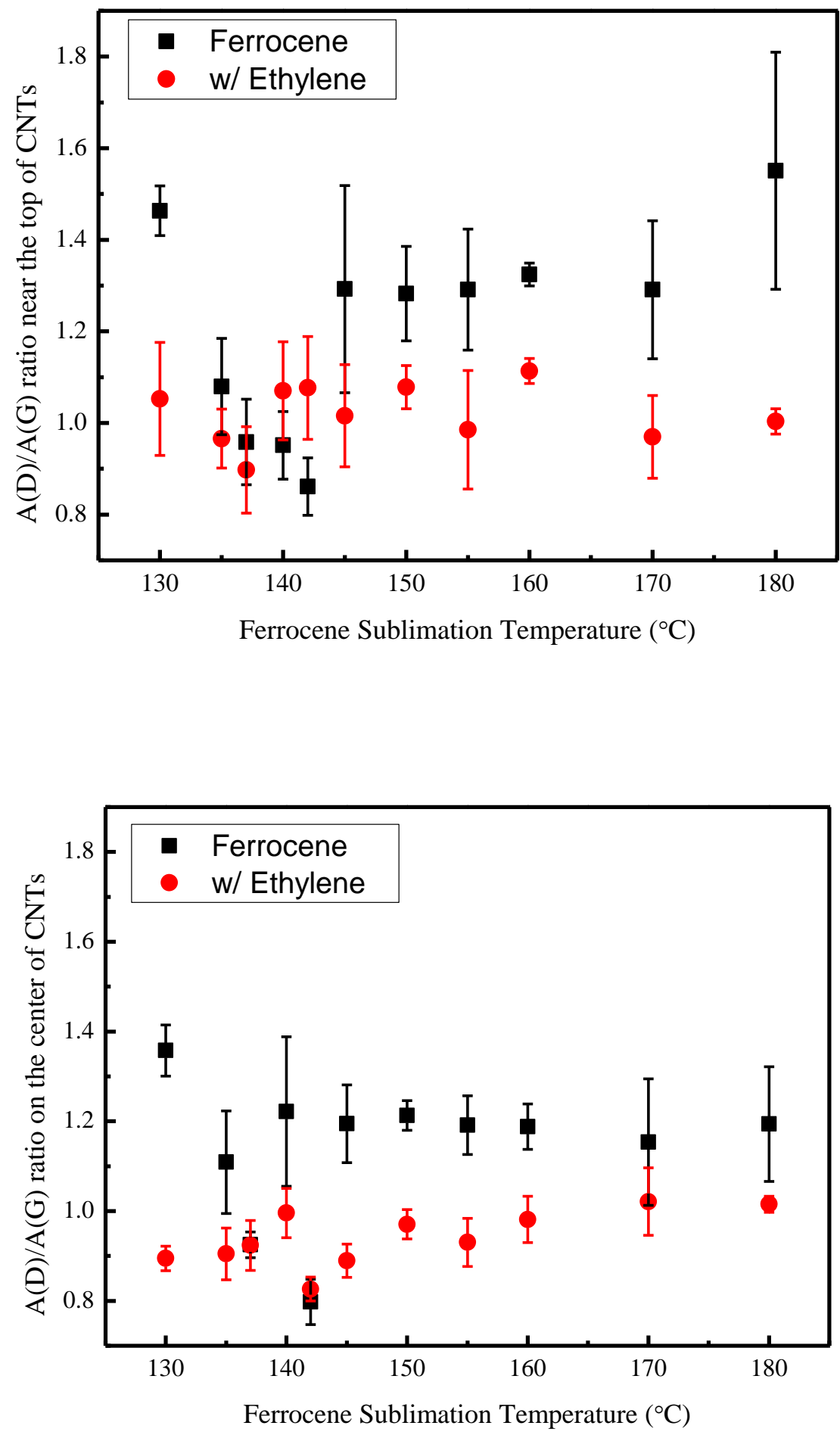


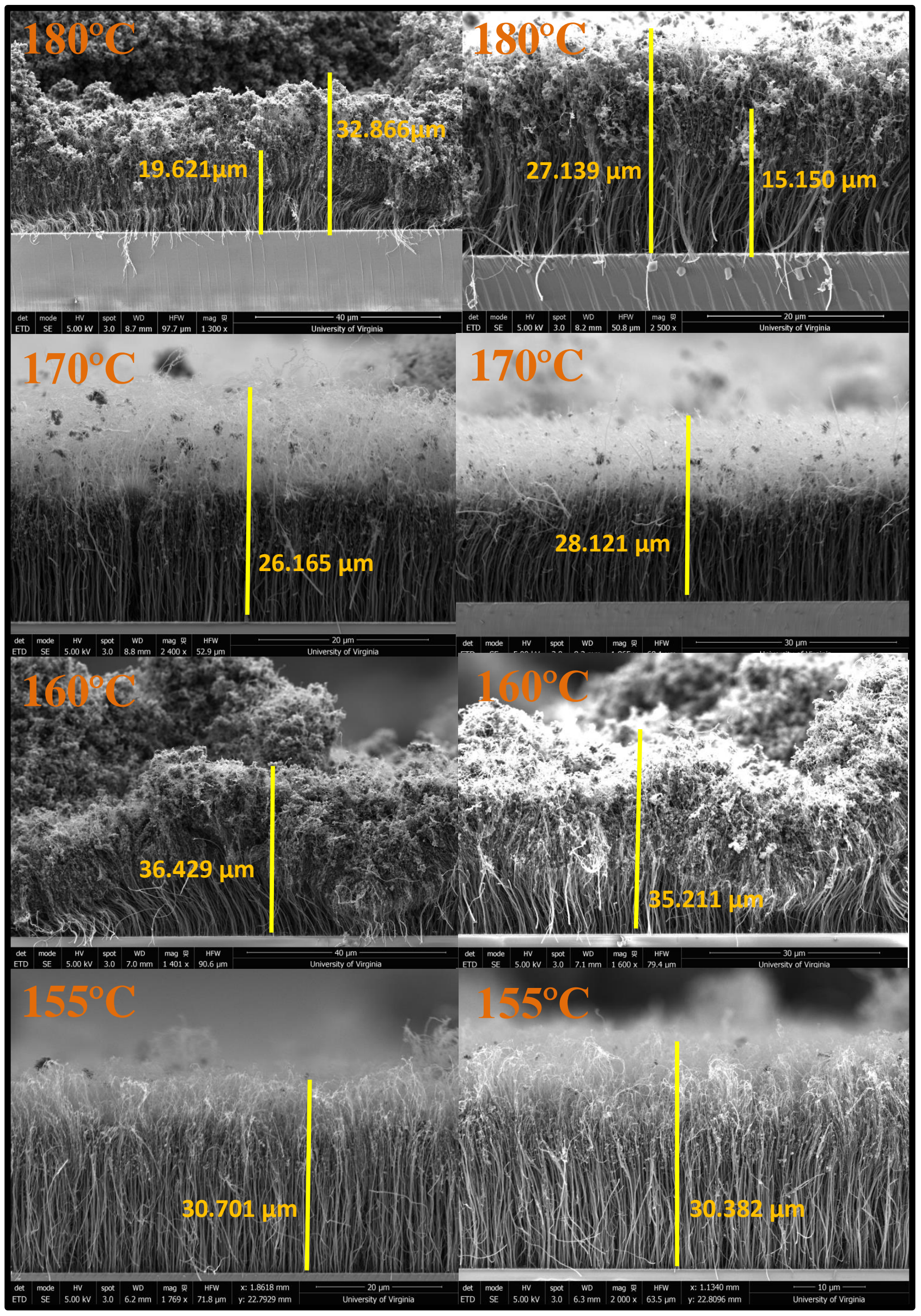




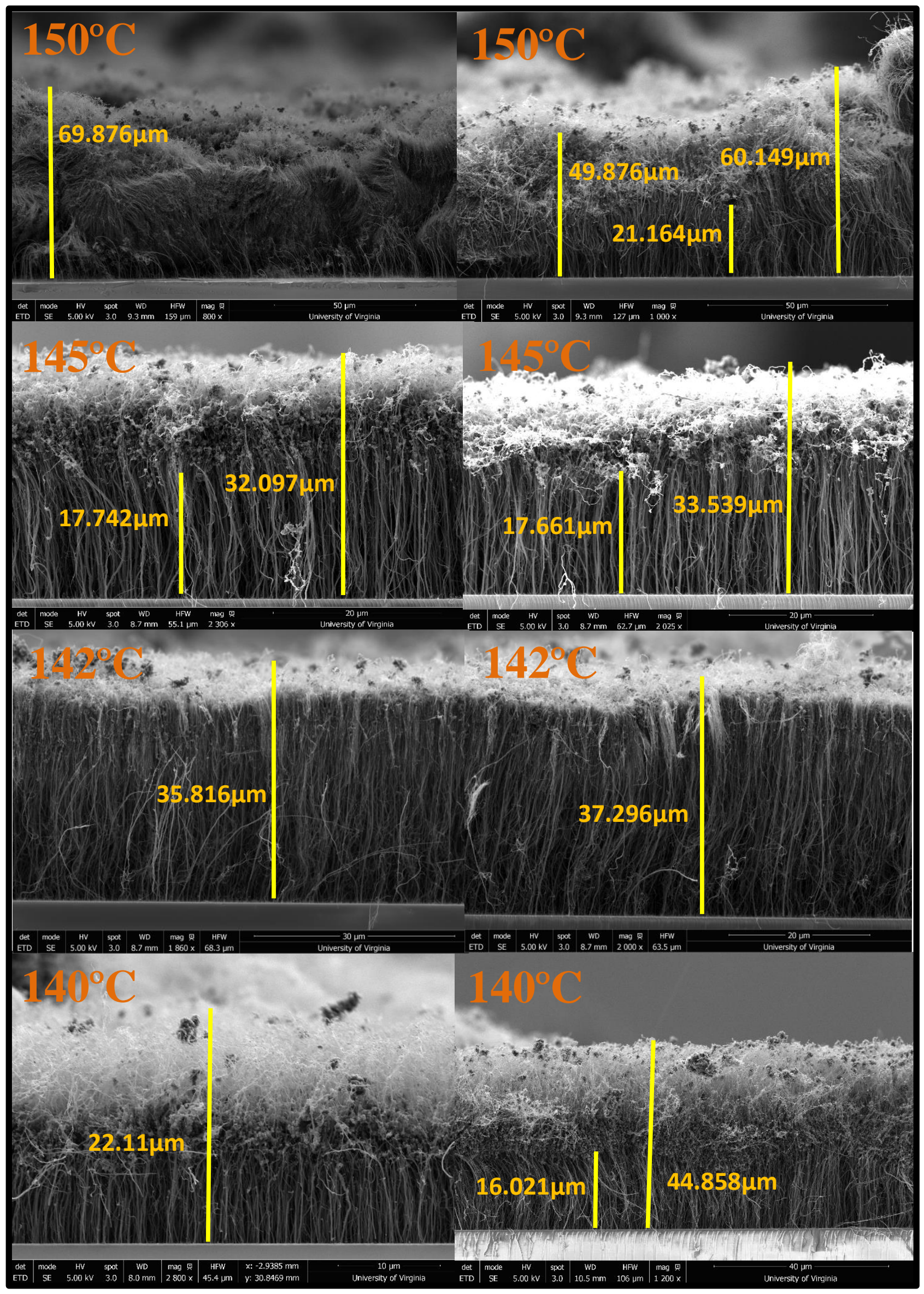




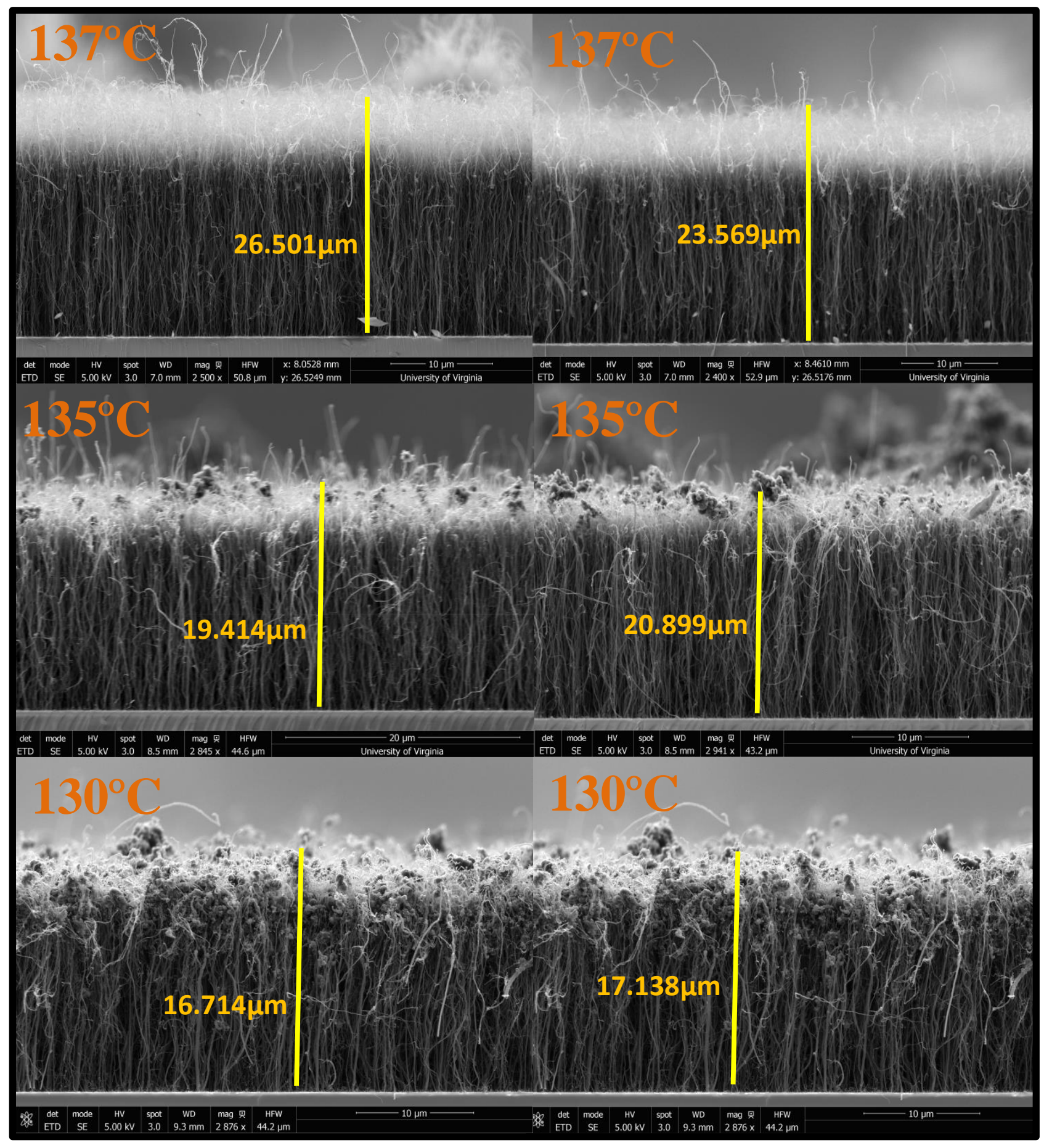

*Growths were completed at $800^{\circ} \mathrm{C}$ with Ethylene flowing at $50 \mathrm{sccm}$ for a 10 min duration. All other steps in the CVD procedure are the same as growths completed with ferrocene as the sole carbon source. The ferrocene sublimation temperature is depicted in the top left of each image. 


\section{References}

[1] A. M. Marconnet, M. A. Panzer, and K. E. Goodson, "Thermal conduction phenomena in carbon nanotubes and related nanostructured materials," Rev. Mod. Phys., vol. 85, no. 3, pp. 1295-1326, 2013.

[2] L. Qiu, X. Wang, G. Su, D. Tang, X. Zheng, J. Zhu, Z. Wang, P. M. Norris, P. D. Bradford, and Y. Zhu, "Remarkably enhanced thermal transport based on a flexible horizontally-aligned carbon nanotube array film," Sci. Rep., vol. 6, no. October 2015, p. 21014, 2016.

[3] P. Norris, “Technical Section Technical Objectives,” N00014-07-1-0723, 2012.

[4] Z. Kai, M. M. F. Yuen, D. G. W. Xiao, Y. Y. Fu, and P. Chan, "Directly synthesizing CNT-TIM on aluminum alloy heat sink for HB-LED thermal management," Proc. Electron. Components Technol. Conf., no. June 2016, pp. 1659-1663, 2008.

[5] B. A. Cola, X. Xu, and T. S. Fisher, "Increased real contact in thermal interfaces: A carbon nanotube/foil material," Appl. Phys. Lett., vol. 90, no. 9, pp. 88-91, 2007.

[6] X. Wang, Z. Zhong, and J. Xu, "Noncontact thermal characterization of multiwall carbon nanotubes," J. Appl. Phys., vol. 97, no. 6, 2005.

[7] M. L. Bauer, "Nanostructure Dictating Thermal Transport in Heterogeneous Material Systems Nanostructure dictating thermal transport in heterogeneous material systems," 2015.

[8] A. J. McNamara, Y. Joshi, and Z. M. Zhang, "Characterization of nanostructured thermal interface materials - A review," Int. J. Therm. Sci., vol. 62, pp. 2-11, 2012.

[9] C. Sevik, H. Sevin??li, G. Cuniberti, and T. ??an, "Phonon engineering in carbon nanotubes by controlling defect concentration," Nano Lett., vol. 11, no. 11, pp. 49714977, 2011.

[10] C. Laurent, E. Flahaut, and A. Peigney, "The weight and density of carbon nanotubes versus the number of walls and diameter," Carbon N. Y., vol. 48, no. 10, pp. 2994-2996, 2010.

[11] a. Ferrari and J. Robertson, "Interpretation of Raman spectra of disordered and amorphous carbon,” Phys. Rev. B, vol. 61, no. 20, pp. 14095-14107, 2000. 
[12] H. High-Tech, "Easy-to-Read Textbook for TEM." UVA NMCF, p. 35.

[13] J. Njuguna, O. A. Vanli, and R. Liang, "A Review of Spectral Methods for Dispersion Characterization of Carbon Nanotubes in Aqueous Suspensions," J. Spectrosc., vol. 2015, 2015.

[14] K. W. Kolasinski, "Catalytic growth of nanowires: Vapor-liquid-solid, vapor-solid-solid, solution-liquid-solid and solid-liquid-solid growth," Curr. Opin. Solid State Mater. Sci., vol. 10, no. 3-4, pp. 182-191, 2006.

[15] S. Hofmann, G. Csanyi, A. C. Ferrari, M. C. Payne, and J. Robertson, "Surface diffusion: The low activation energy path for nanotube growth," Phys. Rev. Lett., vol. 95, no. 3, pp. $1-4,2005$.

[16] I. P. on C. S. (IPCS), “ICSC 1512 - FERROCENE.” European Commision, 2012.

[17] Q. Liu, Z. G. Chen, B. Liu, W. Ren, F. Li, H. Cong, and H. M. Cheng, "Synthesis of different magnetic carbon nanostructures by the pyrolysis of ferrocene at different sublimation temperatures," Carbon N. Y., vol. 46, no. 14, pp. 1892-1902, 2008.

[18] K. A. Shah and B. A. Tali, "Synthesis of carbon nanotubes by catalytic chemical vapour deposition: A review on carbon sources, catalysts and substrates," Mater. Sci. Semicond. Process., vol. 41, pp. 67-82, 2016.

[19] Z. Ren, Y. Lan, and Y. Wang, "Aligned Carbon Nanotubes: Physics, concepts, fabrication and devices," NanoScience and Technology, vol. 5. 2012.

[20] T. S. Fisher, "Enhanced thermal contact conductance using carbon nanotube array interfaces," Components Packag. Technol. IEEE Trans., vol. 29, no. 2, pp. 261-267, 2006.

[21] S. Kaur, N. Raravikar, B. a. Helms, R. Prasher, and D. F. Ogletree, "Enhanced thermal transport at covalently functionalized carbon nanotube array interfaces," Nat. Commun., vol. 5, pp. 141-144, 2014.

[22] B. A. Cola, J. Xu, and T. S. Fisher, "Contact mechanics and thermal conductance of carbon nanotube array interfaces," Int. J. Heat Mass Transf., vol. 52, no. 15-16, pp. 34903503, 2009.

[23] Y. Y. Wei, G. Eres, V. I. Merkulov, and D. H. Lowndes, "Effect of catalyst film thickness on carbon nanotube growth by selective area chemical vapor deposition," Appl. Phys. Lett., vol. 78, no. 10, pp. 1394-1396, 2001. 
[24] H. Huang, C. Liu, Y. Wu, and S. Fan, "Aligned carbon nanotube composite films for thermal management," Adv. Mater., vol. 17, no. 13, pp. 1652-1656, 2005.

[25] W. Xu, Y. Chen, H. Zhan, and J. N. Wang, "High-Strength Carbon Nanotube Film from Improving Alignment and Densification," Nano Lett., vol. 16, no. 2, pp. 946-952, 2016.

[26] T. Tong, Y. Zhao, L. Delzeit, A. Kashani, M. Meyyappan, and A. Majumdar, "Dense vertically aligned multiwalled carbon nanotube arrays as thermal interface materials," IEEE Trans. Components Packag. Technol., vol. 30, no. 1, pp. 92-100, 2007.

[27] D. J. Yang, S. G. Wang, Q. Zhang, P. J. Sellin, and G. Chen, “Thermal and electrical transport in multi-walled carbon nanotubes," Phys. Lett. A, vol. 329, no. 3, pp. 207-213, 2004.

[28] D. Yang, Q. Zhang, G. Chen, S. Yoon, J. Ahn, S. Wang, Q. Zhou, Q. Wang, and J. Li, "Thermal conductivity of multiwalled carbon nanotubes," Phys. Rev. B, vol. 66, no. 16, pp. 2-7, 2002.

[29] T. Tong, A. Majumdar, Y. Zhao, and A. Kashani, "Indium Assisted Multiwalled Carbon Nanotube Array Thermal Interface Materials ( a ),” no. 510, pp. 1406-1411, 2006.

[30] Y. Zhao, R.-S. Chu, C. Grigoropoulos, O. Dubon, and A. Majumdar, “Array Volume Fraction Dependent Thermal Transport Properties of Vertically Aligned Carbon Nanotube Arrays," J. Heat Transfer, vol. 138, no. c, pp. 1-7, 2016.

[31] M. A. Panzer and K. E. Goodson, "Thermal resistance between low-dimensional nanostructures and semi-infinite media," J. Appl. Phys., vol. 103, no. 9, 2008.

[32] E. H. Martins Ferreira, M. V. O. Moutinho, F. Stavale, M. M. Lucchese, R. B. Capaz, C. A. Achete, and A. Jorio, "Evolution of the Raman spectra from single-, few-, and manylayer graphene with increasing disorder," Phys. Rev. B - Condens. Matter Mater. Phys., vol. 82, no. 12, 2010.

[33] M. T. Pettes and L. Shi, "Thermal and structural characterizations of individual single-, double-, and multi-walled carbon nanotubes," Adv. Funct. Mater., vol. 19, no. 24, pp. 3918-3925, 2009.

[34] J.-J. Park and M. Taya, "Design of Thermal Interface Material With High Thermal Conductivity and Measurement Apparatus," J. Electron. Packag., vol. 128, no. March, p. 46, 2006. 
[35] “Thermal K Values List by Indium Corporation.”.

[36] M. J. Biercuk, M. C. Llaguno, M. Radosavljevic, J. K. Hyun, and A. T. Johnson, “Carbon nanotube composites for thermal management," Appl. Phys. Lett., vol. 80, no. 15, pp. 2767-2769, 2002.

[37] S. T. Huxtable, D. G. Cahill, S. Shenogin, L. Xue, R. Ozisik, P. Barone, M. Usrey, M. S. Strano, G. Siddons, M. Shim, and P. Keblinski, "Interfacial heat flow in carbon nanotube suspensions," Nat. Mater., vol. 2, no. 11, pp. 731-734, 2003.

[38] Y. Yao, J. N. Tey, Z. Li, J. Wei, K. Bennett, A. McNamara, Y. Joshi, R. L. S. Tan, S. N. M. Ling, and C. P. Wong, "High-quality vertically aligned carbon nanotubes for applications as thermal interface materials," IEEE Trans. Components, Packag. Manuf. Technol., vol. 4, no. 2, pp. 232-239, 2014.

[39] P. Taylor, "a Molecular Dynamics Simulation of Heat Conduction of a Conduction of a Finite Length Single-Walled,” vol. 3954, no. 791939330, 2003.

[40] Y. Son, S. K. Pal, T. Borca-Tasciuc, P. M. Ajayan, and R. W. Siegel, "Thermal resistance of the native interface between vertically aligned multiwalled carbon nanotube arrays and their SiO[sub 2]/Si substrate," J. Appl. Phys., vol. 103, no. 2, p. 024911, 2008.

[41] T. Borca-Tasciuc, S. Vafaei, D. A. Borca-Tasciuc, B. Q. Wei, R. Vajtai, and P. M. Ajayan, "Anisotropic thermal diffusivity of aligned multiwall carbon nanotube arrays," $J$. Appl. Phys., vol. 98, no. 5, 2005.

[42] W. J. Parker, R. J. Jenkins, C. P. Butler, and G. L. Abbott, "Flash method of determining thermal diffusivity, heat capacity, and thermal conductivity," J. Appl. Phys., vol. 32, no. 9, pp. 1679-1684, 1961.

[43] J. A. Thomas, R. M. Iutzi, and A. J. H. McGaughey, "Thermal conductivity and phonon transport in empty and water-filled carbon nanotubes," Phys. Rev. B - Condens. Matter Mater. Phys., vol. 81, no. 4, pp. 1-7, 2010.

[44] S. Pearton, S. Richeter, L. Raehm, B. L. Allen, M. B. Keddie, and A. Star, "Impacts of doping on thermal and thermoelectric properties of nanomaterials," Nanoscale, vol. 2, no. 7, p. 1057, 2010.

[45] T. Yamamoto, S. Konabe, J. Shiomi, and S. Maruyama, "Crossover from ballistic to diffusive thermal transport in carbon nanotubes," Appl. Phys. Express, vol. 2, no. 9, pp. 3- 
6, 2009.

[46] A. E. Aliev, M. H. Lima, E. M. Silverman, and R. H. Baughman, "Thermal conductivity of multi-walled carbon nanotube sheets: radiation losses and quenching of phonon modes.," Nanotechnology, vol. 21, no. 3, p. 035709, 2010.

[47] L. Khriachtchev, M. Pettersson, N. Runeberg, J. Lundell, and M. Rasanen, “A stable argon compound," Nature, vol. 406, no. 6798, pp. 874-6, 2000.

[48] Z. L. Wang, H. T. Mu, J. G. Liang, and D. W. Tang, "Thermal boundary resistance and temperature dependent phonon conduction in CNT array multilayer structure," Int. $J$. Therm. Sci., vol. 74, pp. 53-62, 2013.

[49] M. L. Bauer, Q. N. Pham, C. B. Saltonstall, and P. M. Norris, "Thermal conductivity of vertically aligned carbon nanotube arrays: Growth conditions and tube inhomogeneity," Appl. Phys. Lett., vol. 105, no. 15, 2014.

[50] K. Hata, D. Futaba, K. Mizuno, T. Namai, M. Yumura, and S. Iijima, "Water-assisted highly efficient synthesis of impurity-free single-walled carbon nanotubes.," Science, vol. 306, no. 5700, pp. 1362-1364, 2004.

[51] Princeton Instruments, "Raman Spectroscopy Basics - Application Note," Internet: http://content. piacton. com/Uploads/Princeton/, pp. 1-5, 2012.

[52] Cerium Labs LLC, “Q2_2010_newsletter_figure,” 2016. [Online]. Available: http://www.ceriumlabs.com/104/Q2_2010_Newsletter.htm. [Accessed: 04-May-2016].

[53] Z. Gao, K. Zhang, and M. M. F. Yuen, "Fabrication of carbon nanotube thermal interface material on aluminium alloy substrates," Proc. - 2010 11th Int. Conf. Electron. Packag. Technol. High Density Packag. ICEPT-HDP 2010, vol. 265611, pp. 1401-1408, 2010.

[54] E. B.-P. S. COSTA, M. KRUSZYŃSKA, and R. J. K. A. BACHMATIUK, "Characterization of carbon nanotubes by Raman spectroscopy," Mater. Sci., vol. 26, no. 2, pp. 433-441, 2008.

[55] FEI, “Quanta Training Manual - X50 series," p. 706.

[56] L. Reimer., "Transmission Electron Microscopy. Physics of Image Formation and Microanalysis," Optica Acta: International Journal of Optics, vol. 31, no. 8. Springer, 1984.

[57] R. Bhatia and V. Prasad, "Synthesis of multiwall carbon nanotubes by chemical vapor 
deposition of ferrocene alone," Solid State Commun., vol. 150, no. 7-8, pp. 311-315, 2010.

[58] J.-P. Tessonnier and D. S. Su, "Recent progress on the growth mechanism of carbon nanotubes: a review.," ChemSusChem, vol. 4, no. 7, pp. 824-847, 2011.

[59] W. Zhou, Z. Han, J. Wang, Y. Zhang, Z. Jin, X. Sun, Y. Zhang, C. Yan, and Y. Li, "Copper catalyzing growth of single-walled carbon nanotubes on substrates," Nano Lett., vol. 6, no. 12, pp. 2987-2990, 2006.

[60] R. T. K. Baker, D. J. C. Yates, and J. A. Dumesic, "Filamentous Carbon Formation over Iron Surfaces," Coke Form. Met. Surfaces, vol. 202, no. 1, pp. 1-21, 1982.

[61] M. Argyle and C. Bartholomew, "Heterogeneous Catalyst Deactivation and Regeneration: A Review," Catalysts, vol. 5, no. 1, pp. 145-269, 2015.

[62] K. T. Kashyap and R. G. Patil, "On Young's modulus of multi-walled carbon nanotubes," Bull. Mater. Sci., vol. 31, no. 2, pp. 185-187, 2008.

[63] M. K. K. Oura, V.G. Lifshits, A.A. Saranin, A.V. Zotov, Surface Science an Introduction. Berlin; New York: Springer, 2003.

[64] J. K. Kim, W. D. Moon, K. S. Lee, and K. Jung, "Formation of a highly oriented FeO thin film by phase transition of Fe 3 O 4 and Fe nanocrystallines," Thin Solid Films, vol. 360, pp. 118-121, 2000.

[65] Q. N. Pham, C. C. Lisboa, L. S. Larkin, C. B. Saltonstall, and P. M. Norris, "Selective Growth of Carbon Nanotube Arrays and Amorphous Carbon for Thermal Applications," pp. 1-7.

[66] I. B. Johns, E. A. McElhill, and J. O. Smith, "Thermal stability of some organic compounds,” J. Chem. Eng. Data, vol. 7, no. 2, pp. 277-281, 1962.

[67] K. Elihn and K. Larsson, "A theoretical study of the thermal fragmentation of ferrocene," Thin Solid Films, vol. 458, no. 1-2, pp. 325-329, 2004.

[68] K.-E. Kim, K.-J. Kim, W. S. Jung, S. Y. Bae, J. Park, J. Choi, and J. Choo, "Investigation on the temperature-dependent growth rate of carbon nanotubes using chemical vapor deposition of ferrocene and acetylene," Chem. Phys. Lett., vol. 401, pp. 459-464, 2005.

[69] R. H. Baughman, A. a Zakhidov, and W. a de Heer, "Carbon nanotubes --- the route toward applications," Science (80-. )., vol. 297, no. 5582, pp. 787-92, 2002. 
[70] L. X. Benedict, S. G. Louie, and M. L. Cohen, "Heat capacity of carbon nanotubes," Solid State Commun., vol. 100, no. 3, pp. 177-180, 1996.

[71] L. Lindsay, D. A. Broido, and N. Mingo, "Diameter dependence of carbon nanotube thermal conductivity and extension to the graphene limit," Phys. Rev. B - Condens. Matter Mater. Phys., vol. 82, no. 16, pp. 4-7, 2010.

[72] B. Hinds, N. Chopra, T. Rantell, and R. Andrews, "Aligned Multiwalled Carbon Nanotube Membranes," Sci. (New York, NY), vol. 303, no. October 2003, 2004.

[73] G. D. Nessim, A. J. Hart, J. S. Kim, D. Acquaviva, J. Oh, C. D. Morgan, M. Seita, J. S. Leib, and C. V. Thompson, "Tuning of vertically-aligned carbon nanotube diameter and areal density through catalyst pre-treatment," Nano Lett., vol. 8, no. 11, pp. 3587-3593, 2008.

[74] S. Amelinckx, X. B. Zhang, D. Bernaerts, X. F. Zhang, V. Ivanov, and J. B. Nagy, “A formation mechanism for catalytically grown helix-shaped graphite nanotubes.," Science, vol. 265, no. July, pp. 635-639, 1994.

[75] A. Elements, "Iron carbide nanoparticles ...." The Material Science Manufacturer, p. 3675.

[76] L. Ci, R. Vajtai, and P. M. Ajayan, "Vertically aligned large-diameter double-walled carbon nanotube arrays having ultralow density," J. Phys. Chem. C, vol. 111, no. 26, pp. 9077-9080, 2007.

[77] G. Gouadec and P. Colomban, "Raman Spectroscopy of nanomaterials: How spectra relate to disorder, particle size and mechanical properties," Prog. Cryst. Growth Charact. Mater., vol. 53, no. 1, pp. 1-56, 2007.

[78] Q. Shi, D. Yang, Y. Su, J. Li, Z. Jiang, Y. Jiang, and W. Yuan, “Covalent functionalization of multi-walled carbon nanotubes by lipase," J. Nanoparticle Res., vol. 9, no. 6, pp. 1205-1210, 2007.

[79] S. Hofmann, R. Sharma, C. Ducati, G. Du, C. Mattevi, C. Cepek, M. Cantoro, S. Pisana, A. Parvez, F. Cervantes-Sodi, A. C. Ferrari, R. Dunin-Borkowski, S. Lizzit, L. Petaccia, A. Goldoni, and J. Robertson, "In situ observations of catalyst dynamics during surfacebound carbon nanotube nucleation," Nano Lett., vol. 7, no. 3, pp. 602-608, 2007.

[80] W. Lin, J. Shang, W. Gu, and C. P. Wong, "Parametric study of intrinsic thermal transport 
in vertically aligned multi-walled carbon nanotubes using a laser flash technique," Carbon N. Y., vol. 50, no. 4, pp. 1591-1603, 2012.

[81] C. Guéret, M. Daroux, and F. Billaud, "Methane pyrolysis: Thermodynamics," Chem. Eng. Sci., vol. 52, no. 5, pp. 815-827, 1997.

[82] V. K. Kayastha, Y. K. Yap, Z. Pan, I. N. Ivanov, A. A. Puretzky, and D. B. Geohegan, "High-density vertically aligned multiwalled carbon nanotubes with tubular structures," Appl. Phys. Lett., vol. 86, no. 25, pp. 1-3, 2005.

[83] K. Xue, "Process Parameters for Successful Synthesis of Carbon Nanotubes by Chemical Vapor Deposition Implications for Chemical Mechanisms and Life-cycle Assessment," Duke, 2014.

[84] N. Matsumoto, A. Oshima, S. Sakurai, T. Yamada, M. Yumura, K. Hata, and D. Futaba, "The Application of Gas Dwell Time Control for Rapid Single Wall Carbon Nanotube Forest Synthesis to Acetylene Feedstock," Nanomaterials, vol. 5, no. 3, pp. 1200-1210, 2015.

[85] L. Bokobza and J. Zhang, "Raman spectroscopic characterization of multiwall carbon nanotubes and of composites," Express Polym. Lett., vol. 6, no. 7, pp. 601608https://mail.google.com/mail/u/0/?ui=2\&ik=d, 2012.

[86] A. C. Ferrari, "Raman spectroscopy of graphene and graphite: Disorder, electron-phonon coupling, doping and nonadiabatic effects," Solid State Commun., vol. 143, no. 1-2, pp. 47-57, 2007.

[87] S. L. Pirard, S. Douven, C. Bossuot, G. Heyen, and J. P. Pirard, "A kinetic study of multiwalled carbon nanotube synthesis by catalytic chemical vapor deposition using a FeCo/Al2O3 catalyst," Carbon N. Y., vol. 45, no. 6, pp. 1167-1175, 2007. 